\title{
Um Middleware para Coreografias de Serviços Web Escaláveis em Ambientes de Computação em Nuvem
}

\author{
Thiago Furtado de Mendonça \\ TEXTO APRESENTADO \\ AO \\ Instituto DE MATEMÁticA E EstatísticA \\ DA \\ UNIVERSIDADE DE SÃO PAULO \\ PARA \\ A OBTENÇÃO DO TÍTUlO \\ $\mathrm{DE}$ \\ Mestre em Cî̂nCIA DA ComputaÇÃO
}

Orientador: Prof. Dr. Fabio Kon

Durante o desenvolvimento deste trabalho o autor recebeu auxílio financeiro do projeto CHOReOS, financiado pela Comissão Europeia, do projeto Baile, financiado pela HP Brasil e do $\mathrm{CNPq}$

São Paulo, Julho de 2015 


\section{Um Middleware para Coreografias de Serviços Web Escaláveis em Ambientes de Computação em Nuvem}

Esta versão da dissertação contém as correções e alterações sugeridas pela Comissão Julgadora durante a defesa da versão original do trabalho, realizada em 08/07/2015. Uma cópia da versão original está disponível no

Instituto de Matemática e Estatística da Universidade de São Paulo.

Comissão Julgadora:

- Prof. Dr. Fabio Kon (orientador) - IME-USP

- Prof. Dr. Francisco José da Silva e Silva - UFMA

- Prof. Dr. Alfredo Goldman Vel Lejbman - IME-USP 


\section{Agradecimentos}

Agradeço primeiramente ao meu orientador, professor Fabio Kon pelo modo como conduziu a orientação em minha pesquisa. Durante a pesquisa foi quem cobrou qualidade e dedicação; essa cobrança me fez crescer no meio científico. Foi um grande orientador, o qual tenho admiração não só na minha pesquisa, mas também na preocupação com o bem-estar de cada um dos alunos do grupo. Claro que não poderia esquecer o seu empenho no CCSL, o qual sou feliz em dizer que faço parte.

Agradeço aos colegas de laboratório com quem pude aprender, discutir e tirar dúvidas sobre os vários desafios que encontramos durante o projeto CHOReOS. São eles: Felipe Pontes, Eduardo Hideo, Alfonso Phocco, Paulo Moura, Carlos Eduardo, Paulo Meirelles e Yanik Ngoko.

Não poderia deixar um agradecimento especial aos amigos Nelson Lago, Emílio Francesquini e Leonardo Leite. Nelson, foi um grande aliado com suas ajudas dadas em assuntos técnicos. Emílio, pelo aprendizado acadêmico recebido durante a escrita de artigos. Por último, Leonardo que esteve comigo em todo o decorrer da implementação do middleware aqui desenvolvido.

Finalmente, agradeço a minha noiva Juliana Kelly pelo apoio durante o decorrer do projeto e por ter entendido o meu tempo curto e à minha família, pois sem eles nada do que aconteceu teria acontecido. 


\section{Resumo}

Composição de serviços é um tópico que tem atraído cada vez mais o interesse por parte de pesquisadores na área de sistemas distribuídos. Além disso, o interesse por ambientes baseados em nuvem tem crescido significativamente conforme o seu uso aumenta e se firma como um importante modelo de negócios. Coreografias são formas de composições de serviços em que não há pontos centrais de falha; a responsabilidade da sua execução é distribuída entre os vários serviços componentes. Devido à natureza distribuída do fluxo de informações e dados de controle, o cumprimento de Service Level Agreements (SLAs) depende estritamente do monitoramento da Qualidade de Serviços (QoS), recursos virtuais da nuvem e mecanismos de reconfiguração dinâmica, capazes de automaticamente adaptar composições a mudanças de estado no sistema. Nesta dissertação, abordamos o estudo do gerenciamento de QoS em coreografias de serviços. Para isso desenvolvemos um sistema de middleware capaz de implantar e gerenciar o QoS de composições. Este teve seu desempenho avaliado utilizando o serviço Amazon EC2. Os resultados da avaliação mostram que com pouco esforço por parte dos desenvolvedores de composições, é possível cumprir o SLA de composições dentro do esperado utilizando escalabilidade horizontal ou vertical provida pelo middleware automaticamente. Adicionalmente, a nossa proposta traz economias em relação ao custo de implantação pois diminui a quantidade de recursos subutilizados.

Palavras-chave: Qualidade de Serviços, Reconfiguração Dinâmica, Composição de Serviços, Middleware, SOA, Monitoramento de recursos. 


\section{Abstract}

Service composition has been a hot topic that has attracted the interesting of researchers in the distributed system area. Moreover, the interesting in cloud computing based environment has grown significantly. Its use has grown and it became to be a important business model. Choreographies are an specific kind of service composition that has no single point of failure; the responsibility of execution is distributed among the services. Due to the distributed nature of the these systems, the fulfilment of Service Level Agreements (SLAs) depends strictly on and automatic way to monitoring Quality of Service (QoS) and virtual computional resources as well as dinamic reconfiguration mechanisms, to be capable of automatically adapting compositions to changing environment. In this work, we studied QoS management in service choreographies. In order, we devised a middleware system capable of deploy service compositions and manage QoS of them. The middleware was evaluated using the Amazon EC2 cloud provider. The results shows that with less effort from the composition providers, it is possible to fulfil SLAs using horizontal or vertical scalability provided by the middleware automatically. Additionaly, our proposal brings up a cost reduction of deploy by decreasing the amount of underused resources.

Palavras-chave: Quality of Services, Dinamic Reconfiguration, Service Composition, Middleware, SOA, Resource Monitoring. 


\section{Sumário}

$\begin{array}{ll}\text { Lista de Abreviaturas } & \text { ix }\end{array}$

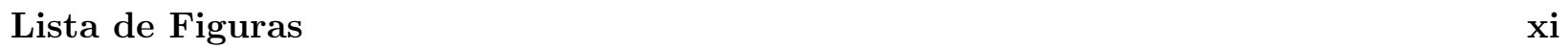

Lista de Tabelas $\quad$ xiii

1 Introdução $\quad 1$

1.1 Motivação . . . . . . . . . . . . . . . . . . . . . . . . . . 3

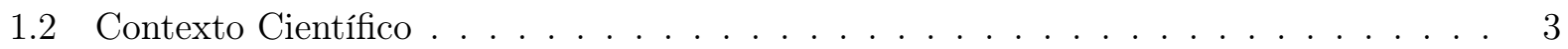

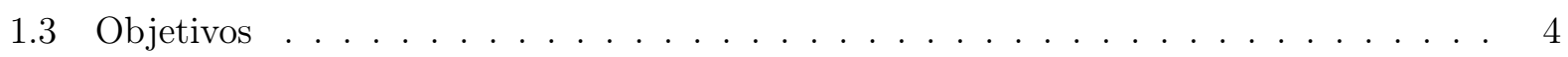

1.4 Organização do Trabalho . . . . . . . . . . . . . . . . . . . . . 5

2 Conceitos Fundamentais $\quad 7$

2.1 Composições de Serviços . . . . . . . . . . . . . . . . . . . . 7

2.2 Computação em Nuvem . . . . . . . . . . . . . . . . . . . . . . . . . . 9

2.3 Modelo de QoS . . . . . . . . . . . . . . . . . . . . . . . . 10

2.3.1 Modelo de composições de serviços . . . . . . . . . . . . . . . . . . . . . . 11

2.3.1.1 Serviços e Instâncias . . . . . . . . . . . . . . . . . . . . . . . 12

2.3.1.2 Coreografias . . . . . . . . . . . . . . . . 12

2.3 .2 Métricas e Atributos de QoS . . . . . . . . . . . . . . . . . . . 12

2.3.2.1 Tempo de Execução . . . . . . . . . . . . . . . . . . . . . . . . . 14

2.3.2.2 Latência . . . . . . . . . . . . . . . . . . . . . 14

2.3.2.3 Tempo de resposta . . . . . . . . . . . . . . . . . . 15

2.3.2.4 Vazão . . . . . . . . . . . . . . . . . . . 15

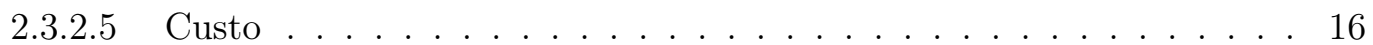

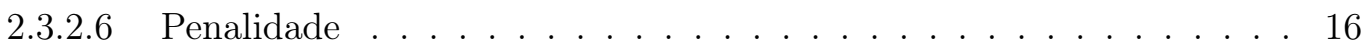

2.3.2.7 Disponibilidade . . . . . . . . . . . . . . . . . . . 16

2.3.2.8 Acessibilidade . . . . . . . . . . . . . . . . . 16

2.3.2.9 Confiabilidade . . . . . . . . . . . . . . . . . 16

2.3.2.10 Acurácia . . . . . . . . . . . . . . . . . . . 17

2.3.2.11 Robustez . . . . . . . . . . . . . . . . . . . 17

2.3.2.12 Segurança no Funcionamento . . . . . . . . . . . . . . . . . 17

2.3.2.13 Manutenibilidade . . . . . . . . . . . . . . . . . . . . . 17

2.3.2.14 Interoperabilidade . . . . . . . . . . . . . . . 18

2.3.2.15 Integridade . . . . . . . . . . . . . . . . . . . 18 
2.3.2.16 Segurança . . . . . . . . . . . . . . . . . . . 18

2.3.2.17 Reputação . . . . . . . . . . . . . . . . . . . . . 18

2.3.2.18 Testabilidade . . . . . . . . . . . . . . . . . . . . . . 19

2.3.2.19 Escalabilidade . . . . . . . . . . . . . . . . . . . . 19

2.3.3 Monitoramento de métricas . . . . . . . . . . . . . . . . . . . . . . . . . . . . . 19

2.4 Reconfiguração de Composições de Serviços . . . . . . . . . . . . . . . . . . . . . 20

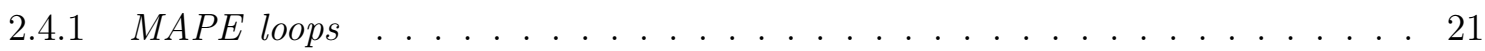

2.4.2 Processamento de eventos complexos . . . . . . . . . . . . . . . . . . 22

2.4 .3 Dependências dinâmicas . . . . . . . . . . . . . . . . . . . . . 24

3 Trabalhos Relacionados $\quad 27$

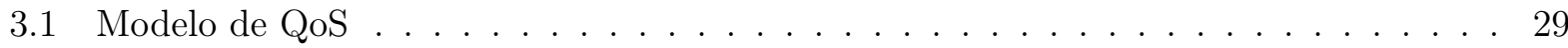

3.2 Seleção de Serviços . . . . . . . . . . . . . . . . . . . . . . . . 30

3.3 Reconfiguração dirigida por $\mathrm{QoS} \ldots \ldots \ldots \ldots$. . . . . . . . . . . . . 32

3.4 Processamento de eventos complexos . . . . . . . . . . . . . . . . . 33

4 Middleware $\quad 35$

4.1 O Enactment Engine . . . . . . . . . . . . . . . . . . . . . . . . . 36

4.2 Gestão de QoS no CHOReOS EE . . . . . . . . . . . . . . . . . . . . . . 40

4.2 .1 Arquitetura . . . . . . . . . . . . . . . . . . . . . . 41

4.2.1.1 Monitoramento . . . . . . . . . . . . . . . . 44 4

4.2 .1 .2 Análise . . . . . . . . . . . . . . . . . . . . 43

4.2 .1 .3 Planejamento . . . . . . . . . . . . . . . . . 44

4.2.1.4 Execução . . . . . . . . . . . . . . . . . . . . . . 44 44

4.2 .2 Implementação . . . . . . . . . . . . . . . . . . . . . . . 45

4.2.2.1 Monitoramento . . . . . . . . . . . . . . . . . . . 45

4.2 .2 .2 Análise . . . . . . . . . . . . . . . . . . . 4 47

4.2 .2 .3 Planejamento . . . . . . . . . . . . . . . . . . . . 48

4.2.2.4 Execução . . . . . . . . . . . . . . . . . . . . 51

4.3 Suporte a coreografias reflexivas . . . . . . . . . . . . . . . . . . 52

5 Avaliação Experimental $\quad 55$

5.1 Configuração dos experimentos . . . . . . . . . . . . . . . . 55

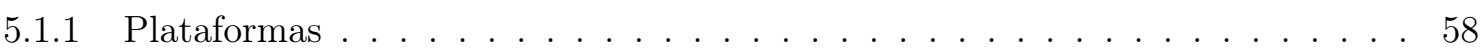

5.2 Resultados . . . . . . . . . . . . . . . . . . . 58

5.2 .1 Escalabilidade horizontal . . . . . . . . . . . . . . . . . . 59

5.2 .2 Escalabilidade Vertical . . . . . . . . . . . . . . . . . . . . . . 61

5.3 Considerações . . . . . . . . . . . . . . . . . . . . . . . . . 62

6 Conclusões $\quad 65$

6.1 Desafios e Limitações . . . . . . . . . . . . . . . . . . . . . . . . . . . . 66

6.2 Trabalhos Futuros . . . . . . . . . . . . . . . . . . 66

$\begin{array}{ll}\text { Referências Bibliográficas } & 69\end{array}$ 


\section{Lista de Abreviaturas}

ADL Linguagem de Descrição Arquitetural. 39

API Application Programming Interface. 9, 10, 35

BPEL Business Process Execution Language. 29

CD Choreography Deployer. 44

CEP Processamento de Eventos Complexos. 3, 22, 24, 27, 33, 36, 40, 41, 43, 44, 47, 51, 56, 65-68

CHOReOS EE CHOREOS Enactment Engine. xi, 35-37, 39, 40, 43, 44, 46-48, 51, 52, 59, 61, 65, 67,68

CORBA Common Object Request Broker Architecture. 7, 29

DM Deployment Manager. 41, 44, 48, 51, 52, 56, 58, 65, 67, 68

IaaS Infrastructure as a Service. 9, 21, 24, 35, 45

JMS Java Message Service. 40, 47

MAPE Monitoramento, Análise, Planejamento, Execução. xi, 3, 21-24, 27, 32, 33, 40, 41, 43, 44, $51,65,66,68$

MPL v2 Mozilla Public License v2. 36, 55

NIST National Institute of Standards and Technology. 9

PaaS Platform as a Service. 4, 9, 21, 25, 32, 35, 45, 68

PM Platform Monitor. 41-43, 45, 67

PNL Performance Non-Scalability Likelihood. 19

POJOs Plain Old Java Objects. 37

QoE Quality of Experience. 43

QoS Qualidade de Serviço. xi, 2-5, 7, 8, 10-24, 26-33, 35-37, 39, 41-48, 51-53, 55, 56, 59, 61-63, $65-68$

REST Representational State Transfer. 36

RMA Resource Manager Aggregator. 41-44, 46-48, 51, 52, 58, 59, 65, 67, 68

SaaS Software as a Service. 9, 39

SE Scalability Explorer. 67

SLA Service Level Agreement. 2-4, 9, 10, 12-18, 21-23, 25, 28-31, 35-37, 41, 43, 44, 48, 52, 55-59, $62,65-68$ 
SM Status Monitor. 44, 52

SOA Service-Oriented Architecture. 1, 7, 24, 32, 35, 41

SOC Computação Orientada a Serviços. 27, 29

WS-CDL Web Service Choreography Description Language. 29

XML eXtensible Markup Language. 36 


\section{Lista de Figuras}

2.1 Estruturas de agregação de serviços . . . . . . . . . . . . . . . . . 8

2.2 Diagrama geral do modelo de Qualidade de Serviço (QoS) . . . . . . . . . . . . . 11

2.3 Modelo de Sistema. . . . . . . . . . . . . . . . . . . . . . . . . . . . . 12

2.4 Atributos. . . . . . . . . . . . . . . . . . . . 13

2.5 Diagrama do modelo de monitoramento . . . . . . . . . . . . . . 20

2.6 Fases do Laço Monitoramento, Análise, Planejamento, Execução (MAPE). . . . . . . 22

2.7 Atualização inconsistente de componente (Considere $t_{0}<t_{1}<t_{2}<t_{3}$ ) . . . . . . 25

4.1 Modelo de dados para implantação de coreografias. . . . . . . . . . . . . . . . 37

4.2 Níveis de tratamento de eventos no CHOREOS Enactment Engine (CHOReOS EE) 40

4.3 Diagrama arquitetural do Enactment Engine . . . . . . . . . . . . . . . . 42

4.4 Mecanismo de válvulas do Tomcat. . . . . . . . . . . . . . . . . . . . . 47

5.1 Taxa de acessos de um dia da página principal em português da Wikipedia. . . . . . 56

5.2 Regra usada para deteç̧ão de tempo de resposta alto. . . . . . . . . . . . . . . 57

5.3 Regra usada para detecção de máquinas virtuais subutilizadas. . . . . . . . . . . . 58

5.4 Tempo de resposta e uso de CPU durante o experimento com política horizontal. . . 60

5.5 Regra usada para notificar que adição de uma réplica é necessária. . . . . . . . . . . . 60

5.6 Regra para notificar que uma réplica de serviço pode ser removida. . . . . . . . . . . 61

5.7 Tempo de resposta e uso de CPU durante o experimento com política horizontal. . . 62 


\section{Lista de Tabelas}

2.1 Classificação dos atributos quanto a forma de medição. . . . . . . . . . . . . . 15

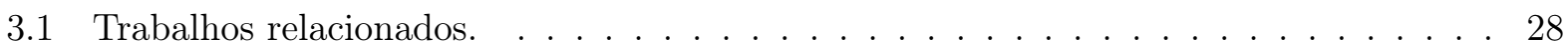

5.1 Especificação das plataformas usadas nos experimentos . . . . . . . . . . . . . . 59 


\section{Capítulo 1}

\section{Introdução}

Sistemas computacionais são escaláveis quando são capazes de executar suas tarefas obedecendo os limites mínimos de desempenho esperados pelos usuários em quaisquer condições dentro do seu limite operacional [MN93]. A variação do número de usuários conectados, a natureza da aplicação e os padrões de uso de recursos computacionais de seus componentes causam flutuações de carga. Quando essas flutuações atingem valores altos, os sistemas precisam de mais recursos para que possam servir suas funcionalidades mantendo bons valores de desempenho. Quando tais flutuações atingem valores mais baixos, é possível ainda a redução de recursos reduzindo assim o custo de manter a aplicação em execução. Ambientes de computação em nuvem oferecem meios de adicionar ou remover recursos computacionais de uma forma simplificada. Um middleware pode usar as facilidades providas pela nuvem para implantar sistemas nesses ambientes e ainda, mantê-los em execução provendo elasticidade. Para isso, deve refletir a elasticidade que há na camada de recursos computacionais na camada de aplicação [MSKC04]. Desse modo, é possível a implementação de sistemas escaláveis que, automaticamente, são reconfigurados em tempo de execução. Para atingir escalabilidade, é necessário também que a arquitetura das composições implantadas pelo middleware possibilite tal característica.

Service-Oriented Architecture (SOA) é uma abordagem de criação de aplicações distribuídas que, dada as características naturais, favorece a escalabilidade. Princípios de SOA são cada vez mais usados para construção de sistemas distribuídos complexos, consolidando-se como uma das principais abordagens para construção de sistemas complexos, despertando cada vez mais o interesse por parte de pesquisadores da área, bem como da indústria de software. Nessa abordagem, sistemas são implementados como composições de serviços web independentes [BDNG06, QZCY07]. Esses componentes, expõem suas funcionalidades como recursos acessíveis em pontos da rede. Orquestração e coreografia são formas bem aceitas de construir composições de serviços. Enquanto orquestrações centralizam o gerenciamento do processo de negócio, coreografias oferecem um controle distribuído entre os nós da composição [IGH+11, BWR09, RT05]; a distribuição lógica da coordenação faz com que as regras de negócio sejam controladas de maneira distribuída, isto é, cada serviço participante da coreografia controla autonomamente para onde envia mensagens e de quem as recebe. A distribuição da lógica pode ser vista como meio de prover maior escalabilidade para cada um dos serviços, atingindo escalabilidade no nível da composição como um todo. Para clientes dessas composições, isso é transparente pois, em geral, a exposição dos recursos acontece por meio de portais que escondem a arquitetura interna da composição de serviços, aparentando para os diversos clientes como sendo um único serviço.

Diferentes serviços de uma composição oferecem funcionalidades distintas. Por isso, apresentam diferentes padrões de uso de recursos computacionais. Sendo assim, um serviço específico pode requerer mais tempo de processamento enquanto outro, mais largura de banda ou acesso a disco. Não somente a funcionalidade inerente dos serviços pode influenciar a carga de trabalho de uma composição, como também a flutuação de carga devida a hora do dia ou, dias especiais em uma semana. Por exemplo, uma sistema de e-commerce recebe pouca carga de trabalho durante o período da noite, porém durante o dia, o número de usuários ativos é maior, gerando mais carga. Esse cresci- 
mento se torna maior e mais impactante quando algum evento promocional acontece. Flutuações desse tipo implicam na necessidade de gerir os recursos alocados para cada serviço de maneira que os usuários da aplicação não sintam queda de desempenho. Dado a composição arbitrária desses serviços e o padrão de utilização de recursos, o conhecimento prévio da quantidade necessária de recursos computacionais é algo difícil de prever. Nesse contexto, um middleware implementado para executar composições de serviços, deve contar com mecanismos para que, durante flutuações de carga, consiga manter os recursos necessários para que o sistema seja executado em boas condições, cuidando para que não haja desperdício de recursos.

Clientes dessas composições esperam que os recursos expostos respondam com resultados corretos e um nível adequado de Qualidade de Serviço (QoS). QoS é um conjunto de requisitos que associa métricas e valores desejáveis a atributos de qualidade referentes a propriedades não-funcionais de um serviço. Por exemplo, a vazão (atributo) de uma determinada operação, avaliada em requisições/segundo (métrica), deve estar acima de 100 (valor mínimo desejado). Normalmente, esses requisitos esperados são formalizados por meio de Service Level Agreements (SLAs), que definem (na forma de contratos) conjuntos de propriedade não-funcionais e valores limites para estas, de maneira individual para cada composição de serviço. SLAs, são conjuntos que formalizam restrições de QoS que definem o comportamento não-funcional esperado de um serviço. A quebra desse contrato corresponde a alguma penalidade financeira.

Para garantir níveis desejados de QoS durante o tempo de execução das composições de serviços, os recursos alocados para cada serviço precisam ser continuamente avaliados e, se necessário, realocados conforme a condição da carga de trabalho. Portanto, qualquer alocação estática de recursos que não possa se adaptar a mudanças do ambiente de execução, como por exemplo o número de clientes simultâneos que acessam um determinado serviço, causa degradação do QoS da composição de serviços. A forma como é implantado cada serviço, bem como o gerenciamento de suas dependências deve ser levado em consideração pelo middleware. Caso contrário, o aumento e diminuição de carga pode causar violações de SLA.

Considerando ambientes de nuvem, o SLA é tratado em diferentes perspectivas:

Usuário final: SLA formalizado junto ao usuário final da composição de serviços. Nesse caso, o cliente contrata o sistema como um serviço e espera consumir os recursos oferecidos pela aplicação com o QoS no nível desejado.

Provedor/desenvolvedor da aplicação: O provedor da aplicação deve entregar as funcionalidades dos serviços sem que o SLA com o cliente seja violado. Para tal, é necessário receber os serviços de infraestrutura dentro do SLA esperado. Do contrário, cumprir SLAs se torna uma tarefa complexa. Por exemplo, a indisponibilidade intermitente de máquinas virtuais causa a indisponibilidade nos serviços nela implantados. Para redução do custo, é necessário que recursos sobre-alocados sejam desalocados.

Provedor da infraestrutura: É necessário que o provedor de recursos virtuais respeite o SLA formalizado junto ao provedor de serviços. Para que seja possível o cumprimento de SLA dentro de valores acordados por parte do provedor de serviços, é imprescindível que seja cumprido o SLA por parte do provedor de recursos. A violação de SLA acarreta prejuízos financeiros assim como acontece no caso anterior, geralmente como algum desconto para o provedor da aplicação.

O custo para manter ligados os recursos físicos presentes no ambiente de computação em nuvem é considerado como atributo de QoS a ser diminuído. É importante para provedores de infraestrutura que, com a diminuição do consumo de recursos virtuais, máquinas físicas sejam postas em estado de suspensão. A otimização do uso de recursos com intuito de diminuir gastos com energia tem sido objeto de interesse em pesquisa na atualidade [ZWW11].

O estudo de abordagens em que a análise de QoS é usada compreende uma área ampla. Dentre as abordagens vistas na literatura, as que se destacam são: seleção de serviços web baseada 
em QoS, composição de serviços ideal, serviços web tolerantes a falha, recomendação de serviços com funcionalidades semelhantes, previsão de QoS em composições de serviços e reconfiguração de composições de serviços [ZL13b]. Neste trabalho, o interesse está na última abordagem.

\subsection{Motivação}

Reconfiguração dinâmica $\left[\mathrm{CdLG}^{+} 09\right]$, habilita sistemas a adaptar-se devido a mudanças nas condições do ambiente em que estão sendo executados. A variação de carga durante o tempo de execução demanda reconfiguração para que SLAs sejam cumpridos. A finalidade é manter aplicações funcionando corretamente diante dessas flutuações de carga. Ambientes de computação em nuvem provêm a seus usuários recursos virtuais com elasticidade. A adição e remoção de recursos pode ser realizada dinamicamente nesses ambientes, com baixo impacto na execução das aplicações. É importante destacar também que essa elasticidade é feita de maneira simples e em um curto intervalo de tempo. Com o crescente aumento na adoção desses ambientes, reconfiguração dinâmica é um tópico de grande relevância como meio de gerenciar QoS e custo financeiro. Além disso, se as reconfigurações são executadas a tempo, sistemas tornam-se mais robustos e tolerantes a falhas. Um middleware projetado para implantar e gerenciar QoS de composições de serviços nesses ambientes, deve ser implementado usando modelos de adaptação que utilizem essa elasticidade da nuvem.

Modelos de adaptação dinâmica normalmente levam em conta as informações de estado do sistema obtidas durante o tempo de execução por algum sistema de monitoramento. Com base nessas informações, são então modificadas algumas propriedades do sistema. Várias abordagens para a realização de adaptação dinâmica são descritas na literatura. Entre elas, o uso de control loops denominados MAPE [MBEB11] aparenta ser bastante promissor. Muitas vezes, uma base de conhecimento é usada em conjunto com os resultados de monitoramento para melhorar o processo de decisão, seja como um meio para melhorar a precisão de uma previsão de QoS ou como um repositório de soluções comprovadas para uma situação recorrente [MBEB11]. Nesse caso, temos a especialização da abordagem citada MAPE-K (Knowledge), em que bases de conhecimento são usadas para aumentar o desempenho do sistema. Outros modelos usados fazem análises do comportamento de serviços baseados em sistemas biológicos onde os componentes cooperam entre si e, por meio de operações de cruzamento e mutações, reconfiguram-se para encontrar uma configuração adequada para atingir níveis esperados de QoS.

Processamento de Eventos Complexos (CEP) [LF98] é uma técnica de processamento de eventos que, a partir da coleta de eventos, infere situações diversas dentro de um sistema. O uso de CEP em ambientes distribuídos adiciona a capacidade de lidar com eventos de múltiplas fontes distribuídas. Se utilizado para realizar as fases do MAPE, adiciona flexibilidade em várias situações envolvidas no processo de reconfiguração. Na fase de monitoramento dos recursos e atributos de QoS, há possibilidade de gerar eventos a partir de diversas métricas de acordo com o domínio da aplicação a ser monitorada. A análise de eventos e a escolha de um plano reconfiguração são feitas por meio de mecanismos de regras lógico-temporais que fazem a correlação entre dois ou mais exemplos. Regras podem ser definidas de acordo com a necessidade da aplicação, podendo ser desde regras simples e genéricas até regras complexas, dependentes do domínio da aplicação, para validação de SLAs. As decisões que serão tomadas no momento da execução também se beneficiam da vantagem de poder criar gatilhos específicos para cada regra. Embora neste trabalho estamos focando em regras relacionadas a desempenho, a flexibilidade da arquitetura do sistema de middleware proposto permite regras que atende a níveis de SLA relacionados a confiabilidade e segurança.

\subsection{Contexto Científico}

O trabalho de pesquisa realizado está no contexto dos projetos $\mathrm{CHOReOS}^{1}$ e Baile ${ }^{2}$. Ambos tinham o propósito de estudar a aplicação de coreografias como forma de composição de serviços

\footnotetext{
${ }^{1}$ http://www.choreos.eu

${ }^{2}$ http://ccsl.ime.esp.br/baile
} 
suficientes para melhor escalabilidade. No CHOReOS, o objetivo foi a criação de um ambiente de síntese e encenação de coreografias. Vários parceiros acadêmicos e industriais participaram desse projeto financiado pela Comissão Europeia ${ }^{3}$. No Baile, estudamos características de desenvolvimento voltados à composições de serviços. Neste último, participou a empresa Hewlett-Packard tanto em pesquisa como financeiramente.

Como resultados preliminares publicamos os seguintes artigos, os quais tiveram em colaboração com o pós-doutorando Emílio Franscesquini da Universidade de Campinas e o gerente técnico do Centro de Competência em Software Livre (CCSL) da USP, Nelson Lago:

- Towards an Enactment Engine for Dynamically Reconfigurable and Scalable Choreographies Proceedings of IEEE First International Workshop on Service Orchestration and Choreography for the Future Internet (OrChor 2014)

Thiago Furtado, Emílio Francesquini, Nelson Lago e Fabio Kon

IEEE 10th World Congress on Services (SERVICES 2014), Anchorage, Alaska, USA

- A Middleware for Reflective Web Service Choreographies on the Cloud

The 13th Workshop on Adaptive and Reflective Middleware (ARM 2014)

Thiago Furtado, Emílio Francesquini, Nelson Lago e Fabio Kon

ACM/IFIP/USENIX ACM International Middleware Conference 2014, Bordeaux, France, December 8-12

\subsection{Objetivos}

Sendo o IME-USP participante no Projeto CHOReOS, sua responsabilidade foi de criar o middleware responsável pela implantação automatizada de coreografias de serviços. Leonardo Leite, em sua pesquisa de mestrado tratou de problemas ligados a implantação de serviços, criando então a base do middleware. Embora o papel fosse de implantar coreografias, o middleware está preparado para implantar composições em geral tais como orquestrações e serviços isolados. Esse middleware executa o papel de um Platform as a Service (PaaS) para composições. O middleware tem a capacidade de, automaticamente, criar e configurar recursos computacionais virtuais em ambientes de nuvem pré-configurados, implantar os serviços e suas dependências e executá-los.

O objetivo desta pesquisa de mestrado é estender esse middleware, habilitando ele a gerir QoS nas composições de serviços implantadas. Adicionalmente, para que seja possível manter o QoS durante o tempo de execução, o middleware monitora métricas de QoS e de recursos virtuais no intuito de, por meio de mecanismos de reconfiguração dinâmica, prover elasticidade mantendo o QoS dentro dos valores desejados, especificados por meio dos contratos de SLAs.

Este trabalho ainda apresenta um modelo de QoS em que descrevemos os atributos e métricas usados para análise dos serviços e o modelo de composições de serviços utilizado. Com esse modelo, o desenvolvedor fica apto a construir composições de serviços escaláveis. Não é nosso foco o julgamento de quais os melhores valores para os atributos de SLAs nem a importância de cada métrica para o usuário. O uso de mecanismos de regras permite que cada cliente configure os valores preferíveis de acordo com o domínio da aplicação.

A fim de avaliar a eficácia do nosso sistema, realizamos uma avaliação experimental que monitora um subconjunto de atributos e métricas de QoS na tentativa de evitar violações de SLA. Quando necessário, é aplicado escala vertical e horizontal nas composições implantadas. Mostramos que o sistema é capaz de, dinâmica e automaticamente, manter o QoS dentro dos níveis esperados, durante períodos de variação de carga. O objetivo é alcançado por meio de adição de recursos (no caso de sobrecarga), e remoção de recursos (no intuito de não sobre alocar recursos quando a carga diminui). O middleware apresenta facilidades para o desenvolvedor das composições quanto à descrição da arquitetura da composição (serviços individuais e dependências entre si) e quanto à criação das regras de análise e reconfiguração.

\footnotetext{
${ }^{3}$ http://ec.europa.eu/index_pt.htm
} 


\subsection{Organização do Trabalho}

Este trabalho, está organizado da seguinte forma. O Capítulo 2 descreve os conceitos necessários sobre composições de serviços, modelos de QoS e reconfiguração dinâmica. O Capítulo 3 apresenta os trabalhos relacionados com a pesquisa realizada, incluindo a comparação entre as abordagens. A arquitetura e os detalhes de implementação do middleware apto a reconfigurar dinamicamente composições de serviços é apresentado no Capítulo 4. No Capítulo 5 são mostrados os resultados obtido a partir da avaliação experimental do middleware. Finalmente, no Capítulo 6 concluímos o trabalho destacando pontos de pesquisas que podem ser abordados na sequência da pesquisa. 


\section{Capítulo 2}

\section{Conceitos Fundamentais}

Neste capítulo, apresentamos os conceitos básicos necessários para o desenvolvimento deste trabalho. Inicialmente, na Seção 2.1, apresentamos conceitos sobre composições de serviços. Em seguida, na Seção 2.2 abordamos conceitos fundamentais sobre computação em nuvem. Na Seção 2.3, é detalhado a proposta de modelo de QoS incluindo os atributos que devem ter seus valores monitorados para que uma composição possa atender a diferentes níveis de QoS. Esse modelo será usado para monitoramento e manutenção de QoS na avaliação experimental. Finalmente, na Seção 2.4, é mostrada a importância que há em gerenciar o QoS de composições implantadas em ambientes de computação nuvem. Além disso, é mostrado os detalhes técnicos que possibilitam o monitoramento de cada composição, no âmbito de automaticamente reconfigurá- las para atender seus clientes com eficiência e bom desempenho.

\subsection{Composições de Serviços}

SOA é uma abordagem arquitetural cada vez mais utilizada para o desenvolvimento de sistemas distribuídos complexos [OMB07]. Sistemas baseados em SOA, são compostos por serviços web que colaboram entre si. Esses serviços são componentes plugáveis que oferecem tarefas bem definidas. Assim, a colaboração entre os componentes tem a finalidade de executar tarefas complexas. Esse modelo de colaboração entre tarefas com sequências bem definidas é comumente conhecido como processo de negócio. Tais sistemas expõem suas funcionalidades na forma de recursos por meio da interface de seus serviços componentes, as quais podem ser publicadas, encontradas e utilizadas [PTDL07, Pou11]. SOA define um modelo de arquitetura para sistemas distribuídos, deixando a cargo do desenvolvedor a escolha das tecnologias que serão usadas para implementação dos componentes do sistema.

Serviços são entidades independentes, implementados de forma independente que encapsulam seus detalhes de implementação e funcionamento. Consequentemente são heterogêneos tanto em relação à tecnologia usada para sua construção quanto à plataforma usada para execução. Serviços web expõem suas funcionalidades através de pontos de acessos que, assim como os objetos presentes na especificação Common Object Request Broker Architecture (CORBA), oferece meios para que seja possível criar sistemas compostos de entidades conectáveis. Sistemas que utilizam SOA ainda tem a vantagem de permitir o reúso de seus componentes por meio da interface dos serviços publicados [SAS11]. Isso porque os detalhes e lógicas utilizadas na implementação das operações ficam encapsulados; o que fica exposto é a interface usada para comunicação, cujo modo de comunicação é bem definido. Assim, fica transparente as interações que ocorrem entre os serviços componentes de uma aplicação. Com isso, podemos considerar serviços sendo atômicos ou compostos (Serviços web, serviços ou componentes serão usados intercambiavelmente no decorrer deste trabalho).

Serviços atômicos São serviços que processam requisições sem que uma chamada remota a outros serviços seja necessária [ $\left.\mathrm{TZC}^{+} 04\right]$, ou seja, serviços que não têm dependências. É caracterizado por serem as unidades básicas de sistemas baseados em SOA e, consequentemente, as operações 
expostas por esses serviços têm sua computação indivisível, ou seja, os serviços são autônomos em relação à geração dos resultados finais; recebem requisições, executam todo o processamento internamente e responde ao cliente que o chamou. É importante ressaltar que, para fins de manutenção de QoS, a degradação do QoS de um serviço atômico influencia no QoS do sistema como um todo [CHK07]. Por exemplo, se um serviço atômico tem seu tempo de resposta muito alto, serviços que fazem chamadas remotas a esse serviço apresentarão baixo desempenho.

Serviços compostos São agregações estruturais de serviços $\left[\mathrm{ZBD}^{+} 03\right]$ (atômicos ou outros serviços compostos) que, para a execução de uma operação, necessitam de processamentos parciais realizados pela cooperação entre eles. De acordo com o processo a ser executado, uma requisição à uma operação de um serviço composto irá desencadear requisições subsequentes para outros serviços. Devido ao encapsulamento das operações, são vistos como serviços atômicos, em razão do acesso que é feito via um único ponto de conexão. Conforme a maneira como essas agregações são feitas, podemos classificá-las como estruturas em sequência, em alternância, em laço ou em paralelo [JRGM04] (Veja Figura 2.1).

Figura 2.1: Estruturas de agregação de serviços

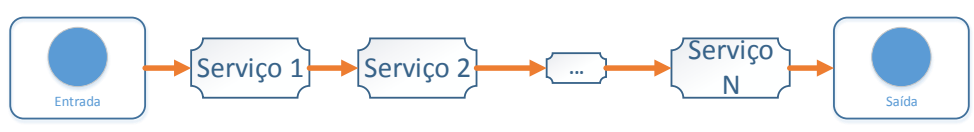

(a)

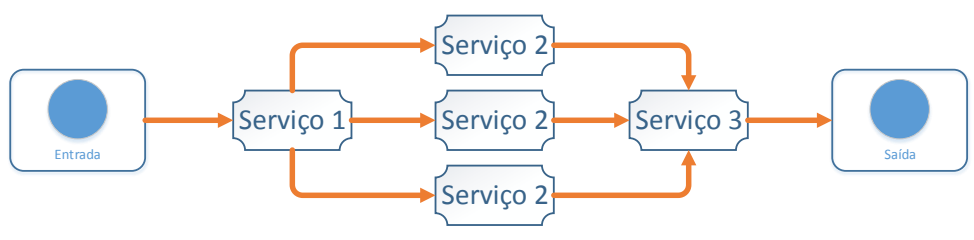

(b)

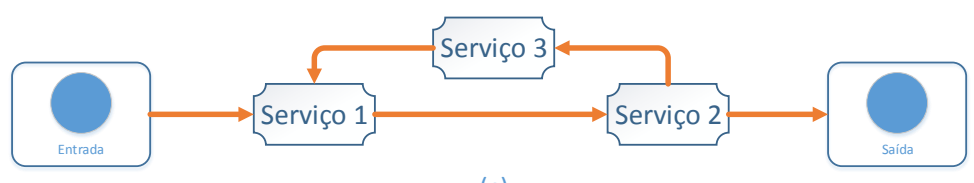

(c)

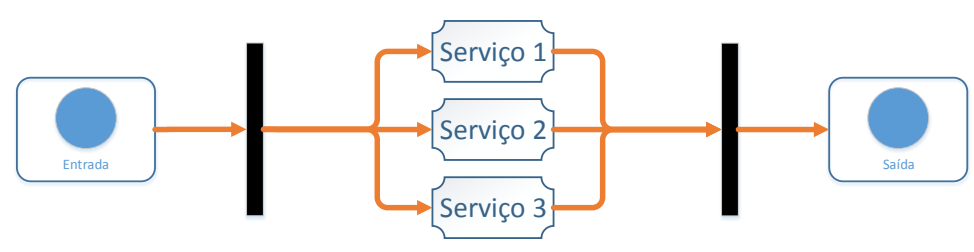

(d)

Duas principais abordagens para construção de composições de serviços são largamente utilizadas: orquestração e coreografia. Ambas são bem aceitas e têm sido abordadas por vários pesquisadores [RT05, $\mathrm{DNGM}^{+}$08, BWR09, $\left.\mathrm{IGH}^{+} 11\right]$. Além disso, oferecem facilidades arquiteturais para adaptação dinâmica. Este trabalho não tem propósito de definir formalmente as características de cada uma, nem descrever as vantagens e desvantagens que há na escolha de cada uma delas. No entanto, existem pesquisas que apontam como ponto fraco a existência de ponto único de falha quando orquestrações são utilizadas [AS14].

Orquestrações são caracterizadas por ter o controle de interação entre os serviços feito por um nó orquestrador [PvdH07]. Esse serviço central, detém o conhecimento de toda a composição e coordena o fluxo de dados trocados entre os vários serviços componentes do sistema. Orquestrações definem 
um processo de negócio em forma de composição. Em coreografias, não existe um componente central; o controle sobre a interação entre os serviços é distribuído. Cada serviço participante de uma coreografia é responsável por papéis pré-definidos. Através desses papéis, serviços são capazes de fazer sua própria gestão de dependências. Além disso, é necessário que os resultados produzidos estejam corretos, pois não há um intermediador para aferí-los. Portanto, a manutenção da qualidade dos resultados é de extrema importância. Coreografias tendem a ser mais escaláveis pois as regras do processo de negócio executado pela composição está distribuída.

Para ser escalável, um sistema deve estar preparado para receber grandes quantidades de carga, sem que suas funcionalidades sejam afetadas ocasionando queda de desempenho. Serviços podem atender a requisições em múltiplos pontos de acesso. Assim, réplicas de um mesmo serviços podem ser criadas para fazer balanceamento de carga. Sendo representação do mesmo serviço, podem ser usadas intercambiavelmente pois expõem seus recursos por interfaces idênticas. No entanto, para que isso seja possível, é comum o uso de serviços sem estado (stateless services). O uso de serviços com estado (stateful services) não impede a replicação de serviços. No entanto, seria necessário o uso de controle de sessão, restringindo os serviços quanto à escolha de quais réplicas usar.

\subsection{Computação em Nuvem}

Segundo o National Institute of Standards and Technology (NIST) [MG09] computação em nuvem é um modelo que define um padrão de computação em que recursos são oferecidos através de grupos compartilhados. Tais recursos são requisitados sob demanda e de forma ubíqua e a alocação e desalocação são realizadas com facilidade e rapidez. Ambientes de computação em nuvem são considerados uma boa alternativa para alcançar escalabilidade em sistemas distribuídos. Na nuvem, é possível alocar inicialmente uma quantidade inicial mínima de recursos e, conforme a demanda, aloca-se recursos adicionais rapidamente. O conceito de computação em nuvem não adiciona nenhuma novidade tecnológica na área de sistemas distribuídos. Pelo contrário, define um modelo de negócios onde o propósito é oferecer recursos computacionais como serviços, agregando tecnologias já existentes como, por exemplo, virtualização.

A nuvem pode ser vista como uma infraestrutura "infinitamente" escalável. Tais ambientes são conjuntos de recursos virtuais, providos dinamicamente sob contratos feitos baseados em SLAs [BYV $\left.{ }^{+} 09\right]$. Recursos físicos são interconectados por rede e entregues como recursos compartilhados [HK11]. O provedor tem a vantagem de aproveitar ao máximo seus recursos físicos. A nuvem oferece meios de facilmente escalar recursos devido ao tempo curto suficiente para criação de novas máquinas virtuais ou migração para novas configurações.

Recursos na nuvem são oferecido em três modelos de negócio: Infrastructure as a Service (IaaS), Platform as a Service (PaaS) e Software as a Service (SaaS). No modelo IaaS, o serviço provido ao consumidor é geralmente a criação sob demanda de máquinas virtuais. É usual o provimento de nós computacionais para fins bem determinados como processamento, armazenamento e demais recursos de infraestrutura. Exemplos de serviços disponibilizados no modelo IaaS são Amazon $A W S^{1}$ e Rackspace $^{2}$. Nesse modelo, clientes não precisam se preocupar com manutenção de clusters privados nem com a instalação de sistema operacional em suas máquinas.

No modelo PaaS, o produto entregue ao consumidor é uma plataforma de software em um nível mais alto, geralmente vista como uma pilha de sistemas que possibilita a criação de aplicações, deixando transparente a camada de nós virtuais. Neste modelo, clientes são capazes de criar aplicações em linguagens específicas, utilizando ferramentas disponibilizadas a partir de Application Programming Interfaces (APIs). A plataforma Google App Engine ${ }^{3}$ é um exemplo desse modelo. Nela, desenvolvedores podem desenvolver suas aplicações baseadas nas linguagens Java, Python, PHP e Go. Como facilidades, oferece bibliotecas base para autenticação e armazenamento de dados.

Por fim, o modelo SaaS promete a entrega de aplicações finais, acessíveis remotamente por

\footnotetext{
${ }^{1}$ http://aws.amazon.com/Amazon AWS

${ }^{2}$ http://www.rackspace.com/Openstack

${ }^{3}$ https://cloud.google.com/appengine/docs
} 
interfaces web e aplicativos móveis. Esse modelo está no nível mais alto dos ambiente de computação em nuvem; utiliza as facilidades providas pela infraestrutura. Serviços de e-mail e sincronismos de arquivos são exemplos de aplicações possíveis de ser entregues como serviços. Um exemplo real é o serviço de controle de versões Bitbucket ${ }^{4}$.

O modelo de nuvem favorece a implantação e gestão de QoS de composições de serviços. Os serviços de entrega de máquinas virtuais somado às APIs via interfaces remotas permite a automatização dos processos de implantação e manutenção das composições. Entretanto, para que seja possível promover escalabilidade por meio dessas manutenções é necessário o uso de modelos de composições de QoS que facilitem refletir a flexibilidade da nuvem na camada de sistemas. A seguir este trabalho propõe um modelo de QoS para construção de um middleware capaz de gerenciar QoS em composições implantadas em ambientes de computação em nuvem.

\subsection{Modelo de QoS}

Provedores de serviços e seus clientes podem negociar características de QoS. Os detalhes da negociação contém atributos e métricas relevantes que dependem da aplicação e do cliente específico. Isso gera uma variedade de configurações que devem ser especificadas por meio de contratos de SLA. SLAs são acordos feito entre clientes e provedores de serviços que descrevem os serviços, as garantias e possíveis ações caso essas garantias sejam violadas [ADC10]. O padrão usado para a definição de SLAs é o descrito pelo grupo Open Grid $\left[\mathrm{ACD}^{+} 07\right]$. Garantias presentes em SLAs geralmente são fundadas sobre propriedades dos serviços relacionados. Tais garantias são traduzidas em restrições de QoS que são continuamente monitoradas. Logo, é necessário um modelo de QoS que ofereça meios de definir os níveis de qualidade esperados.

Um modelo de QoS é uma descrição formal de atributos e métricas que definem a qualidade de um serviço em termos de propriedades não-funcionais. Propriedades não-funcionais são aquelas que não estão diretamente ligadas às funcionalidades dos serviços, mas interferem no seu correto funcionamento. Por exemplo, um serviço deve responder a requisições num tempo operacional aceitável. Do contrário, mesmo que a resposta esteja correta, a qualidade do serviço estará afetada. Neste trabalho, propomos um modelo de QoS composto por três partes: o modelo da composição de serviços que será implantada e monitorada, o conjunto de atributos de qualidade e métricas de avaliação que irão compor os requisitos de SLA e o modelo de monitoramento de QoS bem como as estratégias de reconfiguração para que os sistemas sejam adaptados dinamicamente em função de seu QoS. A Figura 2.2 mostra a representação geral do modelo proposto nesta dissertação.

É importante que modelos de QoS sejam flexíveis. A diferença entre as várias composições que podem ser monitoradas e a importância que cada atributo tem dependendo do domínio da aplicação devem ser levadas em consideração. Neste trabalho, para cobrir essa necessidade, é possível especificar funções de avaliação específicas para cada métrica a ser medida. Mediante a forma como a função de avaliação é concebida, métricas podem ter características quantitativas ou qualitativas. Um mesmo atributo pode ainda ser medido quantitativa ou qualitativamente dependendo das necessidades dos clientes e responsabilidades dos provedores.

SLAs são definidos por composição de serviços independentemente. A cada serviço componente pode ser adicionado conjuntos de SLAs a ser monitorados sendo que cada item de SLA é definido especificamente conforme a necessidade. Baseado nos limites impostos no SLA, um mecanismo de análise é responsável por detectar eventos criados a partir de monitores. A análise desses eventos pode ativar regras que irão agendar reconfigurações de acordo com as estratégias existentes. Arquiteturas baseadas em eventos favorece a flexibilidade requerida [LF98].

Na Subseção 2.3.1, detalhamos o modelo de composição de serviços usado. Na Subseção 2.3.2, apresentamos o modelo de QoS definindo os atributos relevantes e as métricas usadas para a obtenção das medidas dos atributos. Na Subseção 2.3.3, é mostrado nossa abordagem de monitoramento de QoS baseada em eventos.

\footnotetext{
${ }^{4}$ https://bitbucket.org
} 
Figura 2.2: Diagrama geral do modelo de QoS

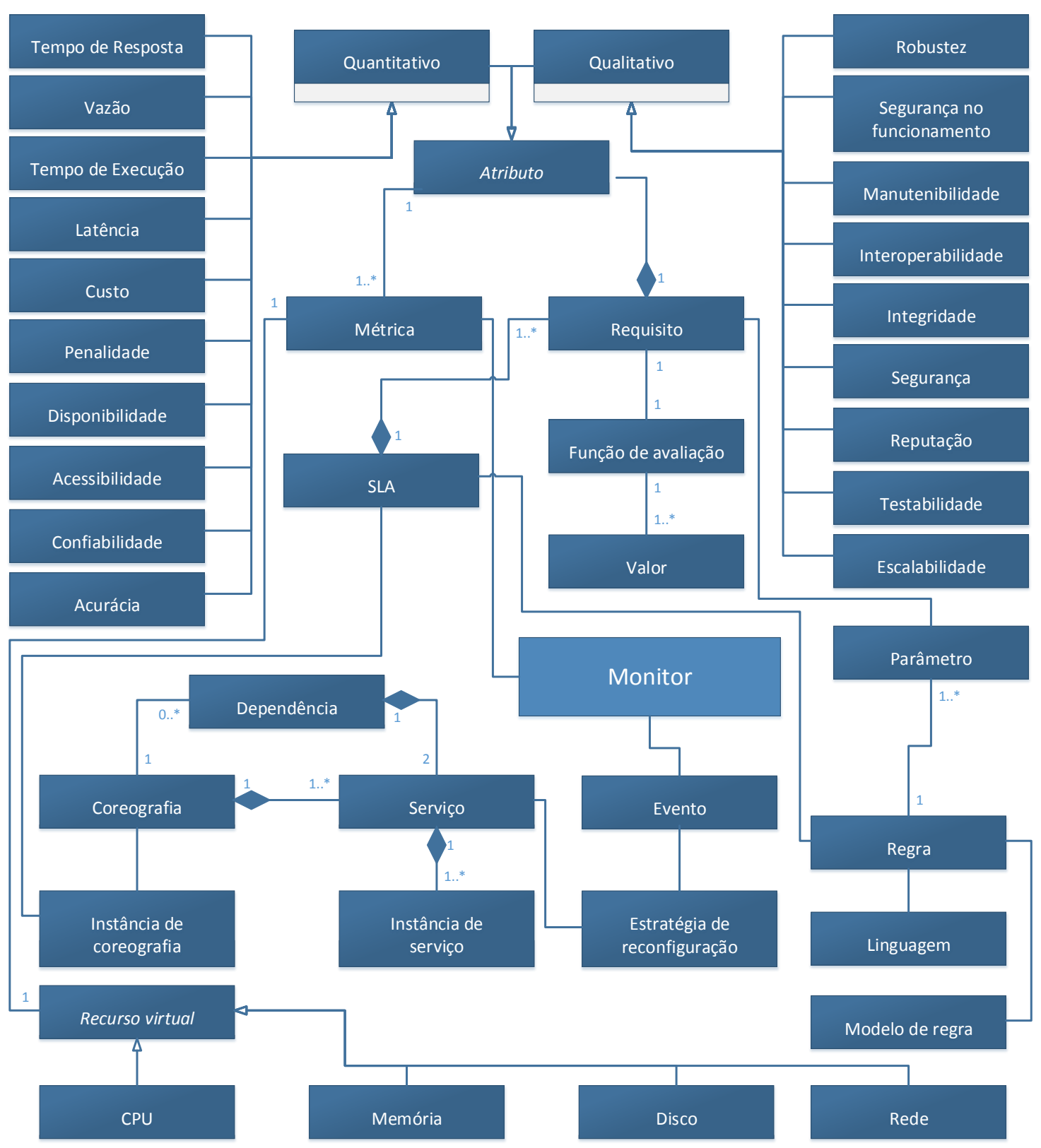

\subsubsection{Modelo de composições de serviços}

Gerir QoS em composições de serviços, envolve a manutenção de cada serviço. O aumento e diminuição da carga de trabalho implica em prover alguma forma de lidar com escalabilidade individual. Como já vimos, a degradação do QoS de um único serviço, causa degradação do QoS da composição como um todo. Uma maneira de prover escalabilidade esta no uso de réplicas de serviços (o uso dos termos réplica e instância de serviço é equivalente neste trabalho). Dessa forma, em nossa representação, um serviço passa a ser uma estrutura de dados que contém informações comuns para um conjunto de instâncias desse serviço.

As funcionalidades descritas para um serviço são de fato, servidas por cada instância uma vez que serviços são entidades abstratas. Cada instância implementa uma mesma interface, podendo ser usadas de forma intercambiável desde que os serviços componentes não troquem mensagens que dependem do estado das transações (Stateless services). Para serviços que fazem troca de mensagens baseadas no estado das transações (Stateful services), o uso intercambiável de réplicas fica restrito apenas para os casos em que alguma forma de gerenciamento de sessões seja implementada. A Figura 2.3 ilustra os componentes do modelo de sistemas usado para implementação das coreografias. 


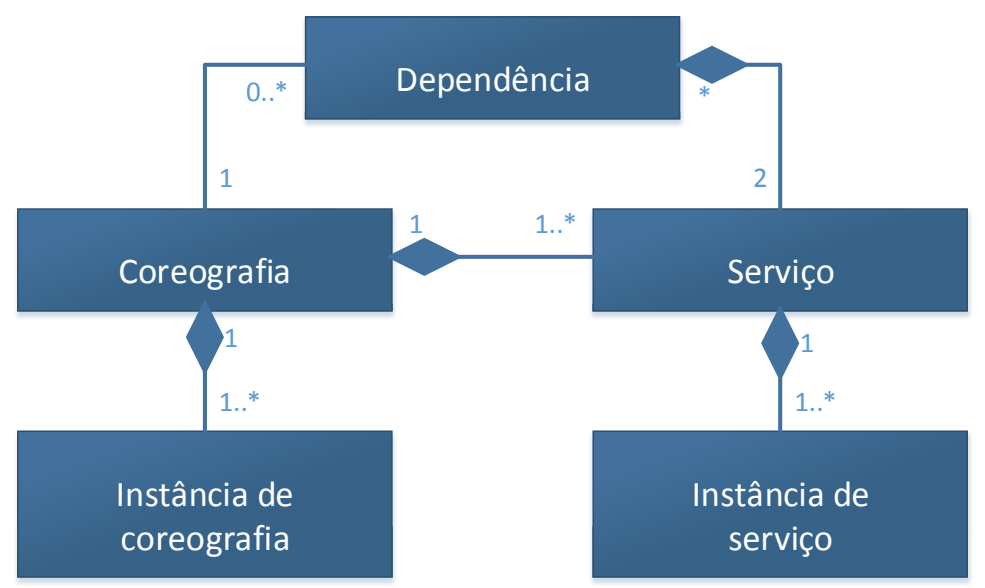

Figura 2.3: Modelo de Sistema.

\subsubsection{Serviços e Instâncias}

Cada componente de uma coreografia é modelado a partir da definição dos serviços e suas instâncias. Esse modelo é usado para permitir melhor escalabilidade para a composição como um todo; a elasticidade se dá no nível das instâncias, as quais são replicadas e removidas conforme a flutuação da carga.

Cada serviço armazena as informações de quais instâncias estão em execução, isto é, a situação atual de implantação do serviços. Adicionalmente, define as informações comuns para as várias réplicas que são implantadas. Essas informações remetem aos dados utilizados para realizar a implantação. Por exemplo, a URL para baixar os arquivos implantáveis, o número atual de réplicas que estão sendo executadas e ainda as definições de requisitos de SLA.

Como foi dito anteriormente, para que possamos criar composições escaláveis, instâncias de serviço executam o papel funcional do serviço representado. São responsáveis por armazenar informações de contexto de implantação dos artefatos, como por exemplo, a URL pública para acesso à instância e as configurações da máquina virtual que hospeda a instância.

\subsubsection{Coreografias}

Representação estrutural de uma coreografia contendo os serviços participantes e suas dependências. Uma dependência associa o Serviço $A$ ao Serviço B. Essa associação indica que o Serviço $A$ depende do processamento parcial que o Serviço $B$ provê para que possa responder às requisições corretamente. Adaptar coreografias dinamicamente requer a redefinição em tempo de execução das dependências entre serviços, isto é, a quantidade de réplicas ou a localização de um serviço movido deve ser informada aos serviços que os utilizam. Para isso, as dependências no modelo proposto estão desacopladas dos serviços.

O modelo de composição usado é de extrema importância na integração de composições e QoS, uma vez que, a manutenção de QoS depende da manutenibilidade que a composição proporciona. Uma composição apresentando arquitetura que limita a elasticidade limita as adaptação possíveis a ser realizadas pelo middleware.

\subsubsection{Métricas e Atributos de QoS}

No modelo de sistemas discutido, para cada serviço participante de uma coreografia, um SLA é associado. Isso porque serviços diferentes têm comportamentos distintos; a variação da quantidade de requisições dos vários clientes e a forma como os recursos virtuais são utilizados torna imprescindível que seus atributos sejam analisados de forma individual e específica. Dessa forma, o requisitos de SLA de cada serviço devem ser configurados separadamente. 
No nosso modelo, requisitos de SLA são definidos como uma tupla $R=(a, m, f)$ onde $a$ é o Atributo que determina qual a propriedade não-funcional que deve ser avaliada, $m$ é a Métrica associada ao atributo que expressa de maneira formal como o atributo deve ser medido e $f$ é a Função de Avaliação, usada para avaliar os valores medidos e compará-los, de acordo as métricas corretas e com os limites impostos para o atributo (Ver Figura 2.4).

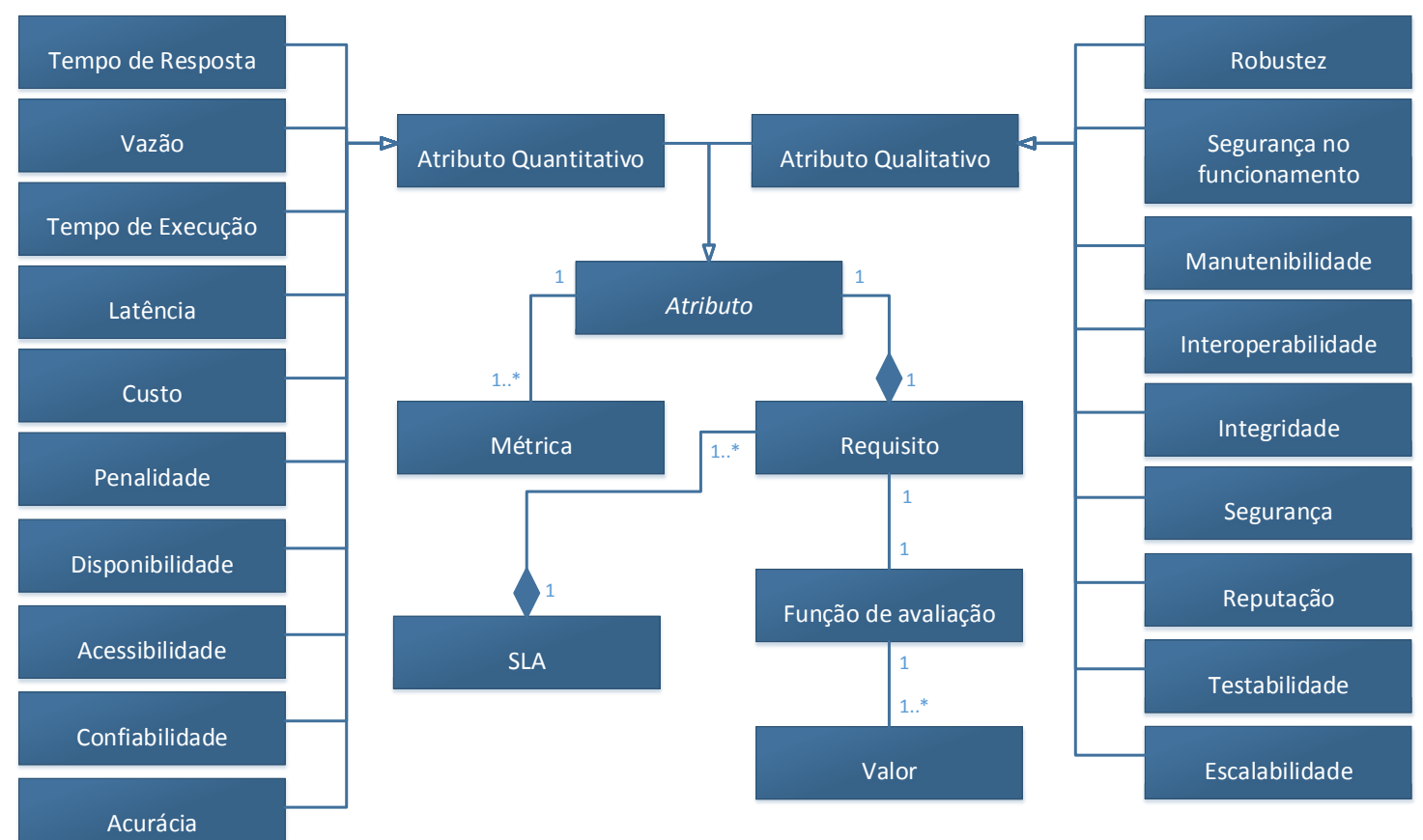

Figura 2.4: Atributos.

Cada atributo é medido por meio de uma métrica apropriada que pode variar dependendo da necessidade do usuário. Métricas formalizam procedimentos para medição de atributos em geral. Métricas de QoS no contexto de serviços, definem como um atributo de QoS deve ser medido. Na busca de definição de métricas para medição de QoS, autores apresentam várias definições de métricas para um determinado atributo. De fato, diferentes aplicações requerem diferentes métricas. Por exemplo, para uma aplicação de mídia em tempo real, a vazão pode ser medida como quantidade de frames trafegados pela rede enquanto que, para um outro serviço, é a quantidade de requisições atendidas num período de tempo.

A fim de permitir a configuração flexível das métricas, desacoplamos destas a sua função de avaliação. Uma função de avaliação é uma instância de uma métrica, e está em conformidade com a forma como deve ser avaliada. A partir da função de avaliação, uma medição é realizada e seu valor pode ser usado para comparação e análise. Há uma grande distinção entre o conceito métrica e de medida; o resultado da avaliação de um atributo tem como saída uma medida, que é um valor que pode ser comparado posteriormente a fim de julgar se aceitável ou não. Por exemplo, o atributo disponibilidade de um serviço é medido pela porcentagem de tempo (métrica) que o serviço permanece executando e respondendo requisições. Sua função de avaliação, deve verificar se o resultado está acima de $99 \%$ (medida). De acordo com a natureza da métrica, a medida obtida será um valor exato ou um conjunto de valores.

A forma como é definida a função de avaliação faz com que seja possível classificar as diferentes propriedades. Atributos de QoS podem ser classificados em atributos de desempenho, confiabilidade (do inglês dependability), segurança e custo [MRLD09]. Atributos de desempenho são aqueles medidos através de métricas que podem ser aplicadas na chamada a um serviço. Atributos de confiabilidade são atributos que medem quão livre de falha um serviço é, levando em conta falhas decorrentes da troca de mensagens entre serviços [ALRL04]. Avizienis trata atributos de segurança como sendo a adição de confidencialidade e integridade aos atributos de confiabilidade. Por último, os atributos de custo são aqueles referentes ao custo de consumir serviços; considerando ambientes 
de middleware, o custo de manter os recursos alocados também são importantes.

É possível também classificar atributos em dependentes ou não dependentes do usuário [ZL13b]. Alguns atributos, como por exemplo, tempo de resposta são diretamente influenciado pelas condições de conexão do usuário. Isso adiciona complexidade na medição desses atributos dada a necessidade de coleta de métricas no lado do usuário [ZL13a]. Levando em consideração o custo, que independe do usuário, este pode ser medido absolutamente no lado do servidor. Por outro lado a disponibilidade e acessibilidade de um serviço deixa claro a complexidade. A acessibilidade (dependente de usuário) pode estar sendo violada para algum usuário enquanto que para outro não, mesmo que a disponibilidade do serviço (independente de usuário) não foi violada, isto é, o serviço está disponível.

No entanto, não somente a forma com é medido influencia na classificação de um atributo de QoS. A aplicação em si pode requerer atributos específicos, bem como métricas específicas. Assim, é natural que alguns atributos sejam tratados como específicos do domínio da aplicação. Considerando coreografias, Kattepur [KGI13] enfatiza a necessidade de uso de atributos que não são estritamente não-funcionais. Sua consideração analisa o formato como a coordenação é realizada. Como não há um componente mediador, são necessários atributos adicionais para fins de aferição de mensagens trocadas.

Outra maneira de classificar atributos é avaliar se a medição indica uma grandeza ou uma qualidade. Assim, podemos dividir atributos de QoS em dois grupos: qualitativo e quantitativo. Esta é a classificação que utilizamos nesta dissertação. Atributos quantitativos, como a própria classificação indica, quantificam atributos sendo que, sua métrica apresenta uma unidade a ser utilizada. Por exemplo, o tempo de resposta é um atributo estritamente quantitativo, pois num SLA, desejamos que esteja abaixo de $x$ milissegundos. Em suma, atributos relacionados a desempenho como, tempos de resposta e execução, latência, etc., são em geral quantitativos.

Atributos qualitativos especificam que a análise do QoS leva em consideração a existência de uma qualidade como, por exemplo, a manutenibilidade. Podemos considerar que, um serviço obedece requisitos de manutenibilidade se provê alguma forma de ser alterado, por exemplo, para a troca de versão. Note que, esse atributo não é estritamente qualitativo quando uma função de avaliação determina uma forma de quantificá-lo [YRPK07]. A manutenibilidade de um serviço pode ser expressa pela taxa de sucesso durante a manutenção, sendo essa taxa, o número de manutenções em que outros atributos de QoS foram mantidos dentro dos valores aceitáveis.

A Tabela 2.1, mostra a classificação dos atributos considerados no modelo.

A seguir, detalhamos cada um dos atributos e as métricas relacionadas.

\subsubsection{Tempo de Execução}

Tempo que um serviço $S$ leva para processar uma requisição. Compreende o tempo entre o momento em que $S$ recebe a requisição e o envio da resposta ao cliente. Em geral, envolve tempos de desempacotamento da requisição (criação dos objetos a partir de documentos XML/JSON), o tempo de processamento das operações sobre a requisição incluindo chamadas a outros serviços e o tempo de empacotamento da resposta (em XML/JSON). O tempo de processamento é medido em milissegundos. A violação do tempo de execução acontece quando o tempo necessário é maior do que o especificado no SLA. O tamanho da requisição/resposta sendo empacotada/desempacotada, a quantidade de processamento necessário para gerar a resposta e quantidade de acessos a disco podem aumentar o tempo de execução causando quebra de contrato de SLA.

\subsubsection{Latência}

Tempo que uma requisição $r$ leva para chegar no serviço $S$, somado ao tempo que a resposta leva para retornar ao cliente. A latência em serviços web é geralmente medida em milissegundos. A degradação de QoS em relação ao atributo latência ocorre quando a requisição/reposta leva um tempo maior que o estipulado no SLA para chegar aos seus destinos. Para latência, a quantidade de bytes contida na requisição ou resposta e a largura de banda da rede onde o serviço está implantado 


\begin{tabular}{l|c|c} 
Atributo & Quantitativos & Qualitativos \\
\hline \hline Tempo de execução & $\checkmark$ & \\
\hline Latência & $\checkmark$ & \\
\hline Tempo de resposta & $\checkmark$ & \\
\hline Tempo de resposta & $\checkmark$ & \\
\hline Vazão & $\checkmark$ & \\
\hline Custo & $\checkmark$ & \\
\hline Penalidade & $\checkmark$ & \\
\hline Disponibilidade & $\checkmark$ & \\
\hline Acessibilidade & $\checkmark$ & $\checkmark$ \\
\hline Confiabilidade & $\checkmark$ & $\checkmark$ \\
\hline Acurácia & $\checkmark$ & $\checkmark$ \\
\hline Robustez & $\checkmark$ & $\checkmark$ \\
\hline Segurança no funcionamento & $\checkmark$ & $\checkmark$ \\
\hline Manutenibilidade & $\checkmark$ & $\checkmark$ \\
\hline Interoperabilidade & $\checkmark$ & $\checkmark$ \\
\hline Integridade & $\checkmark$ & $\checkmark$ \\
\hline Segurança & $\checkmark$ & \\
\hline Reputação & $\checkmark$ & \\
\hline Testabilidade & $\checkmark$ & \\
\hline Escalabilidade & $\checkmark$ & \\
\hline
\end{tabular}

Tabela 2.1: Classificação dos atributos quanto a forma de medição.

influencia o QoS. Em ambientes de computação em nuvem onde o compartilhamento de recursos é comum, deve-se levar em consideração que outros serviços podem estar ocupando a banda em demasia.

\subsubsection{Tempo de resposta}

Tempo que uma requisição $r$ leva para ser atendida. No contexto deste trabalho, é considerada atendida a requisição que foi enviada com sucesso, processada e a resposta correta chegou ao destinatário. O tempo de resposta pode ser calculado considerando a soma dos tempos de execução e latência:

$$
\text { Tempo de Resposta }(S)=\text { Latência }(S)+\text { Tempo de execução }(S)
$$

O tempo de resposta é medido do lado do cliente da composição, o que torna a medição difícil por influências da conexão de rede disponível para cada usuário. A experiência de uso a partir de uma conexão de Internet fixa de banda larga é diferente do uso a partir de um dispositivo móvel usando 3G. O tempo de resposta é geralmente medido em milissegundos. A causas de violações são aquelas citadas no tempo de execução e latência.

\subsubsection{Vazão}

Quantidade de requisições que um serviço $S$ consegue atender em um intervalo de tempo. A vazão é medida geralmente em requisições/segundo. A vazão é violada quando a quantidade de requisições atendidas por segundo ultrapassa o limite mínimo do SLA. A vazão tem forte relação com o tempo de resposta, sendo que as causas de degradação de latência e tempo de execução causam a consequente degradação da vazão. 


\subsubsection{Custo}

Neste trabalho é o valor cobrado pelo provedor de infraestrutura por cada máquina virtual usada para implantação e execução do serviço. Quanto mais recursos são disponibilizados para uma máquina, maior é o preço pago por ela. Em geral, esse valor é cobrado por horas de uso. O custo é medido pela quantidade de máquinas e a quantidade de recursos disponível para cada uma. A violação desse atributo é relativa aos padrões de QoS utilizado. Neste trabalho, a ideia é desalocar recursos sempre que possível, evitando o sobre-custo. É comum encontrar em outros trabalhos o custo sendo relacionado ao uso de um serviço de terceiros necessário dentro de uma composição; esse não é nosso caso.

\subsubsection{Penalidade}

Custo financeiro que cabe ao provedor da infraestrutura pagar ao usuário quando há uma quebra de SLA. A penalidade é geralmente aplicada de acordo com o tempo em que o SLA foi violado. Esse é um atributo importante em aspectos como escolha de provedor de infraestrutura; um provedor que tem altos valores de penalidade pode ser um provedor que fere atributos de disponibilidade ou segurança com uma certa regularidade.

\subsubsection{Disponibilidade}

É a probabilidade de um serviço $S$ estar em execução, isto é, processando requisições. O tempo em que $S$ está em execução e atendendo a requisições é conhecido como $\operatorname{Uptime}(S)$ e o tempo em que $S$ não está em atendendo a requisições é conhecido como Downtime $(S)$. A disponibilidade é calculada da seguinte maneira:

$$
\text { Disponibilidade }(S)=\frac{\text { Uptime }}{\text { Uptime }+ \text { Downtime }}
$$

A disponibilidade assume valores no intervalo $[0,1]$. Valores próximos de 1 indicam que o serviço tem alta disponibilidade. A violação do atributo disponibilidade é detectada quando a razão acima está abaixo do limiar especificado no SLA.

\subsubsection{Acessibilidade}

É a probabilidade de uma requisição $r$ ser atendida por um serviço $S$, isto é, o cliente recebe uma confirmação de que a requisição foi atendida com sucesso. A acessibilidade está fortemente relacionada com a disponibilidade e sofre influência da escalabilidade de $S$. Por exemplo, com o aumento de mensagens na rede, um serviço disponível pode ter sua acessibilidade degradada se este não provê formas de manter a escalabilidade. Além disso, por motivos de segurança, serviços podem estar acessível a apenas clientes de uma determinada sub rede. Nesse caso, o acesso com sucesso de IPs não permitidos e a negação de serviços a IPs permitidos podem implicar na degradação da acessibilidade. A acessibilidade é medida pela razão entre o número de requisições atendidas com sucesso pela quantidade total de requisições da seguinte maneira:

$$
\text { Acessibilidade }(S)=\frac{\text { Número de sucessos }}{\text { Número de requisições }}
$$

A acessibilidade assume valores no intervalo [0,1]; valores mais próximos de 1 são indícios de maior acessibilidade. A degradação é determinada pela queda no valor dado pela razão acima.

\subsubsection{Confiabilidade}

É a taxa de requisições executadas com sucesso por um serviço $S$ durante um intervalo de tempo $\left[\mathrm{ZBD}^{+}\right.$03]. Leva em consideração o funcionamento correto dos serviços, sendo assim, uma requisição $r$ tem execução considerada com sucesso quando a troca de mensagens entre os serviços 
aconteceu sem falhas e a resposta enviada ao serviço que fez a requisição está correta. Seja ts o período em que $S$ respondeu a requisições com sucesso e $t f$ o período em que as respostas provenientes de $S$ foram geradas com falhas, a confiabilidade é calculada usando a seguinte equação:

$$
\text { Confiabilidade }(S)=\frac{t s}{t s+t f}
$$

A confiabilidade assume valores no intervalo $[0,1]$. Quanto mais próximo a 1, maior a qualidade do serviço em relação a esse aspecto.

\subsubsection{Acurácia}

É a taxa de respostas corretas geradas por um serviço $S$ considerando a quantidade de requisições atendidas [YRPK07]. Esse atributo mede a qualidade dos dados que resultam do processamento dos serviços. A acurácia é um atributo que está relacionado à confiabilidade. Por exemplo, quando $S$ está disponível e sua confiabilidade não está afetada, significa que está atendendo requisições normalmente. Para que seus clientes estejam satisfeitos, essas requisições precisam retornar valores corretos para que a acurácia não seja degradada. Pode-de dizer que a acurácia mede a capacidade que $S$ tem de não gerar erros. Seja $r s$ a quantidade de respostas corretas geradas por $S$ e $r f$ a quantidade de respostas que expôs erros aos clientes, pode ser medida da seguinte maneira:

$$
\operatorname{Acurácia}(S)=\frac{r s}{r s+r f}
$$

A acurácia assume valores entre 0 e 1 . Valores próximos a 1 são desejáveis. A violação desde atributo é detectada pela análise das respostas, as quais devem satisfazer a resposta desejada.

\subsubsection{Robustez}

É a capacidade que um serviço $S$ tem de se recuperar de falhas ocorridas por conta de requisição recebidas com erros, por exemplo,incompleta, inconsistente ou conflitante [YRPK07]. É natural que, durante todo o tempo de execução de $S$ algumas requisições sejam processadas gerando falhas. Para isso é necessário definir a diferença entre os conceitos de defeito, erro e falha. De acordo com Avizienis [ALRL04], um defeito é o desvio que há no resultado funcional do serviços, isto é, o cliente recebe uma resposta que apresenta dados incorretos. Defeitos são causados por erros, que podem ser vistos como estado incorreto de parte ou todo do sistema. Falhas são ocorrências de mudanças de um estado de corretude para um estado de não-corretude.

A robustez tem forte relação com a Confiabilidade e Acurácia de $S$. A robustez da composição de serviços garante que, em caso de violação de tais atributos, o sistema foi capaz de ainda gerar respostas não catastróficas aos seus clientes [YRPK07].

\subsubsection{Segurança no Funcionamento}

Segurança no funcionamento, do inglês dependability, é a agregação de outros atributos de QoS. Em outras palavras, é a categoria de atributos que interferem na segurança da composição de serviços considerando a dependência entre os serviços [LS00]. Confiabilidade, Segurança, Safety e Disponibilidade são atributos de segurança no funcionamento. No entanto, outros atributos podem ser classificados como atributos de segurança no funcionamento. Se o serviço $A$ depende de $B$, para que $A$ entregue sua funcionalidade com segurança, é necessário que $B$ cumpra com os requisitos mínimos de SLA. Em suma, mede a qualidade de um serviço $S$ referente à geração de erros tanto funcionais que afetam clientes como não funcionais.

\subsubsection{Manutenibilidade}

É a capacidade que um serviço $S$ tem de ser submetido a manutenção. É definido como um conjunto de atributos que medem o quanto $S$ pode ser analisado, testado, alterado, adaptado e ter 
sua estabilidade medida. A alteração de versão do serviço implantado, a adaptação de sua interface para usos em geral e a exposição de ferramentas que facilitam a análise de suas propriedades são exemplos de boas práticas para melhoria em relação a esse atributo. Um serviço com alta manutenibilidade provê ainda recursos para que, durante a manutenção, não haja degradação de outros atributos de QoS.

\subsubsection{Interoperabilidade}

É a capacidade que um serviço $S$ tem de chamar ou ser chamado remotamente por outros serviços. Pode ser visto também como a razão entre a quantidade de serviços que tiveram sucesso ao interagir com $S$ e o número de serviços que em algum momento tentou interagir, tendo sucesso ou não. Seja si o número de serviços que interagem corretamente com $S$ e sni o número de serviços que não interagem corretamente com $S$, a interoperabilidade do serviço $S$ é dada por:

$$
\text { Interoperabilidade }(S)=\frac{s i}{s i+s n i}
$$

A interoperabilidade assume valores no intervalo $[0,1]$.

\subsubsection{Integridade}

A integridade de um serviço $S$ quantifica a capacidade que $S$ tem de não permitir alterações em suas mensagens. A integridade é violada por meio de interceptações nas mensagens que chegam ou saem de $S$, que modificam o conteúdo das mensagens e o fluxo de controle entre os vários serviços. A integridade é medida levando em consideração as transações que ocorreram sem danos nas mensagens. Seja $M$ o conjunto de mensagens recebidas e enviadas por S, a integridade é dada por:

$$
\text { Integridade }(S)=\frac{\text { MensagensVioladas }}{M}
$$

A integridade assume valores no intervalo $[0,1]$.

\subsubsection{Segurança}

A segurança mede a disponibilidade de um serviço mediante o acesso autorizado, a confidencialidade dos dados e a integridade baseada em permissões de acesso, isto é, a capacidade que o serviço $S$ tem de responder apenas às requisições de usuários autorizados [ALRL04]. Segurança é um atributo que tem forte relação com integridade e disponibilidade. Para o primeiro, desde que o usuário tenha permissão de fazer modificações, qualquer modificação permitida não viola o SLA. Para o segundo, serviços devem ter valor alto de disponibilidade para aqueles clientes que têm autorização de acesso.

\subsubsection{Reputação}

É uma medida de confiança dada ao um serviço $S$ através de feedback dos usuários. Assumindo que o nível mínimo de reputação é 1 e o máximo $R$, a reputação de um serviço $S$ é dada por:

$$
\operatorname{Reputação}(S)=\frac{1}{n} \sum_{1, n} R
$$

onde $n$ é a quantidade de avaliações recebidas. A reputação, por depender do usuário é uma medida estimada. Nem todos os usuários fazem avaliação, e não se sabe ao certo quão correta é feita uma avaliação. A reputação é uma medida entre [0,1] em que quanto mais próximo a 1, maior a reputação de $S$. 


\subsubsection{Testabilidade}

A testabilidade mede o grau de facilidade que um Serviço $S$ provê para fins de testes. Quanto maior a facilidade que um serviço oferece para desenvolvedores criar critérios de avaliação e verificar resultados obtidos, mais testável é esse serviço. A testabilidade é uma medida que varia entre 0 para o pior caso e 1 para o melhor.

\subsubsection{Escalabilidade}

A escalabilidade de um serviço $S$ é a probabilidade de que, com a variação de carga de trabalho em $S$, os outros atributos sejam mantidos dentro dos limites especificados no SLA. A métrica Performance Non-Scalability Likelihood (PNL) [WA02] é utilizada para mensurar valores de escalabilidade. Para realizar a medição, usa-se clientes específicos para fazer requisições, aumentando a taxa até que a escalabilidade comece a sofrer degradação. Entretanto, segundo Gunther [Gun08], a escalabilidade é expressa por uma função, definida pela Lei Universal da Escalabilidade.

\subsubsection{Monitoramento de métricas}

Para ser hábil a reconfigurar a topologia e a infraestrutura que hospeda composições de serviços, um sistema de middleware deve monitorar os atributos de QoS relevantes e as várias métricas de recurso disponíveis no software operacional utilizado [CGK $\left.{ }^{+} 11\right]$. Detectar automaticamente o comportamento em relação ao uso de recursos de um serviço é uma tarefa difícil de ser executada. A forma como um serviço utiliza os recursos disponíveis frente à carga recebida pelo acesso a ele feito, só é sabida durante o tempo em que está em execução [JPC10].

Entretanto, a previsão inicial do comportamento de serviços pode ser realizada com a ajuda de testes de escalabilidade durante a fase de desenvolvimento [MK13]. A execução de testes permite a definição de perfis de comportamento que podem auxiliar no processo de implantação inicial [JPC10, DPC11]. Além disso, uma boa configuração inicial na implantação de uma composição pode postergar o início de um processo de reconfiguração. O uso de uma configuração inicial mal desenvolvida pode iniciar vários processos de reconfiguração durante os primeiros minutos de execução de uma composição. Assim, é importante o uso de tais perfis não apenas para a implantação, como para as decisões a serem tomadas a fim de manter o QoS.

Nesta dissertação, foi adotado um modelo de monitoramento baseado em eventos. Nesse modelo, um monitor funciona como agregador central de eventos de fontes múltiplas como mostra a Figura 2.5. Devido à facilidade de acesso a serviços independentemente dos locais de implantação, o monitor deve estar apto a receber eventos de qualquer serviço ou máquina virtual. Embora central, cabe à arquitetura do sistema lidar com a confiabilidade do sistema de middleware. De acordo com valores medidos através das métricas definidas para os atributos de QoS e recursos virtuais utilizados, eventos são enviados para o módulo monitor que decide quais estratégias de reconfiguração serão aplicadas.

Monitorar composições demanda monitoramento do estado de serviços individuais bem como do estado da composição como um todo. O modelo de monitoramento usado divide o processo em duas fases baseados em dois tipos específicos de eventos:

Eventos locais Remetem ao estado de serviços ou recursos individuais. São criados a partir de dados atômicos, geralmente referentes a um único atributo de QoS. Podem ser vistos como eventos que denotam dados "crus", minimamento filtrados. Eventos locais indicam a alteração do estado de algum atributo de QoS ou recurso computacional em particular.

Eventos globais Remetem ao estado da composição como um todo. São eventos sintetizados no momento do monitoramento, resultantes da correlação entre outros eventos. O uso de eventos globais é alvo de pequisa na área de gerenciamento de QoS. O uso de agregação de diferentes eventos pode auxiliar na análise e decisão de qual serviço deve ser reconfigurado [AR09]. 


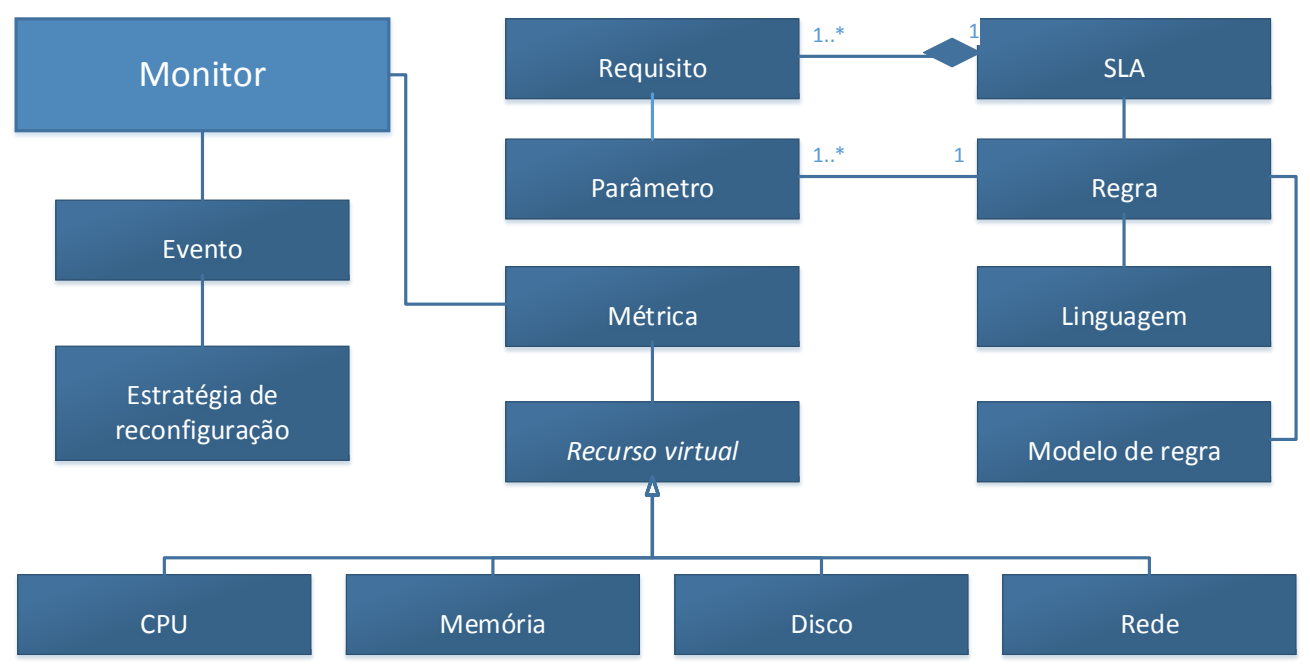

Figura 2.5: Diagrama do modelo de monitoramento.

Para que a manutenibilidade de QoS atinja o nível de composição de serviços, são atribuídas estratégias de reconfiguração para cada um dos eventos globais. O uso de perfis citado anteriormente permite que essas estratégias sejam construídas seguindo padrões que mais se adaptem ao serviço que será reconfigurado.

\subsection{Reconfiguração de Composições de Serviços}

Gerir QoS em composições de serviços demanda não só a adoção de um modelo de QoS, como também o uso de mecanismos de monitoramento e reconfiguração dinâmica. Reconfiguração dinâmica permite que componentes de um sistema sejam adaptados em tempo de execução por meio de substituição de componentes, mudança de componentes para outras máquinas e ainda adição e remoção de recursos. Ainda, cria a possibilidade de dar manutenção em sistemas sem que estes sejam desativados, pois mesmo que haja interrupções, estas são de intervalos curtos. Assim, a qualidade da composição pode ser aumentada tornando-as mais robustas e confiáveis. Na literatura é possível encontrar mecanismos de adaptação dinâmica funcional e não-funcional.

Adaptação funcional Serviços web são usados para criar a possibilidade de interação entre vários componentes distribuídos que são inerentemente heterogêneos. Dessa forma, serviços são entidades independentes implementadas de forma independente também. Sendo assim, incompatibilidades entre as interface dos serviços ocorrem e para que seja possível o uso desses componentes algum tipo de adaptação deve ser feita. Dois tipos de incompatibilidades ocorrem: incompatibilidade de assinaturas e de protocolos [TPPvdH11]. Nesse contexto, é necessário o uso de adaptadores para que seja feita a comunicação correta entre os serviços. Além disso, serviços podem ser adaptados para prover novas funcionalidades por meio desses adaptadores de interface [IT09].

Adaptação não-funcional No contexto deste trabalho aplica-se adaptação não-funcional. Ela focaliza a reconfiguração de composições de serviços baseada em características não funcionais dos serviços a fim de manter a qualidade do seu funcionamento. Em geral, é feita por meio de seleção de serviços [YL12, LZYW10, GMYB05, VS05] ou reconfiguração dos recursos computacionais [CGK $\left.{ }^{+} 11, \mathrm{MBEB} 11\right]$. Embora seja guiada por propriedades não-funcionais, a adaptação é realizada para que serviços entreguem suas funcionalidades com um determinado nível de QoS.

Seleção de serviços é usada para obtenção de composições ótimas de serviços selecionando para uma funcionalidade, um serviço candidato que apresente melhores valores de QoS. Serviços são classificados de acordo com indicadores de degradação de QoS. Fatores de degradação são determinados a partir dos valores limites e métricas individuais de cada atributo de QoS. Quando um serviço em 
uso passa a ter valores mais baixos para algum atributo de QoS, este pode ser substituído por outro candidato. Serviços são candidatos a serem usados em uma substituição quando podem oferecer funcionalidades similares.

No segundo caso, a reconfiguração é aplicada na topologia da composição, isto é, é feita a migração de um serviço para uma nova máquina ou ainda para outro provedor de computação em nuvem, ou a criação e remoção de réplicas a fim de satisfazer os requisitos presentes nos SLAs. Partindo do objetivo deste trabalho - a criação de um middleware servindo de PaaS para composições de serviços - é necessário que o middleware aplique reconfigurações na topologias das composições a fim de manter cada serviço implantado com quantidade suficiente de recursos. Vale ressaltar que, o uso de seleção de serviços é um artifício poderoso. Porém, nada se pode fazer quando não há um serviço candidato a ser utilizado.

Neste trabalho, a solução proposta faz uso da adaptação não funcional. O objetivo é manter composições em execução mantendo seu QoS. Adaptar composições de serviços às diversas condições de trabalho pode ser modelado como um sistema de computação autônoma [ADG10]. Através de um sistema de fases monitoramento-análise-planejamento-execução é possível continuamente monitorar os estados e reagir conforme as necessidades. O modelo MAPE composto de laços que realizam essas fases sucessivamente se tornou um padrão para sistemas que fazem reconfiguração dinâmica. A seguir, introduzimos os conceitos desse modelo.

\subsubsection{MAPE loops}

Qualquer que seja o mecanismo de adaptação dinâmica usado por um sistema, é necessário que haja monitoramento do sistema em questão e reações quando são atingidos estados que possam levar a situações indesejadas. O processo de adaptação dinâmica é, tradicionalmente, visto como sendo a composição de quatro etapas sequenciais (monitoramento, análise, planejamento e execução), os quais são executados repetidamente em um laço infinito [BSG $\left.{ }^{+} 09\right]$. Essas etapas são conhecidas como MAPE [MBEB11].

Laços MAPE foram introduzidos pela IBM com o objetivo de tirar a necessidade de intervenção humana da manutenção de sistemas de computação. A ideia por trás da concepção partiu da comparação feita com o sistema nervoso humano, o qual involuntariamente monitora e "adapta" o corpo a mudanças internas ou no ambiente $\left[\mathrm{KKC}^{+} 07\right]$.

Laços MAPE são bem aceitos por pesquisadores sendo largamente usados consolidando-se como padrão a ser seguido para criação de sistemas autônomos em monitoramento [ADG10]. Os conceitos de MAPE não determinam como deve ser realizado o monitoramento nem indica quaisquer padrões de construção de mecanismos de adaptação. Apenas definem quatro passos essenciais para que um sistema esteja apto a reagir a possíveis estados indesejáveis. A Figura 2.6 mostra um diagrama com os quatro passos. Para um melhor desempenho, bases de conhecimentos podem ser usadas nesses passos.

No fase de monitoramento, são coletadas métricas indicadoras da condição do QoS dos sistemas, através de ferramentas de monitoramento. Métricas de mais alto nível como por exemplo, a disponibilidade de um serviço deve ser realizada criando métricas agregadoras que possibilita o cálculo a partir de métricas disponibilizadas por ferramentas do sistemas operacional [MBEB11].

A fase de análise é usada para processar os dados obtidos a partir do monitoramento. Há possibilidade de aplicação de análise estatística, baseada em eventos, simulação de sistemas genéticos evolutivos, entre outros. O objetivo é, ao final dessa etapa, saber causas e efeitos de mudanças de estado indevidas.

De acordo com o resultado da análise realizada, a fase de planejamento inclui nos laços a decisão da medida a ser tomada. Essa decisão leva em conta que tipo de adaptação deve ser feita, funcional ou não-funcional, qual a estratégia de adaptação será usada, por exemplo, seleção de serviço com melhores parâmetros de QoS ou migração para outro provedor de nuvem, e qual mecanismo utilizar.

$\mathrm{Na}$ fase de execução, o plano de reconfiguração é efetivamente aplicado. Um middleware executando como um sistema de PaaS realiza as alterações no nível de IaaS para que seja possível a 


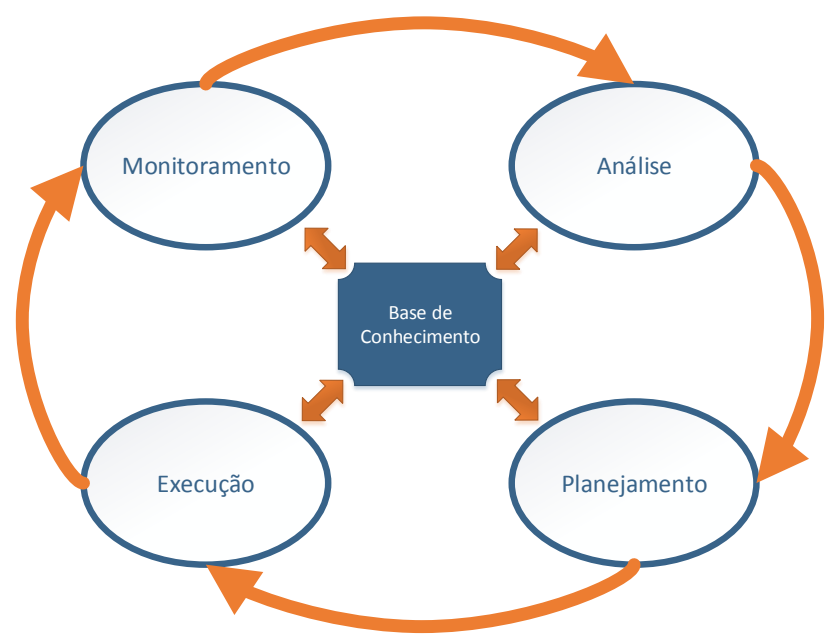

Figura 2.6: Fases do Laço MAPE.

aplicação do plano. Nesse momento, o middleware deve aplicar reconfigurações escolhendo a melhor alternativa disponível pelo sistema de nuvem utilizado; essa escolha pode influenciar o tempo de reconfiguração. A reconfiguração deve ser transparente, não induzindo o sistema que está sendo reconfigurado, a quebrar itens do SLA [Li12]. Todas as fases podem usar uma base de conhecimentos para uma melhor precisão nos resultados da adaptação [MBEB11]. No nosso modelo de QoS, adotamos como modelo de monitoramento, um modelo baseado em eventos como pode ser visto na Seção 2.3.3 . Sendo assim, para realizar as fases do MAPE utilizamos a técnica de CEP que é descrita a seguir.

\subsubsection{Processamento de eventos complexos}

CEP é uma abordagem de monitoramento baseada em eventos, usada para avaliar propriedades de sistemas computacionais através da análise de correlação entre eventos. CEP é usado como meio eficiente para monitoramento e execução de tarefas reativas em sistemas distribuídos [Luc02]. Em geral, usa-se uma análise lógico-temporal para correlacionar eventos capturados gerando eventos complexos. Tais eventos são necessários para inferir causas realistas e possíveis soluções frente a problemas de violação de SLA. A técnica de análise de eventos complexos permite a criação de gatilhos que executam ações reativas ao evento gerado. Esses gatilhos podem definir quais reconfigurações devem ser feitas para que seja mantido o QoS dentro dos níveis desejados. Um evento complexo pode ser definido como a correlação entre um conjunto de outros eventos (simples ou complexos).

A classificação de eventos vista na Seção 2.3.3 pode ser mapeada para o contexto de CEP. Eventos locais são mapeados para eventos simples, os quais contém informações sobre um determinado atributo. Eventos globais podem envolver informações sobre dois ou mais estados agregados, provenientes de um ou mais serviços $\left[\mathrm{BHBC}^{+} 12\right]$. Um evento complexo pode ser gerado, por exemplo, quando um tempo de resposta operacional é medido com valores mais altos do que um limite, simultaneamente a valores de uso de CPU ou E/S (na máquina hospedeira do serviço em questão ou dependente) maiores do que valores estipulados no SLA.

O conceito de CEP determina uma forma de manipulação de tarefas que substitui chamadas a métodos locais ou remotas por um processamento assíncrono, baseado em eventos. Consequentemente, CEP apresenta vantagens quanto à manipulação de grande quantidade de eventos, processando-os de forma distribuída e flexível. Pode ser considerada como sendo uma escolha prática e eficiente para execução de tarefas reativas, tais como adaptação dinâmica. Apesar das vantagens, é importante ressaltar a necessidade de técnicas de sincronismo; a análise de eventos é feita em relação ao tempo. Sendo assim, é necessário manter sincronismo de relógio entre geradores e processadores de eventos.

Para um melhor controle, a reconfiguração de composições pode ter seus resultados melhorados 
com o auxílio de fatos, tipos especiais de eventos que indicam condições da implantação das composições e de seus respectivos SLAs. A diferença entre fatos e eventos é que, eventos são representações de mudanças de estado na composição e seus sistemas subjacentes, como por exemplo, o crescimento dos valores capturados para o atributo de QoS tempo de resposta (atualizado a cada período de tempo). Um fato é uma representação de uma informação estática, tipicamente vinculada a um estado de configuração inicial que perdurará durante toda a execução da composição. Por exemplo, o endereço IP de uma determinada instância de serviço, a lista de máquinas virtuais usadas para as réplicas de um serviço ou ainda o SLA definido para um serviço.

Como já visto, eventos ativam gatilhos definidos para realizar as fases do MAPE. Gatilhos são definidos para detectar a relação entre eventos. Essa relação é verificada a partir de operadores lógicos e temporais. Os operadores temporais encontrados na literatura estão descritos a seguir:

Before Operador usado para análise de antecedência de eventos. A comparação realizada equivale

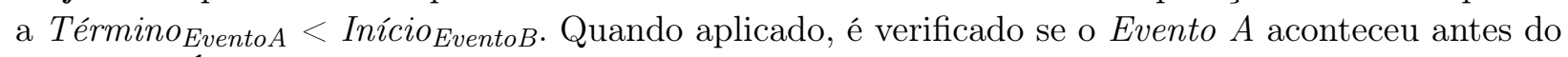
Evento $B$. É opcional o uso de um valor limite para definir uma distância temporal limite entre os Evento $A$ e Evento $B$, isto é, quão antes o Evento $A$ aconteceu.

After Operador usado para análise de sucessão de eventos. A comparação representada por esse operador satisfaz Início Evento A $>$ Término Evento B. Quando aplicado, indica se o Evento A aconteceu depois do Evento B. Assim como o operador Antes, opcionalmente é possível o uso de um valor limite para distância temporal.

Coincides Operador usado para análise de simultaneidade de eventos. A comparação equivale a

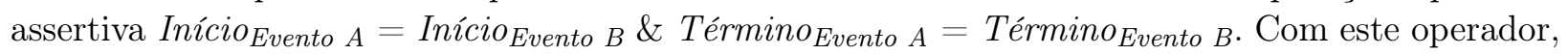
é possível verificar se o Evento $A$ aconteceu simultaneamente ao Evento $B$, isto é, o momento de início e término são coincidentes.

During Operador usado para análise de inclusão de eventos. Este operador verifica se a assertiva ${\text { Início Evento } A>\text { Início }_{\text {Evento } B} \& \text { Término Evento } A<\text { Término }}_{\text {Evento } B}$ é verdadeira. Com este, é possível verificar se o Evento $A$ aconteceu durante o tempo de duração do Evento $B$.

Finishes Operador usado para análise de simultaneidade no término de dois eventos. Através da comparação Início Evento $A>$ Início $_{\text {Evento } B} \&$ Término Evento $A_{A}=$ Término $_{\text {Evento } B}$, verifica se o Evento $A$ começou após o início do Evento $B$ e ambos terminaram simultaneamente.

Finished By Operador usado também para análise de simultaneidade no término de dois eventos. Através da comparação Início Evento $A<$ Início $_{\text {Evento } B} \&$ Término $_{\text {Evento }} A=$ Término $_{\text {Evento }}$, verifica se o Evento $A$ começou antes do início do Evento $B$ e ambos terminaram simultaneamente.

Includes Operador usado para análise de inclusão de eventos. Utilizada a asserção realizada pela

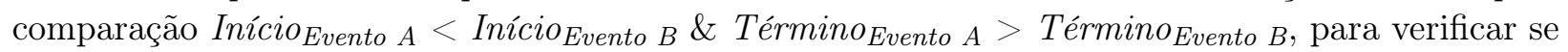
o Evento $B$ aconteceu durante o tempo de duração do Evento $A$. Este realiza a comparação inversa do operador During.

Meets Operador usado para análise de adjacência entre início de um evento e término de outro. A comparação Início $_{\text {Evento } B}=$ Término Evento $A_{A}$ usada por este operador,verifica se o Evento $B$ iniciou exatamente no momento em que o Evento $A$ terminou.

Met $\boldsymbol{B y}$ Operador usado para análise de adjacência entre o término de um evento e o início de outros. Utiliza a comparação Início Evento $A=$ Término $_{\text {Evento } B}$ para verificar se o Evento $A$ iniciou exatamente no momento em que o Evento $B$ terminou. Equivale à comparação inversa do operador Meets 
Overlaps Operador usado para análise de simultaneidade parcial de eventos. Realiza a comparação Início $_{\text {Evento } A}<$ Início $_{\text {Evento } B} \&$ Término $_{\text {Evento } A}<$ Término $_{\text {Evento }} B$ \& Início Evento $B<$ Término Evento A, para detectar se o Evento $B$ iniciou antes do Evento $A$ terminar e este por sua vez, terminou antes que o Evento $B$ terminasse criando um intervalo de tempo de intersecção temporal.

Overlaped By Operador usado para análise de simultaneidade parcial de eventos. Realiza a

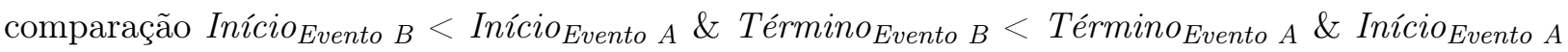
$<$ Término Evento $B$, para verificar se o Evento $A$ iniciou antes do Evento $B$ terminar e este por sua vez, terminou antes que o Evento $A$ terminasse criando um intervalo de tempo de intersecção temporal.

Starts Operador usado para análise de simultaneidade na criação de eventos. Faz a comparação Início Evento $A_{A}$ Início Evento $B_{B} \&$ Término $_{\text {Evento }} A<$ Término $_{\text {Evento } B}$, para verificar se o Evento $A$ foi criado simultaneamente ao Evento $B$ e terminou antes que o Evento $A$ terminasse.

Started By Operador usado para análise de simultaneidade na criação de eventos. Faz a comparação Início Evento $A_{A}=$ Início Evento $B_{B} \&$ Término $_{\text {Evento } A}>$ Término $_{\text {Evento } B}$, para indicar se o Evento $A$ iniciou simultaneamente ao Evento $B$ e terminou depois que o Evento $A$ terminasse.

Operadores personalizados podem ser criados a partir da junção lógica entre os operadores temporais. Os operadores lógicos and, or, not e o operador de pertinência in podem ser utilizados. Por exemplo, é possível definir um operador que detecta a ocorrência de dois eventos em conformidade com o operador Before com inexistência de um terceiro evento.

Em suma, o uso de CEP para prover a execução das fases do ciclo MAPE demonstra ser uma abordagem promissora para sistemas distribuídos provendo flexibilidade na definição de eventos a partir dos dados de monitoramento. Concomitantemente, CEP permite a criação de regras desde a mais simples até a mais complexa para realizar a análise dos eventos gerados. Dessa forma, o uso de CEP é bem visto para fins de monitoramento de quaisquer atributos definidos por usuários.

\subsubsection{Dependências dinâmicas}

Devido aos princípios de SOA, serviços podem ser implantados em localidades diferentes uma vez que o processo de enlace entre serviços é realizado em qualquer momento após a implantação de cada um deles. Com o advento da computação em nuvem, serviços utilizam ainda múltiplos provedores de IaaS de maneira frequente. Devido a essa característica, o ponto de acesso dos serviços é definido após a implantação, isto é, a composição de serviços é construída após essa implantação. Logo, uma composição de serviços tem seus serviços independentes de localidade; não é necessário saber, de antemão, os endereços de IP de cada serviço.

Durante a execução, composições enfrentam momentos de variação da carga imposta sobre os serviços. Isso causa reconfigurações que objetivam manter o desempenho em boas condições. $\mathrm{O}$ processo de reconfiguração modifica os pontos de acesso que estão disponíveis. Por exemplo, a migração de um serviço para uma nova máquina virtual, implica na mudança do endereço IP de acesso. Além disso, o endereço anterior deixará de responder a requisições. Dessa forma, o enlace entre serviços também é reconfigurado. Portanto, inconsistências podem vir a acontecer [BN10]. Isso torna importante que o processo de manutenção de QoS seja contínuo, inclusive durante o processo de reconfiguração.

Para exemplificar, considere que o Serviço A depende do Serviço B. Levando em conta o processo de atualização do Serviço $A$ conforme a Figura 2.7, se o Serviço $A$ envia uma requisição para Serviço $B$ no instante $t_{0}$, recebe uma requisição de atualização no instante $t_{1}$, aplica essa atualização em $t_{2}$ e recebe a resposta do Serviço $B$ no instante $t_{3}$, com $t_{0}<t_{1}<t_{2}<t_{3}$, tanto a resposta obtida pelo Serviço A quanto a obtida pelo cliente da composição podem estar inconsistentes, suscetíveis a 
violações de SLA. Considerando ainda que serviços podem armazenar o estado da sessão aberta por um cliente, há ainda uma complexidade a mais a ser considerada. Para serviços sem estado, durante a reconfiguração é necessário manipular as conexões abertas de maneira que durante a remoção de uma réplica por exemplo, não haja indisponibilidade para seus clientes. Para serviços com estado, as sessões devem ser mantidas de alguma forma [Li12].

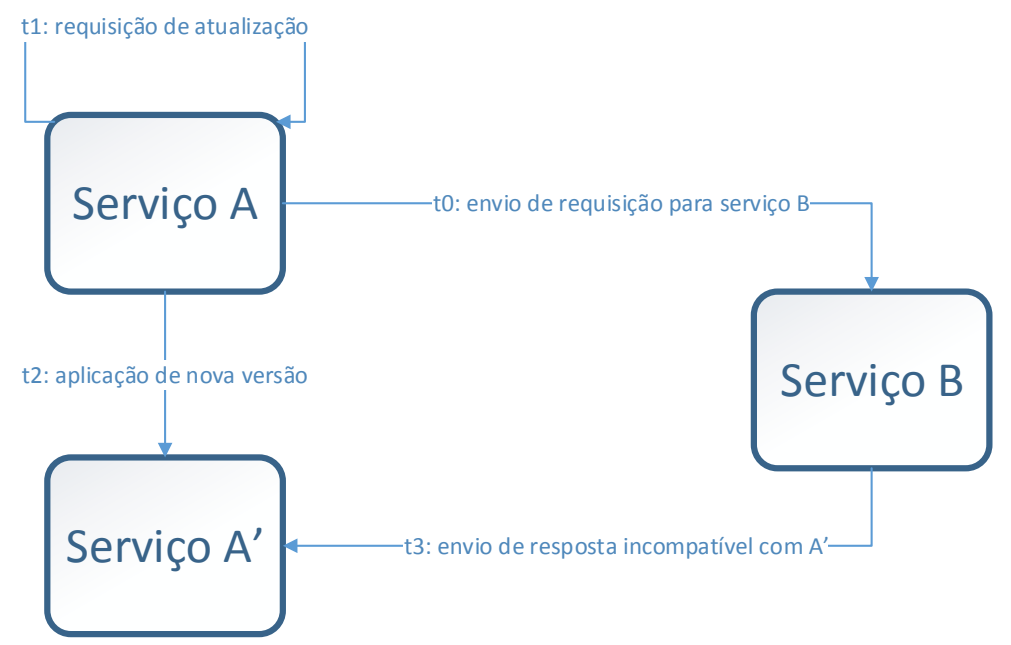

Figura 2.7: Atualização inconsistente de componente (Considere $t_{0}<t_{1}<t_{2}<t_{3}$ ).

Reconfiguração dinâmica com versionamento consistente é um problema bem conhecido e pesquisado desde a década de 1980 [KM90]. Para solucionar esse problema, mudanças nas composições devem ser aplicadas em momentos específicos que sejam favoráveis à reconfiguração. Sistemas de middleware que executam com modelo PaaS devem lidar com esse problema. Induzir o sistema a atingir um estado suficiente para a reconfiguração provocaria um intervalo de interrupção inviável. Além disso, transações que estavam em andamento e foram abortadas deveriam ser reconstruída com alguma forma de rollback. Um estado passível de reconfiguração dinâmica é o estado chamado de quiescência (quiescence) [KM90].

Um serviço está quiescente (quiescent) se as seguintes condições são satisfeitas:

- não está em uma transação iniciada por ele;

- não iniciará nenhuma nova transação;

- não é dependência de nenhum outro serviço que iniciou uma transação não terminada; e

- não é dependência de nenhum outro serviço que iniciará novas transações.

O estado de quiescência pode gerar grandes intervalos de interrupção no sistema, principalmente se o número de dependência entre serviços é alto. O interesse em melhorar esse conceito em relação a esse aspecto negativo levou ao conceito de Tranquility [VEBD07]. Neste caso, não é necessário que todos os serviços estejam em estado passivo, porém apenas aqueles diretamente ligados ao serviço a ser reconfigurado.

Um serviço está em estado de tranquilidade (tranquility) se:

- não está em uma transação iniciada por ele;

- não iniciará nenhuma nova transação;

- não está ativamente processando uma requisição, isto é, pode ser dependência de algum serviço que está em uma transação, mas não está sendo utilizado; e

- nenhum serviço adjacente está participando de alguma transação, nem será usado em alguma outra transação futura. 
Uma vez que o estado de tranquilidade pode ser alcançado naturalmente, a espera por tal estado pode ser longa, o que é ruim quando se deseja manter QoS [Li12]. Além disso, durante uma reconfiguração, é necessário que o estado seja mantido até que a atualização esteja completa. Dessa forma, interrupções ainda ocorrem, porém, em uma quantidade menor de serviços. A implementação dessa funcionalidade pode ser incorporada em um trabalho futuro, sem que interfira nesse trabalho estando assim fora do escopo dessa dissertação. No próximo capítulo, apresentamos um conjunto de trabalhos relacionados que foram importantes para o desenvolvimento dessa dissertação. 


\section{Capítulo 3}

\section{Trabalhos Relacionados}

Devido ao crescente interesse em composições de serviços, a manutenção e avaliação de QoS em sistemas baseados em Computação Orientada a Serviços (SOC) são objetos de frequente pesquisa $\left[\mathrm{ACC}^{+} 14\right]$. Dentre as várias frentes de pesquisa em destaque sobre composições de serviços incluindo restrições de QoS, podemos destacar pesquisas sobre os temas de seleção de serviços, composições de serviços, tolerância a falhas em composições de serviços, recomendação de serviços, predição de QoS e composições de serviços adaptativas.

Como já dito na Seção 1.3, neste trabalho o propósito é a construção de um middleware capaz de manter o QoS de composições de serviços. Para isso, usamos adaptação não-funcional nas composições. Portanto, consideramos que adaptação não-funcional pode ser feita de duas maneiras distintas: seleção de serviços baseada em QoS e reconfiguração de composições baseada em QoS. Na primeira categoria, apresentada na Seção 3.2, se encaixam trabalhos relacionados a encontrar a composição ótima em termos de QoS, usando seleção de serviços já em execução que tenham interfaces similares. Para selecioná-los, fatores de degradação de QoS são calculados para cada serviço. A segunda categoria, mostrada na Seção 3.3, cujo nosso trabalho esta incluso, engloba trabalhos que tentam detectar alterações no comportamento de composições de serviços e aplicar reconfigurações no serviços utilizados para que os mesmos possam manter a QoS geral da composição.

Estamos interessados na reconfiguração das composições provendo elasticidade aos usuários do middleware. No entanto, apresentamos uma relação de trabalhos relacionados que foram relevantes para os resultados aqui obtidos, incluindo os trabalhos nas duas abordagens apresentadas. Tais trabalhos auxiliaram na busca do modelo de QoS discutido anteriormente e no mecanismo de reconfiguração utilizado. O processo de manipulação e manutenção de QoS requer o estudo preliminar de um modelo de QoS para aplicação das técnicas que serão utilizadas. Por conta disso, inicialmente apresentamos na Seção 3.1 a evolução dos modelos de QoS usados para serviços web. Na Seção 3.2 apresentamos os trabalhos relacionados que tratam o problema de manutenção de QoS com seleção e substituição de serviços. Embora nesse trabalho essa abordagem não foi utilizada, conceitos arquiteturais foram de grande valia. Por fim, nas Seções 3.3 e 3.4 apresentamos os trabalhos relacionados que guiaram essa pesquisa, entre eles, os conceitos arquiteturais de MAPE, e o modelo baseado em eventos CEP.

A Tabela 3.1 mostra a relação sumarizada do trabalhos mais relevantes nesta pesquisa. Nela é possível verificar os trabalhos quanto à definição de um modelo de QoS e quanto ao modo como trata o problema de manutenção de QoS.

No contexto dos projetos CHOReOS e Baile, os quais deram suporte financeiro a este trabalho, Leite et al. $\left[\mathrm{LON}^{+} 12\right]$ apresentaram uma revisão sistemática com trabalhos relevantes em adaptação dinâmica de composições de serviços. Em seu trabalho, as composições estudadas são coreografias. O estudo mostra que adaptação dinâmica em composições de serviços é um tema ainda pouco explorado. As estratégias de adaptação foram analisadas de acordo com o objetivo da adaptação quanto aos requisitos funcionais e não-funcionais, o grau de intervenção humana, o impacto na escalabilidade da composição, a implementação da estratégia em ferramentas bem como a disponibilidade do código e os modelos de representação de coreografias usados. 


\begin{tabular}{|c|c|c|c|}
\hline Trabalho & Abordagem sobre QoS & Técnica de reconfiguração & Modelo de QoS \\
\hline Frolund et al. [FK98] & Modelagem de QoS & $x$ & $\begin{array}{c}\text { Considera atributos de } \\
\text { segurança no funcionamento e } \\
\text { propõe a linguagem QML }\end{array}$ \\
\hline Weyuker et al. [WA02] & $\begin{array}{l}\text { Modelagem de QoS com foco } \\
\text { no atributo escalabilidade }\end{array}$ & $x$ & $\begin{array}{c}\text { Foco em métricas para } \\
\text { escalabilidade. RUL como } \\
\text { alternativa a PNL }\end{array}$ \\
\hline Zeng et al. $\left[\mathrm{ZBD}^{+} 03\right]$ & $\begin{array}{c}\text { Composição e seleção de } \\
\text { serviços }\end{array}$ & $\begin{array}{l}\text { Otimização por Programação } \\
\text { Linear sobre grafos }\end{array}$ & $\begin{array}{l}\text { Preço, Tempo de Execução, } \\
\text { Reputação, Disponibilidade e } \\
\text { Confiabilidade }\end{array}$ \\
\hline Cardoso et al. $\left[\mathrm{CSM}^{+} 04\right]$ & Composição de serviços & $\begin{array}{l}\text { Reorganização de workflows } \\
\text { através do algoritmo de } \\
\text { redução SWR }\end{array}$ & $\begin{array}{l}\text { Métricas para computação de } \\
\text { Tempo, Custo e Confiabilidade }\end{array}$ \\
\hline Avizienis et al. [ALRL04] & $\begin{array}{l}\text { Modelagem de atributos de } \\
\text { segurança no funcionamento }\end{array}$ & 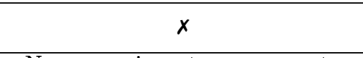 & Segurança e confiabilidade \\
\hline Wang et al. $\left[\mathrm{WWC}^{+} 05\right]$ & $\begin{array}{c}\text { Reconfiguração dirigira por } \\
\text { QoS }\end{array}$ & $\begin{array}{l}\text { Nos experimentos, apresenta } \\
\text { compressão de dados como } \\
\text { reconfiguração para tempo de } \\
\text { execução alto }\end{array}$ & $\begin{array}{c}\text { Atributos de desempenho, } \\
\text { latência, tempo de execução, } \\
\text { etc. }\end{array}$ \\
\hline Yu et al. [YRPK07] & Não abordado & $\begin{array}{c}\text { Modelagem de métricas para } \\
\text { atributos de QoS considerados } \\
\text { pela W3C }\end{array}$ & $\begin{array}{c}\text { Desempenho, confiabilidade, } \\
\text { escalabilidade, robustez, } \\
\text { acurácia, integridade, } \\
\text { disponibilidade, acessibilidade, } \\
\text { interoperabilidade e segurança }\end{array}$ \\
\hline Choi et al. [CHK07] & Não abordado & $\begin{array}{l}\text { Modelagem de atributos e } \\
\text { métricas de QoS }\end{array}$ & $\begin{array}{c}\text { Disponibilidade, desempenho, } \\
\text { confiabilidade, usabilidade, } \\
\text { discoverability, } \\
\text { adaptabilidade, composability }\end{array}$ \\
\hline Gunther et al. [Gun08] & Não abordado & Modelos de escalabilidade & $\begin{array}{c}\begin{array}{c}\text { Especificamente, } \\
\text { escalabilidade }\end{array} \\
\end{array}$ \\
\hline Mabrouk et al. $\left[\mathrm{MBK}^{+} 09\right]$ & $\begin{array}{c}\text { Composição e seleção de } \\
\text { serviços }\end{array}$ & $\begin{array}{l}\text { Otimização local aplicando } \\
\text { K-means e heurística global }\end{array}$ & $x$ \\
\hline Michlmayr et al. [MRLD09] & $\begin{array}{l}\text { Composição e seleção de } \\
\text { serviços }\end{array}$ & $\begin{array}{c}\text { Detecção de quebras de SLA } \\
\text { baseada em eventos }\end{array}$ & $\begin{array}{c}\text { Classes de atributos: } \\
\text { desempenho, segurança no } \\
\text { funcionamento, segurança e } \\
\text { custo } \\
\end{array}$ \\
\hline Littlewood et al. [LSO0] & Não abordado & $\begin{array}{c}\text { Modelagem probabilística de } \\
\text { QoS }\end{array}$ & $\begin{array}{l}\text { Confiabilidade e segurança no } \\
\text { funcionamento }\end{array}$ \\
\hline Kattepur et al. [KGI13] & $\begin{array}{l}\text { Cita adaptabilidade proposta } \\
\text { no projeto CHOReOS }\end{array}$ & $\begin{array}{c}\text { Métricas para validação de } \\
\text { mensagens trocadas em } \\
\text { coreografias }\end{array}$ & $\begin{array}{c}\text { Qualidade na troca de } \\
\text { mensagens: deadlock freeness, } \\
\text { conformance e realizability }\end{array}$ \\
\hline Zeng et al. $\left[\mathrm{ZBN}^{+} 04\right]$ & Seleção de serviços & $\begin{array}{c}\text { Otimização local e global } \\
\text { usando ontologias e } \\
\text { Programação Linear }\end{array}$ & $\begin{array}{l}\text { Preço, Tempo de Execução, } \\
\text { Reputação, Disponibilidade e } \\
\text { Confiabilidade }\end{array}$ \\
\hline Vienne et al. [VS05] & Seleção de serviços & $\begin{array}{l}\text { Aprendizado de máquina sobre } \\
\text { políticas de ações a ser tomada }\end{array}$ & $x$ \\
\hline Canfora et al. [CDPEV05] & Seleção de serviços & $\begin{array}{l}\text { Algoritmo genético sobre } \\
\text { fatores de criticidade de QoS }\end{array}$ & $\begin{array}{c}\text { Serviços abstratos } \\
\text { (funcionalidades) e concretos } \\
\text { (candidatos) }\end{array}$ \\
\hline Halima et al. [HGDJ08] & $\begin{array}{c}\text { Substituição de serviços } \\
\text { degradados SLA }\end{array}$ & $\begin{array}{c}\text { Algoritmo de localização de } \\
\text { serviços; abordagem local e } \\
\text { global }\end{array}$ & $\begin{array}{c}\text { Tempo de resposta, tempo de } \\
\text { execução, tempo de } \\
\text { comunicação, vazão e } \\
\text { disponibilidade }\end{array}$ \\
\hline Yau et al. [YYSH08] & Seleção de serviços & $\begin{array}{c}\text { Problema de otimização } \\
\text { multi-objetivo: atributos } \\
\text { definem restrições e objetivo é } \\
\text { o QoS esperado }\end{array}$ & $\begin{array}{c}\text { Timeliness, acurácia, vazão e } \\
\text { segurança }\end{array}$ \\
\hline Alrifai et al. [AR09] & Seleção de serviços & $\begin{array}{c}\text { Programação Inteira e seleção } \\
\text { localizada }\end{array}$ & $\begin{array}{c}\text { Tempo de resposta, } \\
\text { disponibilidade, vazão, } \\
\text { likelihood of sucess, } \\
\text { confiabilidade, compliance, } \\
\text { best practices, latência e } \\
\text { documentação } \\
\end{array}$ \\
\hline Lizangyinwu et al. [LZYW10] & Seleção de serviços & $\begin{array}{c}\text { Substituição de serviços únicos } \\
\text { e múltiplos baseados em } \\
\text { parâmetros de degradação }\end{array}$ & $\begin{array}{c}\text { Tempo de resposta, custo, } \\
\text { confiabilidade e } \\
\text { disponibilidade }\end{array}$ \\
\hline Yin et al. [YL12] & Substituição de serviços & $\begin{array}{l}\text { Semelhante ao trabalho de } \\
\text { Lizangyinwu et al. [LZYW10] }\end{array}$ & $x$ \\
\hline Silva et al. [eSEK03] & $\begin{array}{c}\text { Reconfiguração de } \\
\text { componentes }\end{array}$ & $\begin{array}{c}\text { Reconfiguração baseada em } \\
\text { deteç̧ão de eventos }\end{array}$ & $x$ \\
\hline Silva et al. [eSKYJ05] & $\begin{array}{l}\text { Reconfiguração de } \\
\text { componentes }\end{array}$ & $\begin{array}{c}\text { Reconfiguração baseada em } \\
\text { eventos e regras }\end{array}$ & $\begin{array}{l}\text { Embora o conjunto não esteja } \\
\text { explícito, cita monitoramento } \\
\text { de disponibilidade, uso de } \\
\text { recursos, latência e colisões na } \\
\text { rede }\end{array}$ \\
\hline Gao et al. [GMYB05] & $\begin{array}{c}\text { Seleção de serviços e alocação } \\
\text { de recursos }\end{array}$ & $\begin{array}{l}\text { Algoritmos genéticos para } \\
\text { seleção de serviços e } \\
\text { configurações candidatos }\end{array}$ & Não especificado \\
\hline Andre et al. [ADG10] & Migração de serviços & $\begin{array}{l}\text { Reconfiguração baseado em } \\
\text { eventos; estratégias de } \\
\text { configuração }\end{array}$ & $x$ \\
\hline Calinescu et al. $\left[\mathrm{CGK}^{+} 11\right]$ & $\begin{array}{l}\text { Seleção de serviços e } \\
\text { reconfiguração de recursos }\end{array}$ & $\begin{array}{c}\text { Algoritmo estatístico para } \\
\text { decisão de qual reconfiguração } \\
\text { aplicar }\end{array}$ & Desempenho e confiabilidade \\
\hline Enactment Engine & $\begin{array}{l}\text { Composição de serviços e } \\
\text { reconfiguração de recursos }\end{array}$ & $\begin{array}{l}\text { Realização do ciclo MAPE } \\
\text { com técnica de CEP }\end{array}$ & Veja Seção 2.3.2 \\
\hline
\end{tabular}

Tabela 3.1: Trabalhos relacionados. 


\subsection{Modelo de QoS}

O termo QoS foi primeiramente utilizado e definido para fins de medição de desempenho e de confiabilidade em dispositivos de rede [VKvBG95]. Posteriormente, com o uso de arquiteturas de serviços para criar sistemas distribuídos passou-se a usar o termo para serviços web. No contexto de serviços, não há uma definição formal para o termo utilizado. No entanto, QoS em serviços vem sendo pesquisada desde meados dos anos 2000. Frolund [FK98], em 1998 já mostrava a necessidade de manutenção de serviços em relação a propriedades não funcionais. Seu trabalho foi um dos primeiros nessa área; seu trabalho, mostrava a preocupação em monitorar atributos relacionados a confiabilidade, disponibilidade, desempenho e segurança. No seu modelo de QoS, já enfatizava a importância de definição de quais atributos eram relevantes para cada componente do sistema. Embora um dos primeiros, já abordava a criação de linguagens de definição de QoS, a $Q M L$ e contratos de QoS; no entanto, não definia esses contratos como SLA.

Como a tecnologia CORBA ganhava força na área de sistemas distribuídos, a arquitetura de serviços também ganhou força e várias pesquisas em QoS para serviços web foram realizadas. Cardoso [CSM ${ }^{+}$04] definiu um modelo de QoS que contemplava workflows e processos de negócio para sistemas compostos de serviços. Considerando que o modelo de workflows era promissor para composições, destacava a possibilidade da criação de composições de serviços em função das métricas de QoS mais adequadas para cada um. No modelo de QoS usado, Cardoso classificava os atributos em quantitativos e qualitativos. No grupo dos quantitativos, organizou atributos relacionados a desempenho, tempos e custo enquanto que dentre os qualitativos estavam atributos ligados a segurança e confiabilidade.

Vários outros trabalhos tiveram como um dos propósitos criar definições e taxonomias para atributos de QoS. Mabrouk $\left[\mathrm{MBK}^{+} 09\right]$ também classificou os atributos em dois grupos, quantitativos e qualitativos. De maneira similar, Avizienis [ALRL04] separa os atributos de QoS em atributos de desempenhos e atributos de segurança no funcionamento. Em seu trabalho, destaca como atributo de desempenho aqueles que medem tempos e velocidades enquanto que atributos de segurança no funcionamento são os que remetem a existência de falhas nos serviços. Contudo, Yu [YRPK07] mostra que é possível medir atributos de segurança e confiabilidade se uma função de avaliação for definida.

Para Zheng [ZL13b] é necessário diferenciar entre atributos que necessitam que a coleta seja feita levando em conta a percepção do usuário final (atributos dependentes de usuário) e atributos que podem ser medidos no servidor da aplicação (atributos independentes de usuário). Dentre os vários trabalhos, conjuntos de atributos relevantes são abordados. Blake [BR09], define um conjunto de atributos já levando em conta modelos de computação em nuvem em que a alocação de recursos é feita sob demanda.

A necessidade de atingir qualidade no escopo dos serviços trouxe à tona a discussão sobre decisões arquiteturais a ser tomadas na área de SOC. Curbera [CKM $\left.{ }^{+} 03\right]$, defende em seu trabalho que composições de serviços são estruturas recursivas; uma composição pode ser vista como um serviço, isto é, a forma como foi composta e os serviços inter-conectados são transparentes ao cliente. Numa composição, serviços são componentes mínimos. A partir da agregação desses componentes, vistos como workflows, foram definidas arquiteturas em mais alto nível [CSM $\left.{ }^{+} 04\right]$.

Dustdar [DS05] apresenta uma pesquisa em composições. Fica claro que, há uma aceitação grande em uso de orquestrações. Essa aceitação pode ser vista como uma consequência do sucesso da linguagem para definição de composições Business Process Execution Language (BPEL) [ACD $\left.{ }^{+} 03\right]$, linguagem esta que permite a definição de composições como sequências de ações.

Pouco mais tarde, devido a problemas de escalabilidade, como alternativa ao modelo de orquestrações, passou-se a considerar coreografias como uma evolução para um modelo de composições de serviço mais colaborativo na perspectiva de processo de negócio [Pel03]. Para orquestrações, BPEL era a linguagem padrão usada para modelar composições. Porém, para coreografias havia a necessidade de definir uma linguagem para sua modelagem. Kavantzas [KBR $\left.{ }^{+} 05\right]$ descreveu a linguagem Web Service Choreography Description Language (WS-CDL) usada para modelagem de tais composições. 
Embora pesquisado desde 2003, o conceito de coreografias continua sendo discutido constantemente. Autores tentam definir formalmente o que caracteriza uma coreografia. Qiu [QZCY07] apresenta uma tentativa de avanço na definição formal desse conceito. No entanto, esta dissertação não apresenta uma definição e nem tem este objetivo. Ao invés disso, consideramos coreografias como um modelo onde serviços implementam funcionalidades definidas por papéis. Dessa forma, as operações de publicar, encontrar e utilizar os serviços levam em conta quais os papéis que estes podem executar $\left[\mathrm{DNGM}^{+} 08\right]$.

Durante o projeto citado, ainda tivemos pesquisas na área de predição de QoS. Yanik [GN12] pesquisou sobre predição usando algoritmos de grafos. Nesse trabalho, coreografias são modeladas como grafos compostos de três camadas que abstraem o processo de negócio, os serviços web e o conjunto de máquinas virtuais. Uma notável vantagem em relação a algoritmos vistos na literatura tais como baseados em programação linear $\left[\mathrm{ZBN}^{+} 04\right]$ está no desempenho de execução do algoritmo. Contudo, aplica técnicas de programação linear sobre grafos também [GNM12].

\subsection{Seleção de Serviços}

Seleção de serviços habilita composições a manter seu QoS dentro de um limiar esperado, fazendo com que serviços com melhor capacidade sejam utilizados preferencialmente. Ainda, ao se tornar vulnerável a uma quebra de SLA, serviços são substituídos por aqueles que apresentam melhores indicadores de QoS. Dentre as estratégias de seleção, são utilizadas as baseadas em algoritmos genéticos, estatísticas e aprendizado de máquina, técnicas baseadas em Programação Linear e otimização em grafos.

Trabalhos nesta categoria têm como objetivo fazer com que uma composição seja mantida com seus valores de QoS otimizados. Para isso, esses trabalhos selecionam serviços, reconfigurando o enlace entre eles de forma a obter tal composição. Esse problema é conhecido como um problema NP-difícil e as técnicas usadas tentam encontrar a melhor solução em tempo hábil [CLZ14].

Zeng et al. [ZBN $\left.{ }^{+} 04\right]$ trabalharam na construção de um middleware para composições de serviços dirigidas por QoS. Para tal, implementaram mecanismos de seleção de serviços em duas abordagens: local e global. Na primeira, a seleção de melhores serviços é feita para cada operação usada. Na segunda, usa Programação Linear Inteira para encontrar valores ótimos de QoS no escopo da composição como um todo, isto é, considerando os serviços candidatos, escolhe o melhor caminho a ser executado. A seleção é feita usando um conjunto reduzido de atributos de QoS: preço, tempo de execução, confiabilidade, disponibilidade e reputação.

Vienne et al. [VS05] utilizam aprendizado de máquina para manutenção de QoS. Sua abordagem é aplicável a ambientes de computação em nuvem dado que considera ambientes que compartilham recursos com capacidade de processamento desconhecida. A partir de políticas de seleção de ações tomadas, aplica um algoritmo de aprendizado por reforço. Esse trabalho não apresenta um conjunto de atributos concreto, porém, cita definição de níveis de QoS para serviços.

Gao et al. [GMYB05] sugerem que o maior objetivo em termos de QoS, quando é usado o paradigma de composição de serviços, é determinar a melhor composição de serviços. Em seu trabalho, os autores usam uma abordagem baseada em algoritmos genéticos em que a configuração do sistema é mapeada para genes. O sistema é iniciado com uma configuração inicial e o algoritmo substitui genes que apresentam valores de QoS baixos na intenção de convergir para a melhor configuração. A partir do início da execução da composição, um número inicial de indivíduos, ou seja, uma coleção de genes, sofre operações de seleção, mutação e cruzamento, na tentativa de chegar à melhor solução. A métrica usada é o tempo de resposta, que é calculado usando cadeias de Markov. Se o tempo de resposta computado é alto, o sistema sofre reconfiguração. É uma abordagem interessante quando não se conhece o comportamento do sistema de antemão, nem é possível obter uma estimativa favorável.

Wang et al. [WWC $\left.{ }^{+} 05\right]$ usam abordagens proativas e passivas. O sistema produz valores para métricas de QoS e envia para um módulo de monitoramento; enquanto isso, esse módulo provê dados de QoS que são usados pelo sistema para encontrar a causa da anomalia que os dados 
providos mostram ter acontecido. O trabalho ainda define um conjunto de mecanismos e políticas de ação que são aplicados dependendo da causa do defeito. O que não fica claro é qual o modelo de QoS usado, isto é, quais métricas de QoS são utilizadas e como elas são processadas.

Canfora et al. [CDPEV05] utilizam também um algoritmo genético para seleção de serviços concretos. No seu trabalho, agrupam serviços em serviços abstratos que determinam grupos de serviços candidatos para uma operação. Continuamente, monitoram os serviços por meio de fitness functions. O modelo de QoS utilizado considera um pequeno subconjunto de atributos. No entanto, a abordagem usada permite a definição de atributos personalizados permitindo flexibilidade no cálculo de QoS dos serviços. Apresenta ainda um estudo comparativo das abordagens genética e de programação linear, mostrando uma melhoria significativa em relação à quantidade de serviços candidatos possíveis.

Halima et al. [HGDJ08] usam uma abordagem proativa monitorando métricas de QoS. Se o tempo de resposta aumenta, é sinal de que a negação de serviço pode vir a acontecer. Assim, o tempo de resposta é medido e um alarme é emitido se for detectada degradação nos valores de QoS. Um algoritmo faz uma busca pela origem da degradação propagada. Apontado a origem do problema, o algoritmo de reconfiguração altera o endereço do serviço que está gerando requisições para que use outro serviço. O algoritmo proposto considera tempos de comunicação e execução. Entretanto, esse trabalho não integra meios de resolver o problema como, por exemplo, a adição de recursos.

Yau et al. [YYSH08] apresentam uma maneira de desenvolvimento de sistemas adaptativos considerando conceitos de atividade, estado e eventos. Em seu trabalho, um modelo de QoS é proposto usando como parâmetros atividades de requisições de usuários, o estado dos recursos das máquinas onde o sistema está sendo executado e eventos gerados pelo comportamento do sistema tais como falhas e tentativas de ataques. O modelo proposto considera esses parâmetros para manter níveis de QoS de tempo de resposta, vazão, acurácia e segurança. Esse trabalho não contempla meios de adaptação de recursos.

Alrifai et al. [AR09] combinam a técnica de otimização local e global proposta no trabalho de Zeng et al. $\left[\mathrm{ZBN}^{+} 04\right]$ com a modelagem de serviços abstratos e candidatos apresentada por Canfora et al. [CDPEV05]. Enfatiza a dificuldade em achar a composição de serviços ótima já que o uso de Programação Linear é aplicável apenas para pequenas composições. Assim, propõe uma heurística dividindo o problema em duas fases. Na primeira fase, decompõe as composições segundo restrições de QoS globais. Na segunda, aplica seleção de serviços nas agregações menores resultados da decomposição das composições feitas anteriormente com algoritmos de seleção local.

Ying Li et al. [LZYW10] usam uma abordagem de seleção múltipla. Seu trabalho usa seleção de serviços substituindo componentes que apresentam falhas em seu funcionamento. Os autores definem o termo fator de criticidade, que é o grau de degradação do QoS de um serviço. De acordo com esse fator, a primeira reconfiguração aplicada é a seleção de serviços individuais. Caso a primeira reconfiguração não surta efeito, a segunda tentativa substitui um serviço composto. Por fim, para que a QoS da composição como um todo seja satisfeita, é possível a substituição de múltiplos serviços. Portanto, continuamente é recalculado o fator de criticidade.

Strunk et al. [Str10] definem o problema da composição de serviços ótima e apresenta uma pesquisa de técnicas utilizadas para a solução. Considerando as formas de agregação de serviços e restrições de QoS, enfatiza que, para encontrar a composição ótima, é necessário garantir cinco fatores: a) a função objetivo deve ser linear; $b$ ) o objetivo deve ser único; $c$ ) a maximização de QoS deve ser calculada de maneira local; $d$ ) inexistência de restrição de QoS; e $e$ ) a solução deve ser um caminho de execução sub-ótimo.

Yin e Li [YL12] apresentam um estudo similar ao estudo de Ying Li et al. [LZYW10]. Analogamente ao fator de criticidade, a chave para o algoritmo proposto é o fator de degradação de QoS. Se restrições de SLA são violadas, o algoritmo de substituição faz tentativas de substituição a partir do serviço com piores valores de QoS, substituindo múltiplos serviços se necessário. Nesse trabalho, é considerado primeiramente componentes que apresentam falhas. Estes são substituídos antes e somente com todos os serviços sem falhas é que a substituição baseada em QoS acontece. Entende-se 
por serviços com falhas aqueles que a degradação de QoS passa a afetar seu funcionamento.

Os trabalhos vistos nesta seção apresentam técnicas para substituição de serviços; isto devido a facilidades que há nos sistemas que usam SOA. No entanto, seleção de serviços se apresenta como uma solução limitada ao problema de manutenção de QoS; caso não haja serviços a serem usados, não há solução factível. Dessa forma, é necessário considerar o uso de técnicas de adaptação dinâmica capazes de manter o QoS de serviços, reconfigurando os recursos utilizados.

\subsection{Reconfiguração dirigida por QoS}

Diferentemente dos trabalhos apresentados na seção anterior, nesta categoria se encaixam os trabalhos que provêm mecanismos para alterar os recursos alocados pela composição a fim de manter o seu QoS. Andre et al. [ADG10], apresentam um estudo em busca de um middleware capaz de adaptar sistemas em geral. Para isso, propõe um arcabouço que dá suporte a adaptação dinâmica. A adaptação aqui é realizada em 4 níveis: serviço, aplicação, sistema e infraestrutura. Cada nível é escolhido por meio de ações, decididas usando técnicas de sistemas autônomos. Em seu trabalho, as decisões utilizam MAPE.

Paralelamente, Vromat et el.[VWMA11] também trabalhou na tentativa de superar as limitações presentes no MAPE. Considerando sistemas específicos, enfatiza a necessidade de sub-loops nas fases de análise e planejamento, bem como a interdependência entre dois ou mais loops que processam sobre um mesmo conjunto de recursos. Para isso, cria um modelo onde é encaixado tais sub-loops aprimorando a qualidade da adaptação automática.

Calinescu et al. $\left[\mathrm{CGK}^{+} 11\right]$ apresentam um estudo sobre trabalhos com foco em reconfiguração dinâmica. Nesse estudo, é mostrado o estado da arte em adaptação dinâmica não-funcional. Comparando trabalhos anteriores, é visível a preferência por adaptação baseada em seleção de serviços. Calinescu defende que adaptação dinâmica vai além de selecionar serviços e componentes ou ainda reconfigurar o workflow da composição de serviços; é necessário reconfigurar a quantidade de recursos alocada para serviços e parametrizar os serviços sobre os quais o usuário tem algum tipo de controle. Os autores propõem um arcabouço unindo vários aspectos de adaptação, que são algoritmos para avaliação probabilística de serviços, um modelo formal para especificação de requisitos de QoS e um método para a análise global do QoS dado o que é sabido sobre os valores de cada um dos serviços individuais. Os algoritmos probabilísticos utilizados têm bom desenpenho funcional, porém com maiores quantidades de dados de monitoramento leva mais tempo para ser executado. O arcabouço reúne ferramentas desenvolvidas anteriormente pelos autores para atingir o objetivo de manter QoS de composições. Assim, esse trabalho é, na maior parte, um esforço de integração. Nosso trabalho se beneficiaria da integração de várias partes do arcabouço, mas a busca inicial não indica se o código é aberto ou não. O arcabouço proposto está atrelado a um ambiente PaaS; com grandes composições de serviços, a reconfiguração pode demorar muito tempo devido aos algoritmos probabilísticos usados.

A reconfiguração de recursos em ambientes em nuvem é realizada de forma facilitada, porém, a determinação do padrão exato de uso de recursos de serviços é uma tarefa difícil de ser realizada. Dejun [JPC10], mostra um modelo de perfis para consumo de recursos de serviços através de execuções assistidas, levando em conta a distinção entre os vários serviços e seus comportamentos. Mecanismos de aferição de desempenho possibilitam ainda a predição da capacidade dos serviços em teste. Baseado nesses mecanismos, desenvolve um arcabouço de testes para predição do uso de recursos por parte dos serviços. Na continuação do trabalho [DPC11] o autor ainda define perfis para máquinas virtuais alocadas em diferentes provedores de computação em nuvem. Consequentemente, formas para balanceamento de carga que levam em conta esses perfis são propostas.

Da mesma forma, Moura [MK13], desenvolve uma ferramenta para testes de escalabilidade. Esta ferramenta é capaz de identificar a quantidade de recursos necessária diante da carga que um serviço está recebendo e seus recursos atuais. Estes resultados auxiliam um desenvolvedor de composições de serviços a criar o plano inicial de configurações.

Comercialmente, a Amazon apresenta uma plataforma que oferece elasticidade para serviços que 
executam em seu ambiente de nuvem. O serviço Elastic Beanstalk ${ }^{1}$ adiciona aos serviços capacidade de elasticidade por meio de configurações de balanceadores de carga automáticos. De acordo com métricas coletadas por meio do serviço CloudWatch ${ }^{2}$, serviços são replicados e disponibilizados nos balanceadores. Naturalmente, o sistema funciona apenas para recursos servidos pela Amazon, uma vez que é o esforço de integração entre seus serviços [BBB $\left.{ }^{+} 11\right]$ Como ocorrido com o trabalho apresentado por Calinescu, o qual teve grande influência nesta pesquisa, não foi possível uma análise detalhada por falta de acesso a códigos-fonte.

Durante a reconfiguração de uma composição de serviços é natural que haja instantes de tempo em que a consistência das transações não é garantida. Wei Li [Li12] desenvolveu um arcabouço para manutenção do QoS de uma composição durante o tempo de reconfiguração. Destaca ainda a importância pois durante o tempo de reconfiguração de uma composição de serviços, serviços podem atingir estados de inconsistência ou ficar completamente indisponíveis. Em seu trabalho, ele cita a importância dos conceitos quiescence [KM90] e tranquility [VEBD07], considerados como marcos para o problema de inconsistências durante atualizações e reconfigurações de uma composição.

\subsection{Processamento de eventos complexos}

Monitoramento de sistemas distribuídos é uma tarefa que, segundo Luckham [Luc02] se encaixa perfeitamente como um problema a ser modelado usando CEP. Sendo o conceito de CEP algo não muito recente [LF98], em seu trabalho mostra as vantagens do uso de eventos, os quais são gerados em diversos pontos dos sistemas e analisados em um ponto central. Tais eventos, chamados de eventos complexos são eventos que só existem quando ocorrem um conjunto de outros eventos. Por meio de um stream de eventos, uma análise correlacional é feita sobre um histórico em um intervalo de tempo.

A natureza genérica de CEP, torna possível o processamento de um conjunto de mensagens contendo quaisquer tipo de eventos, desde eventos que indicam condições de baixo nível como dados de conexões de rede, até eventos com dados que indicam condições de alto nível, como dados de regras de negócio de uma aplicação.

Monitorar sistemas distribuídos envolve a análise de eventos provenientes de várias fontes separadas, isto é, fontes de locais e redes diferentes $\left[\mathrm{BHBC}^{+} 12\right]$. Contudo, é necessário o correto sincronismo para que os eventos sejam processados em conformidade com a história dos eventos. De acordo com o histórico, Bertolino et al. [BDML12] apresenta um conjunto de operadores capazes de analisar um histórico de eventos de acordo com o momento em que ocorreu.

Diferentemente dos trabalhos relacionados, estamos interessados em medir o desempenho de cada serviço individual com o objetivo de manter a QoS das composições como um todo, além de permitir a configuração dos atributos de acordo com o domínio da composição. No entanto, para isso é necessário construir estratégias de adaptação boas sobre um conjunto de requisitos ideal para cada serviço. Isso implica em haver o conhecimento a priori de como as reconfigurações devem ser feitos e quanto o sistema é afetado com reconfigurações. Em alguns casos, utilizando ferramentas e técnicas apropriadas, já é possível saber de antemão o comportamento esperado de uma aplicação diante de alguns cenários de carga de trabalho.

Como visto, a maioria dos trabalhos se preocupam em reconfigurar as composições de serviços. Alguns outros, se preocupam em construir mecanismos de sistemas autônomos. Vimos na literatura apresentada que MAPE é uma padrão a ser seguido para sistemas adaptativos. Para tomada de decisões, autores trabalharam com modelos desde genéticos até estatísticos; cada um apresenta suas vantagens e desvantagens. Nossa abordagem combina o uso de MAPE e CEP em conjunto com o intuito de realizar reconfigurações em tempo hábil.

No próximo capítulo, descrevemos os detalhes da implementação do middleware bem com sua arquitetura e ferramentas utilizadas.

\footnotetext{
${ }^{1}$ http://aws.amazon.com/documentation/elastic-beanstalk

${ }^{2}$ http://aws.amazon.com/cloudwatch/
} 


\section{Capítulo 4}

\section{Middleware}

Neste capítulo, apresentamos os detalhes da solução desenvolvida para realização deste trabalho. Essa solução consiste em um middleware capaz de reconfigurar composições de serviços implementadas na forma de coreografias. Para isso, o middleware provê escalabilidade para cada serviço participante da coreografia, com a finalidade de manter o QoS dentro dos níveis desejados. Provedores de aplicações precisam garantir os SLAs formalizados com seus clientes; para tanto, o middleware realiza adaptação dinâmica nas composições, criando réplicas e modificando os recursos virtuais alocados para cada serviço. Não obstante, é preciso que a adaptação leve em conta recursos subutilizados os quais podem ser removidos. O objetivo final é auxilar desenvolvedores e mantenedores de sistemas baseados em SOA a obter mais elasticidade nas suas aplicações.

Para a realização deste trabalho, utilizamos como base o CHOREOS Enactment Engine. O CHOReOS EE é um middleware desenvolvido para implantação automatizada de coreografias em ambientes de nuvem, cujo desenvolvimento se deu inicialmente no trabalho de mestrado de Leonardo Leite $\left[\mathrm{LMC}^{+} 14\right]$. Seu objetivo inicial era prover uma ferramenta capaz de abstrair os detalhes morosos que há na implantação de coregrafias, deixando transparentes as etapas repetitivas ligadas à configuração de infraestrutura que são necessárias em todo o processo de implantação, como por exemplo, a escolha de uma máquina virtual e a preparação desta para executar corretamente o serviço. Nesta pesquisa, incluímos gestão de QoS no middleware, deixando também transparente o monitoramento dos serviços e suas máquinas hospedeiras, bem como o mecanismo para a reimplantação e reconfiguração automática dos serviços, necessário para a elasticidade das coreografias.

No CHOReOS EE, a implantação de composições acontece de forma ágil e robusta. Sendo um middleware, sua utilização depende de instalação e configuração prévias. Por exemplo, é necessário configurar as credenciais de acesso aos provedores de serviços de IaaS que serão utilizados. O CHOReOS EE é executado como uma plataforma de serviços, isto é, utiliza o modelo de negócios de computação em nuvem PaaS, abstraindo a complexidade de manutenção de infraestrutura virtual dos ambientes entregues pelos provedores de IaaS.

Embora seja uma ferramenta robusta, em sua proposta inicial não havia nenhum meio de fazer gestão de QoS nas composições implantadas. O contínuo funcionamento sem interrupções indesejadas causadas por grande quantidade de carga implica em alguma forma de gerir QoS. Para habilitar o gerenciamento de QoS nas composições implantadas incluímos mecanismos de reconfiguração de acordo com o modelo apresentado na Seção 2.3. No contexto desta dissertação, adicionamos as seguintes funcionalidades ao CHOReOS EE:

- Extensão da API existente para adicionar uma operação de atualização de composições de serviços com suporte a políticas de escalabilidade vertical, horizontal e atualização de componentes com novas versões;

- Plataforma de monitoramento de eventos para monitorar o uso de recursos virtuais das máquinas utilizadas na implantação do serviços;

- Sondas para monitoramento de atributos de QoS dos serviços componentes das coreografias implantadas; 
- Consumidores de mensagens JMS para manipulação de eventos de monitoramento; e

- Análise de eventos de monitoramento utilizando Processamento de Eventos Complexos.

Nosso middleware é distribuído como software livre sob licença Mozilla Public License v2 (MPL v2) ${ }^{1}$ e está disponível para uso e contribuição em https://github.com/choreos/enactment_ engine. A seguir, apresentamos os detalhes arquiteturais e técnicos utilizados na implementação de gestão de QoS no CHOReOS EE. Primeiramente mostramos os detalhes do CHOReOS EE em conjunto com as modificações impostas. Na sequência, apresentamos a arquitetura e os detalhes da implementação dos mecanismos de gestão de QoS.

\subsection{O Enactment Engine}

O CHOReOS EE é um middleware criado no contexto do Projeto CHOReOS. Seu papel tinha como um dos propósitos a criação de um sistema capaz de sintetizar e encenar coreografias a partir de suas definições. O papel do CHOReOS EE era receber requisições com descrições de coreografias sintetizadas, implantá-las e executá-las. O CHOReOS EE é um servidor de aplicação; para o usuário final, comumente o desenvolvedor de coreografias, ele oferece uma interface implementada usando o modelo de comunicação Representational State Transfer (REST), expondo as operações necessárias para manutenção das composições. As operações fornecidas são as que seguem:

Criar coreografia: Registra uma coreografia a partir de uma descrição estrutural, devolvendo o seu identificador único;

Implantar coreografia: Implanta uma coreografia previamente criada utilizando como parâmetro o seu identificador. A etapa de implantação é responsável pela configuração do ambiente de computação em nuvem, instalação dos serviços e configuração dos pontos de comunicação usados para a configuração da composição. Ao final da implantação, a coreografia implantada é devolvida em formato eXtensible Markup Language (XML);

Obter coreografia: Devolve uma coreografia implantada de acordo com o identificador especificado como entrada da operação;

Atualizar coreografia: Operação implementada no contexto desta dissertação. Atualiza uma coreografia especificada pelo seu identificador com uma nova descrição estrutural. Esta operação recebe como parâmetros um identificador e a nova especificação de coreografia que deverá ser utilizada.

A atualização não reimplanta a coreografia; apenas atualiza sua descrição estrutural. A aplicação da atualização deve ser feita utilizando novamente a função que implanta a coreografia, assim como feito na criação. A operação de atualização de coreografia será vista com mais detalhes na Seção 4.2.2.4.

As operações vistas acima permitem que o usuário interaja com o CHOReOS EE. Como vimos, essa interação é realizada por meio de troca de mensagens através de uma interface REST. As mensagens encapsulam seus dados em descrições estruturais de coreografias. Essas descrições arquiteturais contêm as informações necessárias para a implantação das composições e gestão de seus SLAs (Figura 4.1). No CHOReOS EE, essas estruturas são enviadas e recebidas em formato XML. É por meio dessas especificações que o CHOReOS EE mantém o estado de cada composição em execução. Posteriormente, esses estados são considerados para decisões na execução de reconfiguração dinâmica.

Para comodidade, é fornecido como parte do software uma biblioteca contendo um cliente Java usado para as chamadas ao servidor. Através de classes e métodos convenientes, o usuário descreve

\footnotetext{
${ }^{1}$ http://www.mozilla.org/MPL/2.0/
} 


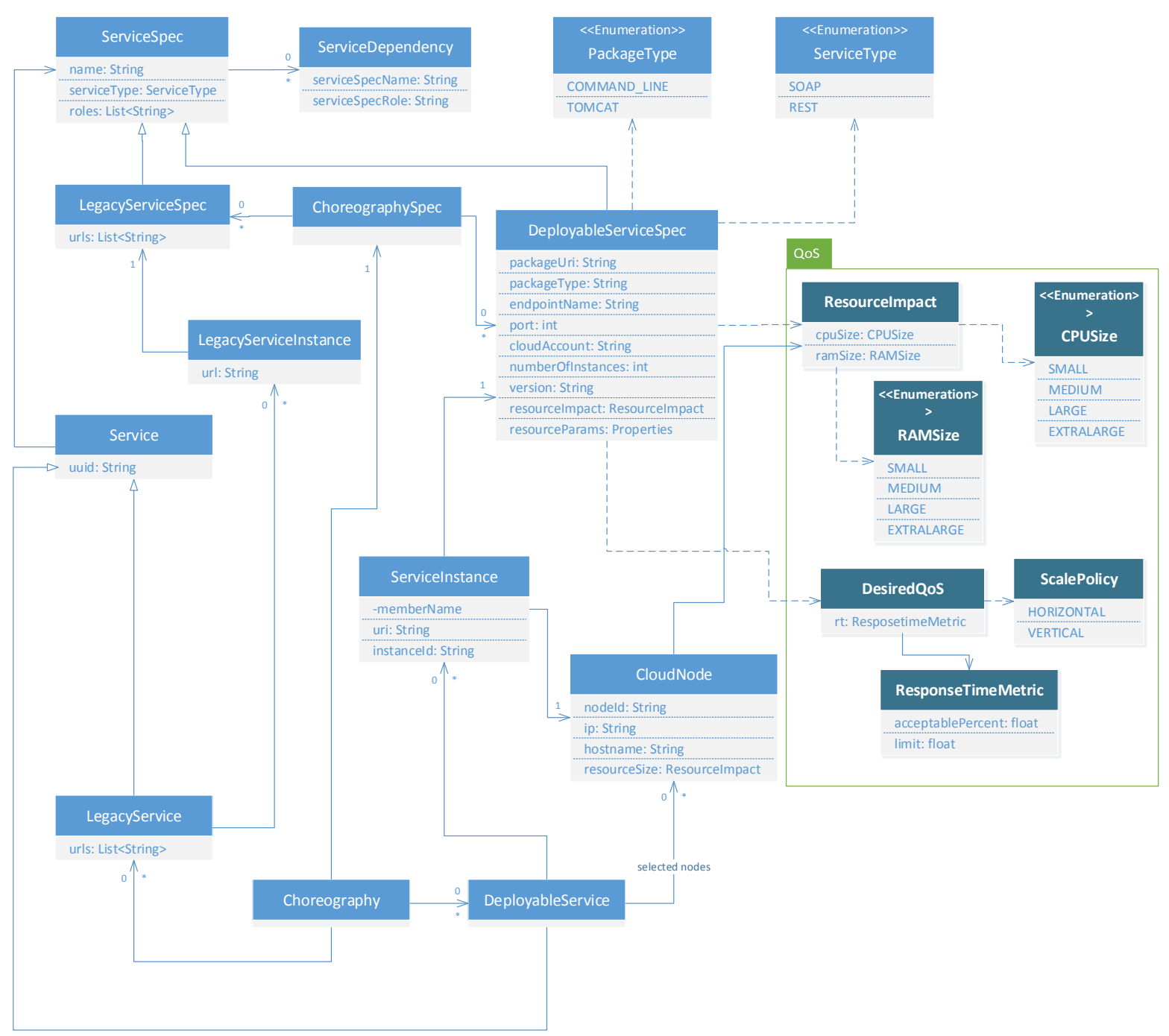

Figura 4.1: Modelo de dados para implantação de coreografias.

a estrutura da composição desejada em seu código como mostra a Listagem 1. Dessa forma, o utilizador do middleware pode interagir com o CHOReOS EE por meio de Plain Old Java Objects (POJOs), isto é, classes simples contendo apenas a definição dos atributos. Na especificação devem ser definidos cada serviço e suas dependências.

Em sua versão inicial, a estrutura de dados compatível com as definições seguia o modelo de dados representado pelas classes que estão fora do pacote "QoS" na Figura 4.1. Para satisfazer as novas funcionalidades relacionadas ao mecanismo de adaptação dinâmica adicionamos novas classes à estrutura inicial. As classes inclusas no pacote "QoS" presentes na Figura 4.1 são usadas para armazenar os dados relacionadas à gestão de QoS. Essas informações são relevantes para a definição do QoS esperado por parte dos clientes da composição e dos itens do SLA formalizado entre clientes e provedores de serviços. Portanto, à definição inicial do middleware foram incorporadas classes de dados para o controle da QoS e asserção de SLAs. Dentre as classes adicionadas podemos destacar o propósito das duas a seguir:

DesiredQoS: Usada para determinar os valores desejados para atributos de QoS. Na implementação atual, utilizamos apenas o tempo de resposta como prova de conceito para os experimentos, muito embora, o middleware ofereça ferramentas para ser estendido neste aspecto. Um dos ponto de extensão é, de fato, o atributo de QoS a ser considerado. Na Seção 4.2.2, retomaremos esse assunto explicando como é possível essa extensão. 


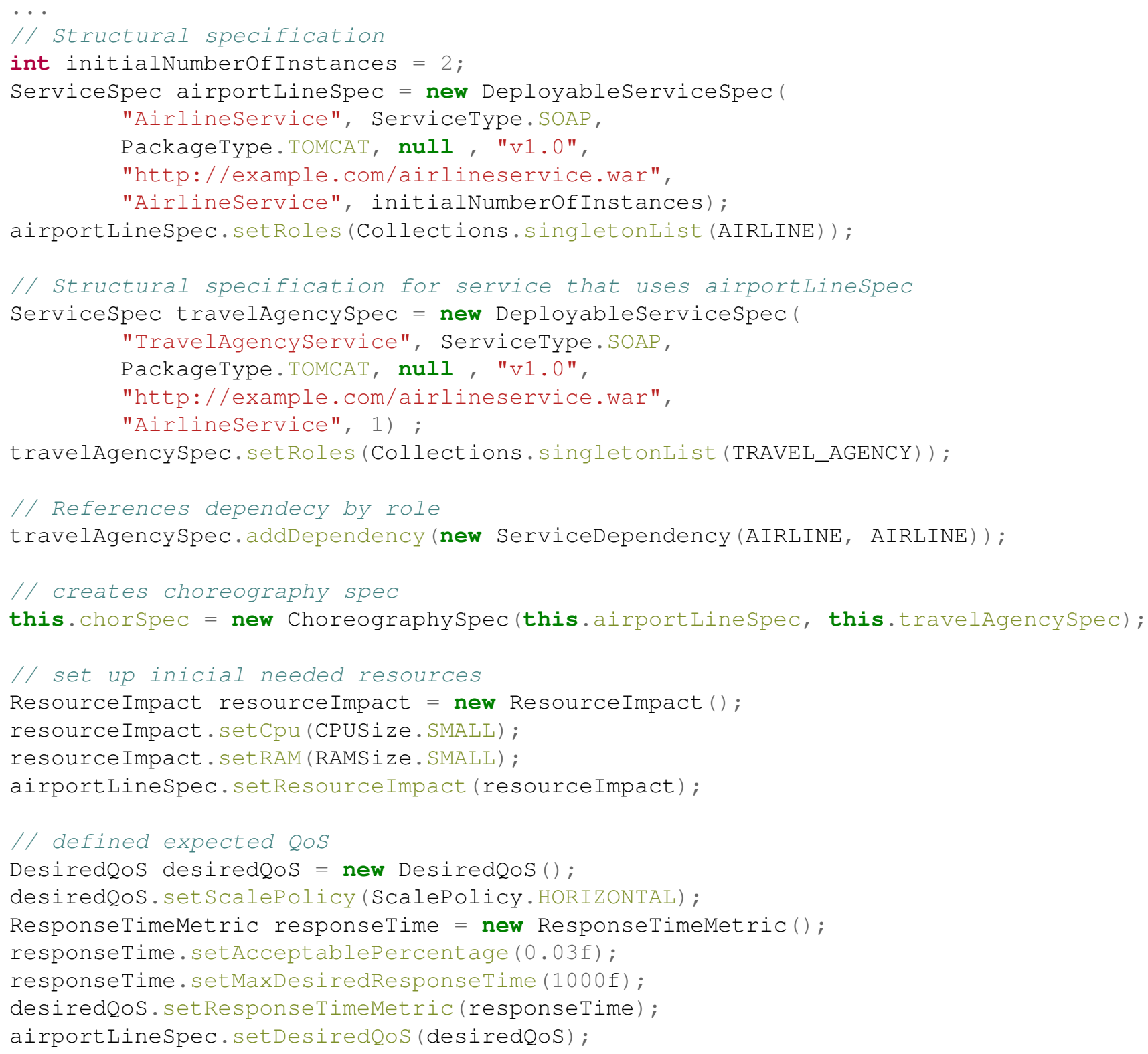

Listing 1: Fragmento de código que configura minimamente uma composição de serviços usando a aplicação cliente. 
ResourceImpact ${ }^{2}$ : Classe que abstrai os tipos de máquinas virtuais usualmente existentes nos ambientes de nuvem. Levamos em consideração valores compatíveis com tamanhos small, medium, large, extra-large. A representação indica qual tipo de máquina virtual deve ser usada para implantação no caso de reconfigurações com escalabilidade vertical, indicando o tamanho da máquina que deve passar a ser usada.

Como visto, a operação responsável pelas mudanças no ambiente (tais como a criação de máquinas virtuais e a configurações dos serviços nessas máquinas) é a operação de implantação. Para tanto, essa operação acontece em fases como podemos ver a seguir:

\section{Criação e configuração de máquinas virtuais na nuvem}

Num primeiro momento, as máquinas virtuais precisam ser criadas.

Para a primeira implantação, é criada uma máquina por serviço (o CHOReOS EE permite o uso de padrões de implantação com número fixo de máquinas, porém, nesta dissertação utilizamos uma máquina por serviço devido ao fato de que esse modo de implantação apresenta uma série de vantagens [New15]).

Para reconfigurações em tempo de execução, são criadas máquinas sob demanda: o CHOReOS EE, responsável pela alocação dos recursos virtuais, seleciona as máquinas de acordo com os dados da especificação contidos no ResourceImpact de cada serviço. Esse é o artifício que possibilita a migração de serviços para máquinas maiores ou menores.

\section{Instalação dos serviços}

A manutenção do ambiente é realizada com o auxílio do software de gestão de servidores $\mathrm{Chef}^{3}$. O CHOReOS EE executa scripts que preparam as máquinas virtuais para receber os serviços. Tais scripts configuram o Chef, suas dependências e os programas básicos para a execução dos serviços nessas máquinas.

Em sua versão solo, é possível escrever receitas de configuração e executá-las diretamente nas máquinas criadas. As receitas são criadas com uma Linguagem de Descrição Arquitetural (ADL) que usa sintaxe da linguagem Ruby. Ao final dessa fase, as máquinas estão prontas para executar os serviços, isto é, as receitas já configuraram a pilha de software de que o serviço depende.

O uso de gestão de QoS no CHOReOS EE foi implementado nesse trabalho como uma funcionalidade opcional. Dessa forma, para habilitar elasticidade da composição de serviços, é necessária a configuração dessa propriedade antes da execução do middleware. Devemos destacar que, quando essa opção está habilitada, a pré-configuração das máquinas virtuais mencionada acima inclui também a implantação e configuração do software de monitoramento Ganglia [MCC04] e da plataforma de monitoramento desenvolvida neste trabalho. Ambos, serão abordados com mais detalhes na Seção 4.2.2.1.

A instalação dos serviços é feita com a execução do Chef nas máquinas. Esta etapa apenas instala os serviços e os coloca em execução; a montagem da composição é feita na próxima etapa.

\section{Enlace dos serviços (definição da composição)}

Como já vimos na Seção 2.3.1, sistemas implementados com serviços web geralmente são formados de componentes que são interconectados para possibilitar a execução de tarefas complexas. É possível ainda utilizar componentes legados de outros sistemas para processamento parcial de uma tarefa; é cada vez mais comum vender funcionalidades por meio de sistemas implementados sob o modelo de negócio SaaS.

\footnotetext{
${ }^{2}$ Versões futuras do middleware usarão esta classe para armazenar informações mais complexas sobre o uso de recursos computacionais.

${ }^{3}$ https://www.chef.io/
} 
A criação de máquinas virtuais em ambientes de nuvem é feita sob demanda. Portanto, a configuração final de uma máquina virtual bem como os parâmetros de acesso para serviços implantados nestas só podem ser conhecidos após a sua configuração ser finalizada. Portanto, a configuração das interdependências entre os serviços implantados só pode ser feita após a implantação de cada serviço individual, isto é, a composição de serviços é formada após todos os serviços estarem prontos para uso.

Nesse contexto, um mecanismo aplicável é a injeção de dependências, onde cada componente que depende de outro recebe o seu "endereço" de acesso. O CHOReOS EE implementa a operação setInvocationAddress responsável por configurar, em cada serviço, quais os pontos de acesso de suas dependências. Para permitir essa configuração, os serviços devem implementar a operação setInvocationAddress. Observe-se que, em uma coreografia, os elementos são vistos como "papéis" que podem ser desempenhados por um ou mais serviços, às vezes diferentes. Assim, a operação setInvocationAddress recebe um mapa de dependências organizado por esses papéis, onde cada papel pode ser desempenhado por mais de uma réplica de cada serviço fazendo com que esta operação tenha três dimensões: papel do serviço, nome do serviço e endereço das réplicas. Dessa forma, fica a cargo do desenvolvedor do serviço a forma como lidará com filas de mensagens não entregues no caso de indisponibilidade diante de uma migração de serviços ou qual réplica escolher, caso um serviço tenha mais de uma réplica.

Finalmente, para automatização do processo de atualização de coreografias, ao CHOReOS EE foi adicionado suporte à manipulação de eventos através de uma arquitetura baseada em eventos, transmitidos via interfaces implementadas usando protocolo Java Message Service (JMS). O uso de JMS permite a comunicação assíncrona, algo que não haveria naturalmente com o uso de HTTP. A Figura 4.2 mostra um diagrama de alto nível da comunicação de eventos:

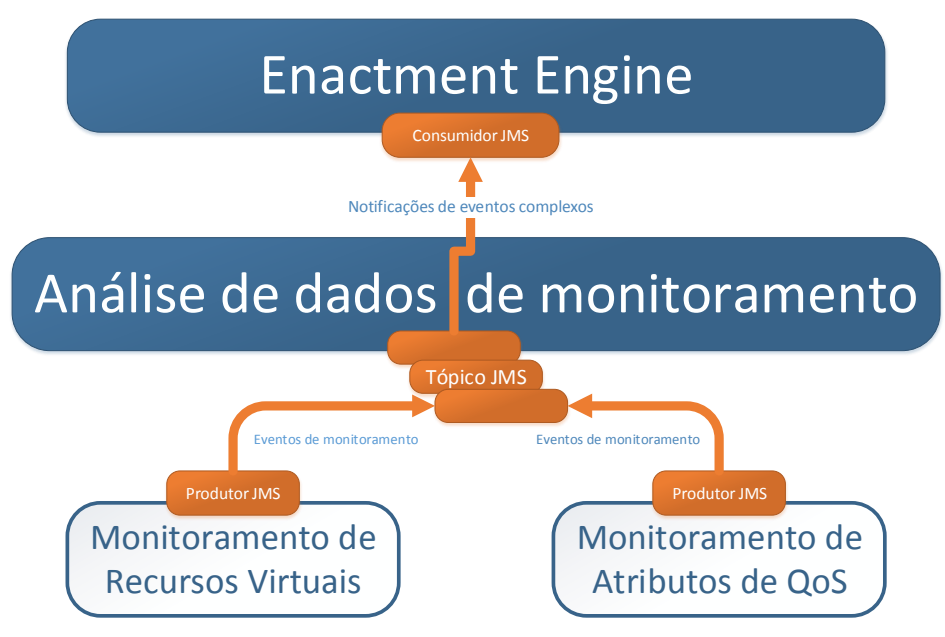

Figura 4.2: Niveis de tratamento de eventos no CHOReOS EE

Nas próximas seções veremos a arquitetura geral da solução de middleware implementada, bem como as técnicas e ferramentas utilizadas para o desenvolvimento descrito até aqui.

\subsection{Gestão de QoS no CHOReOS EE}

A solução implementada nesse trabalho divide a responsabilidade em dois conceitos. O primeiro, um conceito arquitetural, é o conceito de laços de execuções proposto na arquitetura MAPE para realização do monitoramento das composições no middleware. O segundo, CEP, um conceito de processamento de eventos usado para implementar as fases presentes na arquitetura MAPE. 
Para a execução de coreografias em condições distintas de carga, o middleware implementa componentes em sua arquitetura capazes de realizar o monitoramento contínuo obedecendo os padrões presentes no MAPE, gerando e avaliando eventos relacionados à atributos de QoS das composições de serviços implantadas e métricas de utilização de recursos computacionais. Com o uso de CEP, as notificações entre as fases do MAPE ficam sendo baseadas em eventos. Eventos são essenciais para a deteç̧ão de alteração no estados de sistemas. Por outro lado, estratégias de reconfiguração permitem que o sistema se mantenha com bom desempenho usando quantidade de recursos sob demanda. Isto é essencial para a redução dos custos operacionais necessários para manter essas composições em execução.

\subsubsection{Arquitetura}

A arquitetura do middleware é composta de três componentes principais: o Platform Monitor (PM), o Deployment Manager (DM) e o Resource Manager Aggregator (RMA). A Figura 4.3 ilustra a arquitetura geral do middleware.

O PM fornece uma plataforma de monitoramento distribuída composta por ferramentas de monitoramento de recursos e serviços. Para monitorar recursos, sondas estão presentes em cada máquina virtual. Já para monitorar atributos de QoS dos serviços, interceptadores de mensagens operam nas interfaces dos serviços. Ambos são responsáveis pela geração de eventos a partir de dados de monitoramento o que caracteriza-os como componentes da fase de Monitoramento. Tais eventos alimentam o RMA.

O RMA tem o papel de agregar e analisar os eventos de monitoramento capturados pelas sondas e interceptadores do PM. Num primeiro momento, utiliza mecanismos de regras para correlação dos eventos gerados anteriormente (fase de Análise). Uma vez realizada a análise, o middleware já terá determinado que uma reconfiguração precisa ser feita. Contudo, a decisão de qual estratégia utilizar para solucionar o problema ainda não é determinada.

Em um segundo momento, utilizando um conjunto de regras distintos, o RMA associa os eventos resultados da correlação para decidir sobre o problema encontrado. Neste momento, o RMA está preparado para selecionar a estratégia de adaptação (fase de Planejamento). A estratégia a reação a ser tomada, como por exemplo, a estratégia de adicionar mais uma réplica a um serviço. Essa estratégia é enviada ao DM que fará a reconfiguração efetivamente.

Além de realizar a implantação, o DM tem a responsabilidade de permitir a reconfiguração das composições de serviços. Esse módulo é responsável por alocar a quantidade necessária de recursos virtuais, configurar a pilha de software necessária e implantar os serviços que compõem os sistemas. Adicionalmente, o DM permite que uma composição de serviços seja atualizada com novas configurações, implantando as alterações necessárias (fase de Execução). O DM mantém as especificações atuais das composições. Estas contêm informações tais como, endereços de acesso dos serviços e o SLA configurado para este. Quando uma reconfiguração é requisitada, o DM usa as informações atuais para fazer as mudanças de acordo com as novas especificações geradas na fase anterior.

A seguir, cada uma das fases será explicada com maiores detalhes, esclarecendo a arquitetura individual dos componentes do middleware.

\subsubsection{Monitoramento}

A fase de monitoramento é responsável por coletar os dados do estado das aplicações. No nosso caso, as aplicações são composições de serviços. No contexto de aplicações baseadas em SOA, o monitoramento deve ocorrer nos atributos de QoS e métricas de uso de recursos computacionais. Como já visto, é necessário o monitoramento de ambas as dimensões de métricas para que possa ser aplicado reconfigurações de recursos. As métricas coletadas são referentes a cada máquina virtual e/ou serviço gerenciados pelo middleware.

Sondas de monitoramento são utilizadas para coleta de métricas de monitoramento. Sistemas operacionais disponibilizam ferramentas que possibilitam a extração de medidas de uso de recursos. 


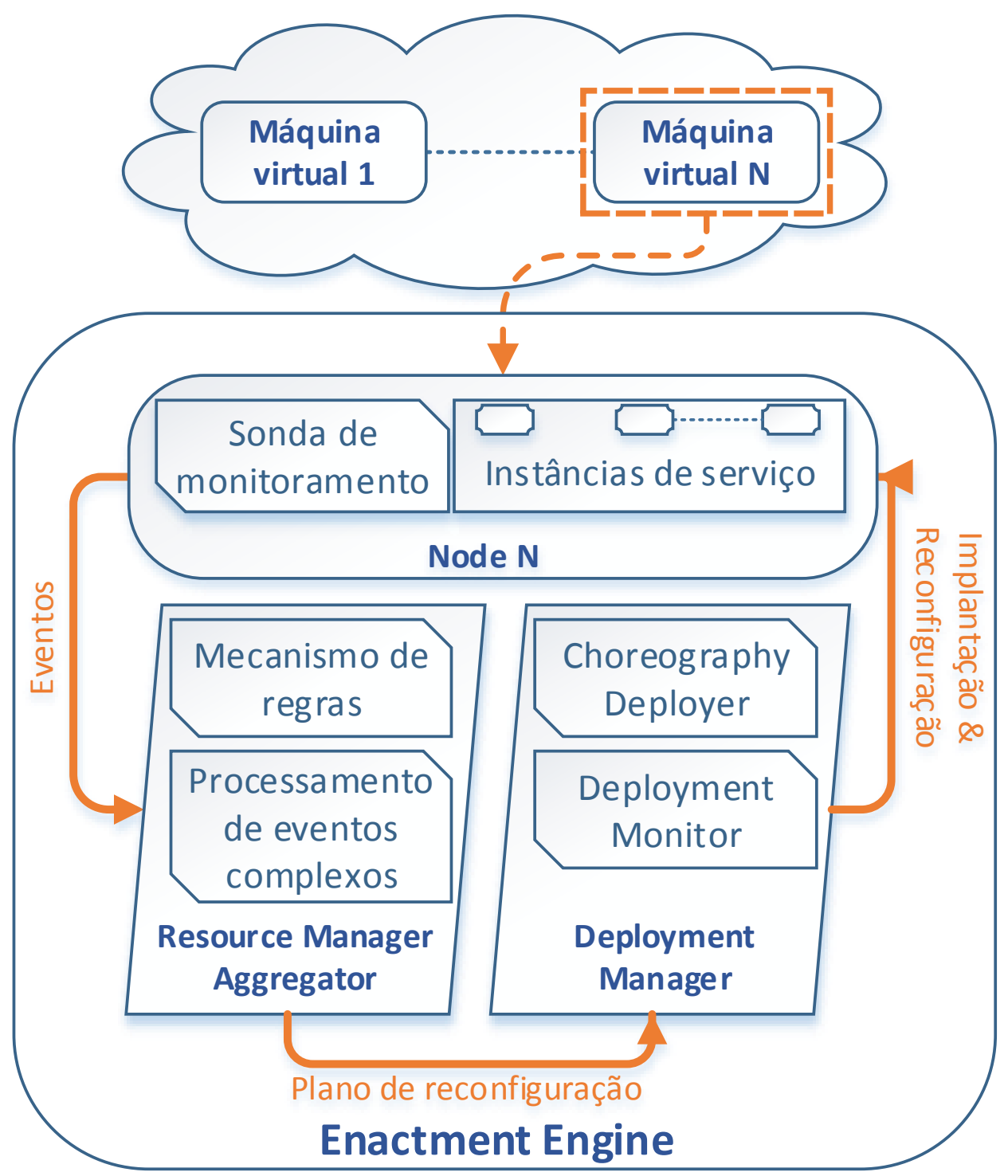

Figura 4.3: Diagrama arquitetural do Enactment Engine

Podemos dizer que essas métricas são padrão se não é necessário a implementação de ferramentas de terceiros para tal coleta. Com isso, o monitoramento se torna menos intrusivo, favorecendo uma dos pontos críticos presentes em sistemas de monitoramento: a intrusividade. Assim, é possível manter a coleta com baixa interferência no desempenho das máquinas; coletar métricas de monitoramento implica em processamento, mesmo que este seja mínimo.

Nessa arquitetura o monitoramento executado pelo PM é independente para cada máquina. Sendo assim, diferentes parâmetros de monitoramento podem ser utilizados, dependendo da necessidade do cliente.

É possível ainda definir regras para filtrar os dados de monitoramento coletados, o que reduz consideravelmente a quantidade de dados de monitoramento trafegados pela rede utilizada pelos serviços bem como a quantidade de eventos gerados que é encaminhado para o RMA. A frequência com que os dados são coletados e os eventos são criados podem influenciar significativamente o desempenho das composições que estão sob monitoramento e por essa razão, esses filtros são essenciais para evitar a degradação da QoS por causa dos dados de monitoramento deixando de interferir negativamente na escalabilidade das composições.

Analogamente às sondas de sistemas operacionais, serviços podem ser monitorados através de sondas. Tais sondas são capazes de extrair valores de métricas de QoS de serviços que tenha em suas descrições algum tipo de suporte a QoS. Q4BPMN [BBC $\left.{ }^{+} 12\right]$ e Q-WSDL [D'A06] são exemplos 
de descrição de serviços que permite essa funcionalidade. Outra possibilidade é usar técnicas de monitoramento de métricas de Quality of Experience (QoE) [FHTG10] as quais consistem em algum tipo de simulação de acessos para subconjuntos de atributos de QoS que podem ser medidos no lado do cliente do serviços. Contrariamente, o uso de padrões de medição implementados por meio interceptadores é promissor [OZD10].

Em adição ao PM, nossa arquitetura usa interceptadores nos servidores de aplicação usados para a execução dos serviços. Considerando que dentre os objetivos do CHOReOS EE o principal é a implantação de serviços em geral, o uso de descritores de serviços modificados implica na utilização de softwares específicos. Já para medição em termos de atributos de QoE, teríamos dois pontos fracos: as complicações relativas ao monitoramento através do clientes como a instabilidade do cliente que pode afetar a medição do serviço e as limitações nos atributos que seriam medidos.

O uso de interceptadores cria a possibilidade de extensão na forma como é medido e ainda, na maneira como foi implantado o serviço. Para estender o middleware, é necessário criar uma sonda usando como base as classes providas pelo RMA. Nessa arquitetura, usamos o padrão de interceptadores de mensagens para captura de métricas de recursos. Mais padrões de monitoramento de composições de serviços foram definidos [OZD10] para medição de atributos de QoS.

\subsubsection{Análise}

A fase de monitoramento provê uma alimentação contínua de dados de monitoramento à fase de análise, que na arquitetura implementada, é realizada pelo componente RMA. Seguindo o fluxo de execução do MAPE, a saída da fase anterior, isto é, fase de monitoramento, é usada como entrada para a fase de análise. Esses dados chegam como notificação em forma de eventos ocorridos, os quais são submetidos a algum tipo de análise. Essas notificações são colocadas em filas, que são consumidas pelo RMA.

Em geral, a fase de análise utiliza técnicas de análise de dados. Dentre as mais utilizadas estão análise estatística como cadeias de Markov e inferência Bayesiana [CGK ${ }^{+} 11$ ], análise baseada em inteligência artificial e análise baseada em eventos.

Para realizar a análise de eventos usamos a abordagem baseada em eventos CEP. No RMA, eventos são analisado com o intuito de encontrar correlações entre eles. Essas correlações podem indicar condições indesejadas nas composições. O RMA recebe eventos simples das sondas e interceptadores. Esses eventos podem por si só indicar anomalias nas composições. Por exemplo, a ocorrência de uma indisponibilidade pontual de um sistema é capturada pelo eventos simples que detecta que o serviço não está acessível ou que a máquina virtual que hospeda-o foi desativada. No entanto, a correlação entre um conjunto de eventos pode indicar anomalias mais complexas; a coexistência de eventos de indisponibilidade e disponibilidade provenientes de acessos em IPs diferentes, leva o sistema a tratar a ocorrência como degradação do atributo de QoS acessibilidade, indicando um possível problema na conexão do usuário.

A realização do CEP é delegada para um mecanismo de regras capaz de analisar lógica e temporalmente os eventos que estão na fila para ser processados. O RMA é munido de um sistema de inferência de eventos realizados por essas regras, que são compostas de duas cláusulas: when-then. Em suas cláusulas when, as regras verificam em uma janela deslizante se há algum conjunto de eventos que se correlacionam de acordo com alguma condição imposta pelo SLA configurado para os atributos de QoS. Tais condições refletem a regra de negócio existente como por exemplo, a regra "Ao menos 95\% dos eventos de tempo de resposta do Serviço A devem estar abaixo do limite imposto no SLA". Enquanto na cláusula when a regra busca por uma expressão com resultado verdadeiro, a cláusula then executa alguma ação. Ações executadas por regras podem remeter a novos eventos ou então ações de notificação que informa que uma violação em alguma política de regra de negócio está ocorrendo ou está prestes a ocorrer.

A fase de análise é realizada com o objetivo de inferir quebras de SLA nas composições. No middleware o RMA executa esse papel tendo como base de conhecimento os eventos e os estados das composições em execução. Em geral, a análise de eventos complexos pode indicar quaisquer estados nas composições. A facilidade arquitetural provida pelo MAPE em conjunto com o uso do 
CEP permite a avaliação flexível e extensível de eventos dado a flexibilidade natural para definição das regras conforme as regras de negócio a ser seguidas. Na fase de análise, o RMA detecta a existência de violações de SLAs, tendo como resultado o problema de fato que está causando as anomalias.

\subsubsection{Planejamento}

Após o término da fase de análise detectar alguma anomalia e notificar alguma violação de SLA, inicia-se a fase de planejamento. Novamente, a saída da fase anterior, fase de análise, é usada como entrada de dados para esta fase dando continuidade no MAPE loop. Esses dados são usados para computar planos de reconfiguração. Em sistemas autônomos, é opcional o uso de bases de conhecimento, embora possa aumentar a eficiência dos planos.

O RMA divide seu trabalho realizando em conjunto as fases de análise e planejamento, ficando transparente a transição uma vez que, são regras similares que realizam essa fase. Regras específicas de planejamento ativam gatilhos para tarefas reativas em seus em suas cláusulas then. Para melhor desempenho, utilizamos uma base de dados contendo as condições de ambiente dos serviços, sua topologia e seus SLAs na memória de trabalho do RMA. Assim, no momento de implantação e manutenção dos serviços, seus dados são armazenados nessa base para auxílio na tomada de decisão.

$\mathrm{Na}$ fase de planejamento o uso do CEP facilita a tomada de decisões. Para cada situação, regras são definidas para a criação de planos de reconfiguração. A escolha do plano é feita de acordo com os eventos complexos sintetizados. Portanto, dados os requisitos de SLA presentes para um serviço, o plano deve favorecer tais requisitos, para que estes sejam mantidos dentro dos valores permitidos. Para isso, estratégias de reconfiguração são escolhidas dentre as existentes no middleware.

A partir da estratégia, um plano de reconfiguração é formado e enviado ao DM que vai efetivamente executar as reconfigurações necessárias. O RMA implementa duas filas, a primeira como já vimos para recepção de eventos de monitoramento. A segunda, para envio de planos computados. A arquitetura projetada não força o uso de nenhuma ferramenta específica, criando outro ponto de flexibilidade; o RMA pode ser substituído por outros arcabouços.

\subsubsection{Execução}

A fase de execução é a última fase realizada por um sistema autônomo que utiliza MAPE como arquitetura de monitoramento. Esta, utiliza os dados de saída da fase de planejamento como entrada de dados fechando assim o ciclo de manutenção de SLA.

O DM é o componente responsável por executar os planos de reconfiguração que são criados. Este é um componente interno ao CHOReOS EE que realiza a implantação de serviços. O DM é formado por dois componentes. O primeiro, Choreography Deployer (CD), é responsável por aplicar as configurações e atualizações nas máquinas virtuais sob gerência do middleware. O CD tem o papel de gerenciar a alocação dos recursos de infraestrutura virtual e os serviços nela implantados. Para a comunicação dos planos, o DM provê um fila de eventos de notificação que é alimentada pelo RMA. Esta fila é consumida realizando as reconfigurações agendadas. Retirado um plano da fila para processamento, o DM cria as tarefas reativas que irão aplicar as ações preventivas para evitar violações de SLA ou ainda recuperar o sistema como um todo de uma degradação de QoS em andamento.

O segundo componente, Status Monitor (SM), provê um mecanismo para controle das especificações que estão sendo executadas por suas respectivas composições. O plano notificado passa por um mecanismo de comparação de especificações de composições que calcula as alterações necessárias a ser feitas utilizando como base as especificações atuais das composições em execução; para otimização do processo, apenas as mudanças necessárias são realizadas, numa maneira incremental. Após a reconfiguração (implantação inicial também), são sincronizados os novos dados de estado da composições com os dados presentes no RMA.

O processo de reconfiguração da suporte a reconfiguração baseada no aumento (upscaling) e diminuição (downscaling) de recursos. Ambas podem ser configurados com estratégias horizontal e 
vertical e mista, isto é, aumentando e diminuindo a quantidade de máquinas virtuais em execução para um serviço, ou migrando as réplicas do serviços para máquinas com maior ou menos capacidade computacional. Algumas tecnologias de virtualização permitem que usuários modifiquem especificações de hardware virtual realizando realocação de recursos sem que seja necessário a reinicialização da máquina virtual. Por exemplo, a quantidade de memória RAM alocada e o número de processadores virtais são alterados em tempo de execução (live migration). No entanto, atualmente ambientes de computação em nuvem não oferece tal funcionalidade. Além disso, não há um padrão em tecnologias de computação em nuvem, o que torna os ambientes heterogêneos. Isso dificulta o trabalho de um middleware flexível.

\subsubsection{Implementação}

O trabalho realizado nessa dissertação tem como foco a implantação de composições de serviços e a gestão de QoS nessas composições. O propósito é a criação de uma plataforma de middleware nos padrões do modelo de computação em nuvem PaaS, com o intuito de permitir escalabilidade para as composições executadas.

Em ambientes de computação em nuvem, os recursos virtuais dedicados a uma tarefa podem ser facilmente aumentados ou diminuídos sob demanda $\left[\mathrm{AFG}^{+} 10\right]$. Em ambientes que oferecem serviços de IaaS, esses recursos são máquinas virtuais, onde serviços podem ser implantados e executados. Durante a execução desses serviços, a carga medida nessas máquinas podem atingir picos elevados demandando assim recursos adicionais, que são requisitados ao provedor de nuvem.

A carga média em cada máquina virtual pode ser reduzida ao passo que serviços implantados são replicados em novas máquinas. Por outro lado, se a carga média está abaixo de um limiar mínimo e com isso, alguns recursos não estão sendo utilizados, parte dos nós alocados podem ser removidos.

Esse conceito de balanceamento simples de nós pode ser estendido para serviços. Por meio do monitoramento de serviços e de suas máquinas hospedeiras, dados de monitoramento permitem que o sistema localize serviços ou máquinas específicas que apresentam desempenho ruim. Monitoramento e adaptação são portanto realizadas da perspectiva do provedor da aplicação. Assim, atributos de QoS específicos de domínios da aplicação não serão abordados na implementação do middleware, uma vez que o propósito do middleware é manter aplicações em geral em execução, sem que haja percepção de degradação de QoS por parte dos seus clientes.

Infelizmente, não são todos os problemas de escalabilidade que podem ser tratados com abordagens simples. Por exemplo, alguns serviços podem não ser fáceis de paralelizar, dificultando assim o tratamento via escalabilidade horizontal. Nesses casos, soluções alternativas poderiam ser adotadas. Um exemplo seria a migração do serviços para máquinas virtuais maiores em termos de CPU, memória, etc.

Um sistema de middleware não pode ser limitado ao monitoramento e deteç̧ão de situações que demandam ações de reconfiguração corretivas. É necessário que esteja apto a fazer decisões de quais ações apropriadas devem ser aplicadas para tais tarefas corretivas, dependendo da situação. Nesse trabalho, criamos um middleware onde consideramos como um requisito esperado para um sistema de reconfiguração eficiente em infraestruturas de nuvem, estar apto a decidir se deve aumentar ou diminuir recursos de forma horizontal (adicionando ou removendo réplicas de serviços), vertical (migrando serviços para máquinas maiores) ou com uma combinação de ambas.

\subsubsection{Monitoramento}

No middleware, como parte da tarefa de implantação de um serviço em alguma máquina virtual, esta é instrumentada com as sondas de monitoramento implementadas pelo PM. Estas sondas são responsável pela coleta de métricas de infraestrutura (memória, uso de CPU, disco, rede, etc.).

Estes componentes utilizam dados coletados através do software Ganglia [MCC04]. O Ganglia é uma ferramenta de monitoramento de código aberto minimamente intrusiva que permite a coleta de métricas sem interferir negativamente no desempenho das aplicações. Ele fornece medições de 
utilização de recursos usando apenas ferramentas pré-existentes nas instalações Linux; caso necessário, ainda é possível definir métricas quaisquer de acordo com a necessidade do usuário, ficando o desempenho dependente do modo como a coleta para a nova métrica foi construída.

As sondas implementam filtros configuráveis para cada métrica. Todas as métricas disponibilizadas podem ser utilizadas (essas métricas posteriormente serão avaliadas nas regras que realizam as fases de Análise e Planejamento). Utilizando configurações em formato YAML, três tipos de filtros são aplicados:

Valor máximo e Valor mínimo: Filtros definidos por limites do tipo SingleThresholds filtram os valores que são enviados ao RMA. Estes tipos de filtros permite a configuração do modo de comparação (parâmetro comparison) como MIN, permitindo o envio de valores menores do que o limite (limit_value) ou MAX para valores maiores do que o permitido. Por exemplo, as linhas 1-4 na Figura 2 filtram métricas de quantidade de memória RAM livre (attibute). Valores menores que 4MB são considerados como indesejados. Nesse caso, um evento é criado e enviado ao RMA.

Intervalo de valores: Filtros também podem ser definidos usando o tipo DoubleThresholds esses são configurados usando como comparação o operador BETWEEN. Como valores limites, os parâmetros limit_inf e limit_sup, definem o intervalo válido (valores máximos e mínimos) aceito para uma determinada métrica de monitoramento. Um exemplo pode ser visto nas linhas de 11 a 15 na Listagem 2 define um filtro em que valores para a métrica load one são passíveis de criação de eventos quando os valores coletados então abaixo de 3 e acima de 5 .

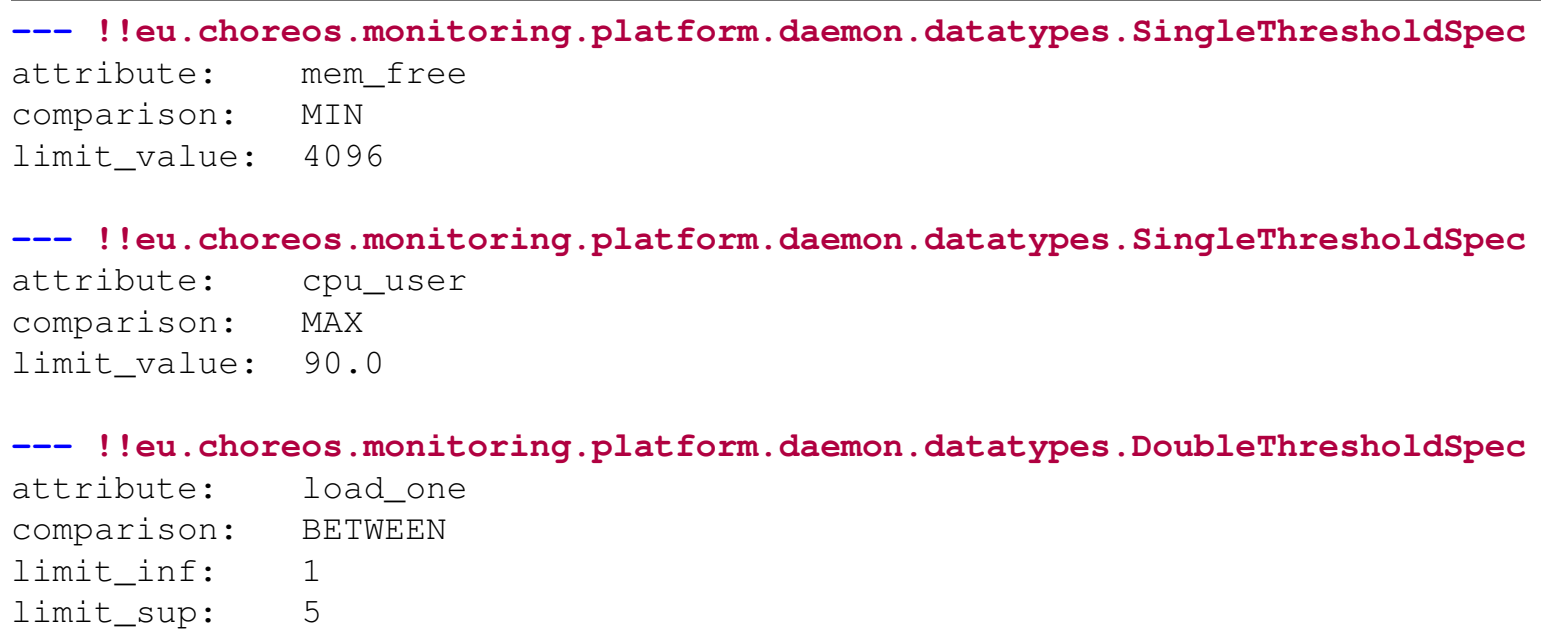

Listing 2: Exemplo de filtros aplicáveis à plataforma de monitoramento.

O monitoramento de atributos de QoS no CHOReOS EE é possível quando na especificação dos serviços estes são configurados com tipo (ServiceType) TOMCAT. Sendo assim, é possível habilitar o monitoramento de QoS no ambiente de middleware.

Cada máquina virtual que executa o Tomcat como servidor de aplicação, tem a instalação deste instrumentada para coleta de métricas de QoS. Os interceptadores utilizados foram implementados de acordo com o mecanismo de válvulas presentes no Tomcat (Valves ${ }^{4}$ ). Válvulas interceptam requisições no escopo da aplicação. No processo de atender uma requisição, uma válvula é um componente inserido que pode ser inserido em três fases. Durante o processamento de uma requisição, o pipeline executado no Tomcat segue o fluxo segundo a Figura 4.4. Uma requisição pode ser interceptada em qualquer uma das etapas. No middleware, usamos válvulas na última etapa, isto é, antes da requisição ser recebida pela aplicação. Cada serviço tem o seu conjunto de válvulas. Portanto, é possível coletar métricas individualmente para cada serviço.

\footnotetext{
${ }^{4}$ https://tomcat.apache.org/tomcat-7.0-doc/config/valve.html
} 


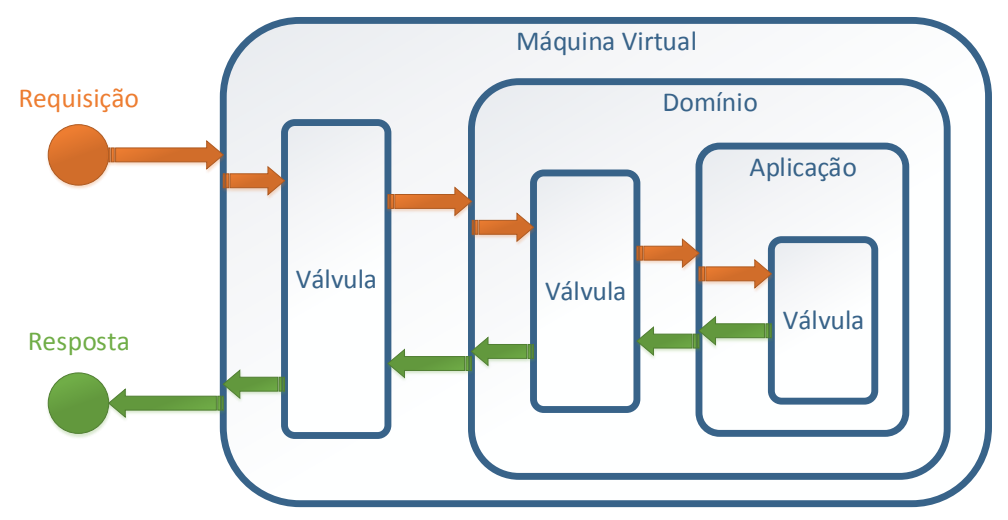

Figura 4.4: Mecanismo de válvulas do Tomcat.

As válvulas implantadas funcionam como consolidadoras de dados, periodicamente enviando esses dados. Por exemplo, a medição do tempo de resposta dos serviços. Válvulas e sondas de monitoramento criam eventos e enviam ao RMA. O RMA disponibiliza uma fila de eventos que é preenchida com tais eventos. Isso é possível dado a concepção do Glimpse [BCLS11], projetado sobre uma plataforma de requisições JMS. O Glimpse é utilizado para o processamento desses eventos nas fases de Análise e Planejamento.

\subsubsection{Análise}

A fim de correlacionar o estado da QoS dos serviços com o estado da utilização do ambiente de nuvem, o RMA é alimentado continuamente por eventos simples ${ }^{5}$ criados na fase de Monitoramento. Para fins de armazenamento desses eventos, disponibiliza filas que são preenchidas pelos dados das sondas e válvulas coletoras e consumidas pelo CHOReOS EE na fase de Execução. Essas filas são concebidas graças ao Glimpse.

O Glimpse é uma ferramenta de monitoramento para ambientes distribuídos que utiliza como base o processamento de eventos complexos. Devido à sua concepção flexível, permite o monitoramento de sistemas em geral. Sua arquitetura implementa nós agregadores que processam eventos por meio de CEP distribuído. Tais nós expõem uma interface que obedece os princípios impostos pelo protocolo publish/subscribe. Por meio dessa interface, sondas de monitoramento criam filas de eventos, os quais podem ser consumidos por consumidores específicos. Vale ressaltar que, essa arquitetura permite que os eventos sejam gerados por múltiplas fontes e agregados numa mesma máquina de análise.

Os recursos expostos por esta interface são as filas criadas para gestão dos eventos gerados. O Glimpse utiliza o software ActiveMQ [SBD11] para implementar tais filas. O ActiveMQ é um servidor de mensagens implementado usando JMS. Dessa forma, as mensagens são trocadas de maneira assíncrona, permitindo uma análise em tempo real dos eventos ativos. Outra vantagem é a possibilidade da criação de vários consumidores, por exemplo, um consumidor de eventos para cada composição; dessa forma, não há interferência entre os eventos.

No momento da implantação da composição, o middleware verifica se a configuração tem gerenciamento de QoS habilitado. Se habilitado, o middleware cria um consumidor de eventos. Este consumidor é responsável por cadastrar regras de processamento de eventos no Glimpse ${ }^{6}$. Tais regras são criadas a partir dos dados de QoS contidos na estrutura de dados da coreografia 4.1. Esses dados são mapeados automaticamente para regras, escritas em formato XML, poupando tempo de configuração do desenvolvedor da composição.

\footnotetext{
${ }^{5}$ Como visto no Capítulo 2, eventos simples remetem ao estado coletado de um único atributos de QoS ou de consumo de recursos virtuais.

${ }^{6}$ É possível a criação de vários consumidores para evitar sobrecargas. Porém, é necessário deixar claro que há duas fases onde são aplicados consumidores. O RMA consome eventos que vêm da fase de Monitoramento. Por outro lado, gera eventos complexos que serão consumidos posteriormente na fase de Execução. Assim, há duas filas de eventos implementadas no RMA
} 
O Glimpse encapsula o Drools [M. 13] como sendo seu processador de eventos complexos. O Drools é um software livre que implementa processamento de eventos complexos baseado em regras de negócio lógico-temporal. As regras de ativação cadastradas no Glimpse são inseridas na memória de trabalho da máquina de regras do Drools. Portanto, a partir dos eventos existentes ele faz asserções lógicas sobre estes levando em conta o tempo em que ocorreram. A definição de regras é bastante flexível, porém, é natural que a escrita das regras vise a correlação entre dois ou mais eventos ocorridos em um intervalo de tempo; o conceito de eventos complexo é justamente a existência de dois ou mais eventos que se relacionam.

No CHOReOS EE, o desenvolvedor da aplicação não precisa se preocupar com a complexidade das regras a ser aplicadas, muito embora, as regras podem ser estendidas de acordo com a peculiaridade da adaptação a ser realizada. A Listagem 3 mostra como é possível definir uma composição de serviços e suas definições de QoS. Neste fragmento de código, o desenvolvedor implanta uma composição com dois serviços (linha 23). Nessa composição, o serviço TravelAgencyService (linha 12) depende do processamento do serviço AirlineService (linha 4). Essa dependência é determinada na linha 20.

Para evitar degradação de QoS na composição, o serviço AirlineService é então configurado com parâmetros de QoS. Inicialmente, este é implantado em duas máquina do tipo small (linhas 27-28). A métrica usada neste exemplo é o tempo de resposta, o qual é configurado com SLA apontando um valor máximo (ResponseTimeMetric\#limit) de 1000ms (linha 35) e porcentagem de quebra de SLA durante o tempo total de execução permitida (ResponseTimeMetric\#acceptablePercentage) sendo $0.03 \%$ (linha 36). Adicionalmente, a política de escalabilidade é configurada para ScalePolicy.HORIZONTAL (linha 33) que causará o aumento de diminuição de réplicas.

A partir dessa definição, o DM automaticamente gera as regras para análise do estado das coreografias. A Listagem 4 mostra o fragmento de regra responsável pela análise do tempo de resposta, mais especificamente, para tempos de resposta acima do desejável. As linhas 27 de 28 definem uma janela de tamanho entre um minuto e meio a 2 minutos. Dentro dessa janela, há uma análise da média do tempo de resposta numa janela interna de 30 segundos (linhas 34-37). A violação permitida de $0.03 \%$ é então verificada (linhas 38-42). Se a porcentagem de violação é maior, o serviço propenso a degradação de QoS não está sob reconfiguração (linhas 43-44) e não está em processo de estabilização ${ }^{7}$ (linhas 45-46), um evento complexo indicador de tempo de resposta alto é inserido na memória de trabalho do Drools.

Consideramos dois tipos de regras relacionado com a forma como são concebidas. Para análise, como vimos, as regras são usadas para detectar a correlação entre eventos, seja simples ou complexos. Essa análise tem o propósito de encontrar situações indesejadas nas coreografias sem se preocupar com a ação corretiva que deverá ser executada. Tais situações poderiam causar violações de SLA, o que acarreta em danos financeiros.

O objetivo das regras de análise é inserir eventos complexos que um segundo conjunto de regras (de Planejamento) irão capturar decidir sobre a situação ocorrente (linhas 49-51). Nesse caso, o eventos complexo HighResponseTime é incluído, com as informações do serviço e o endereço a réplica analisada. Adicionalmente, a política de escalabilidade configurada anteriormente é enviada em conjunto, dando possibilidade do planejamento escolher uma ação.

\subsubsection{Planejamento}

Como visto anteriormente, algumas regras, quando ativadas, demandam reconfiguração por parte do DM. Isso acontece quando a correlação de eventos causa a inserção de um evento complexo desencadeando a ativação de regras que consomem esses eventos. É por meio dessas regras que o RMA notifica o DM com as informações da reconfiguração necessária para solução do problema encontrado.

\footnotetext{
${ }^{7}$ Um serviço está em estabilização se um processo de reconfiguração terminou e sua carga está estabilizando, isto é, a fila de requisições atrasadas está sendo processada. Isso previne o sistema de reconfigurar serviços baseados em resultados falso-positivos
} 


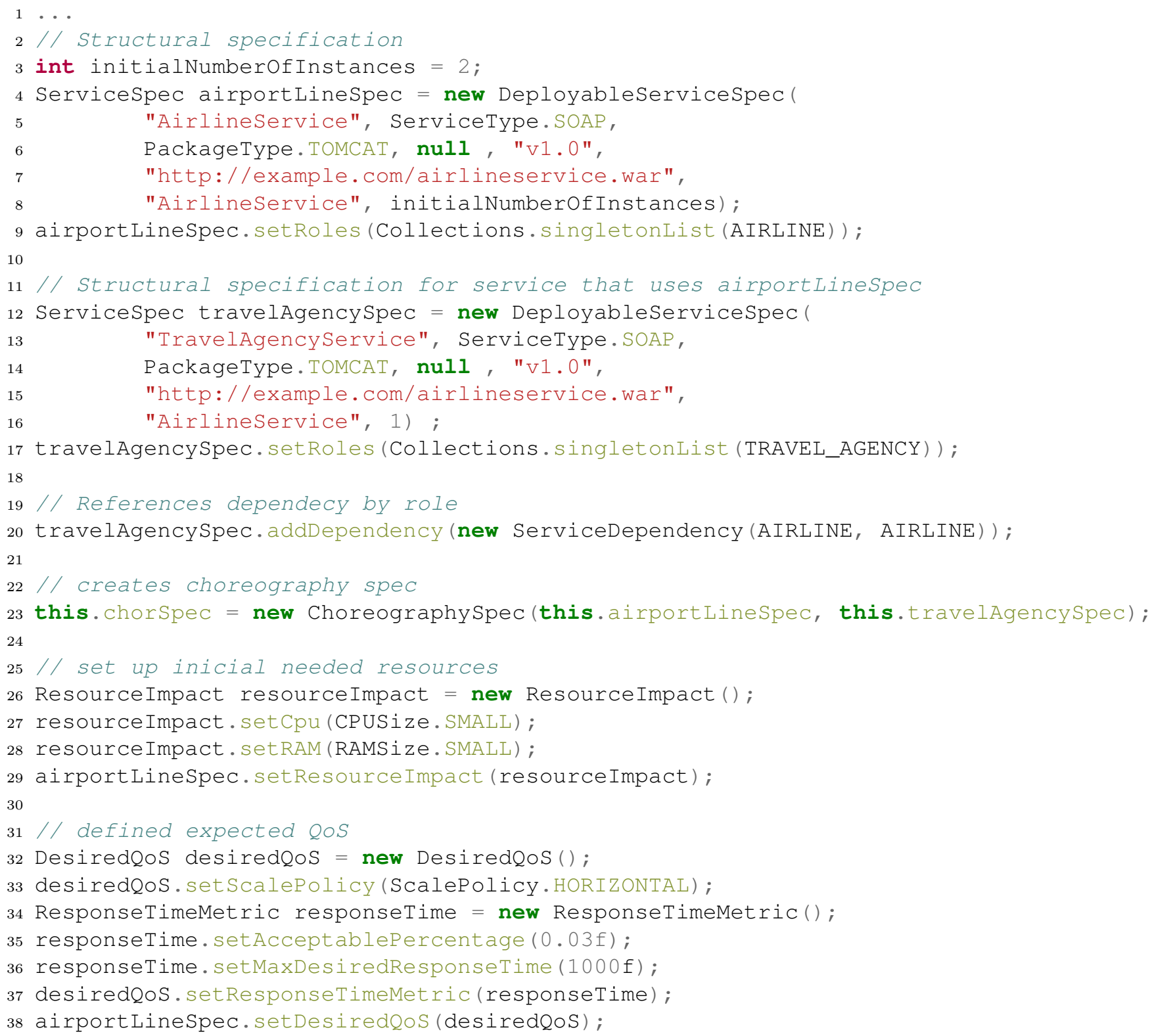

Listing 3: Fragmento de programa Java para criação de composição com parâmetros de QoS. 


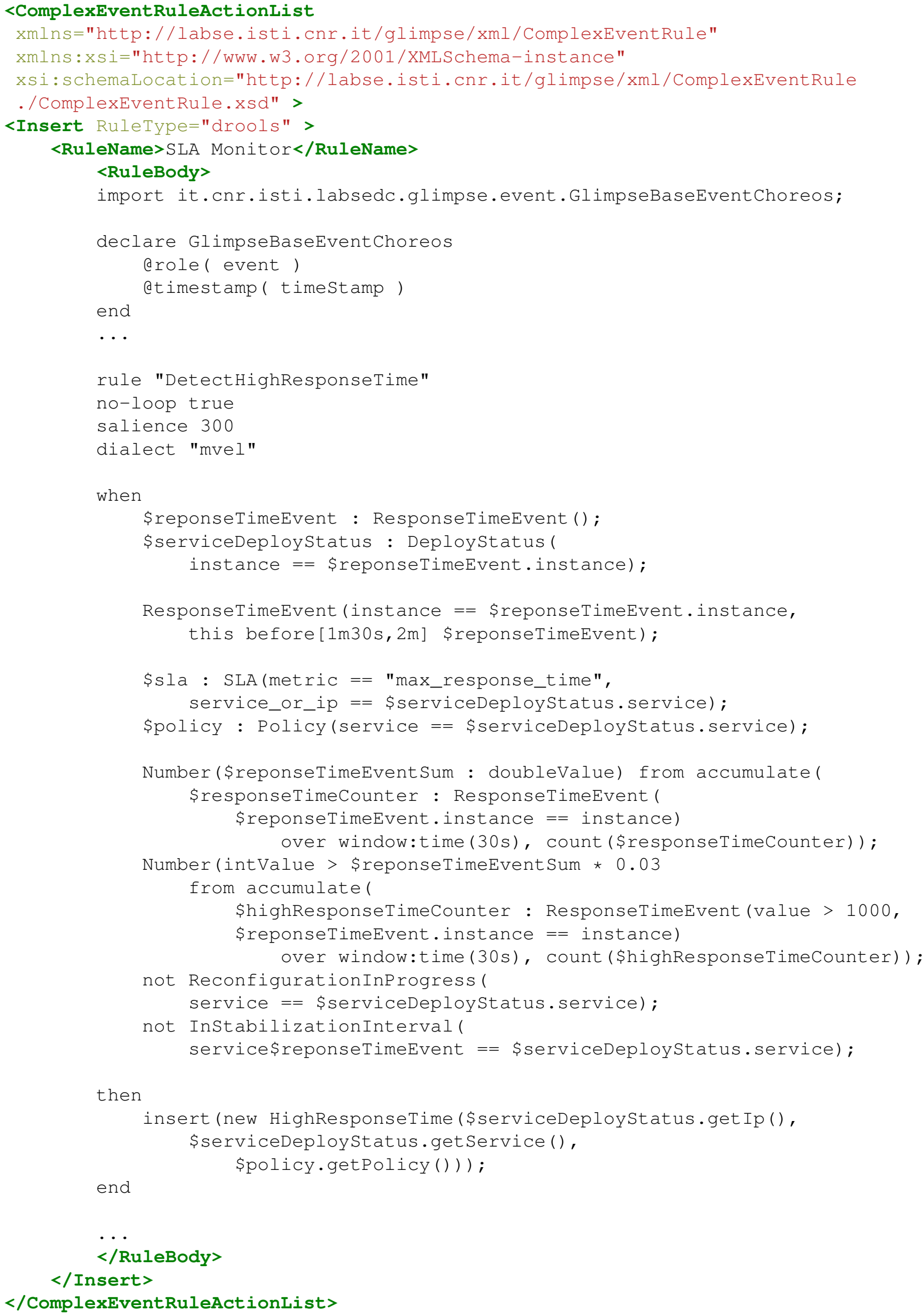

Listing 4: Fragmento de regra do Glimpse para regra de tempo de resposta. 
Além desse segundo conjunto de regras, o RMA utiliza uma segunda fila de eventos. Detectado um evento complexo, a notificação alimenta essa segunda fila, que é consumida pelos consumidores presentes no CHOReOS EE. Graças ao CEP, esse processo é simplificado uma vez que, a ativação da regra é suficiente para que o DM seja notificado em tempo hábil.

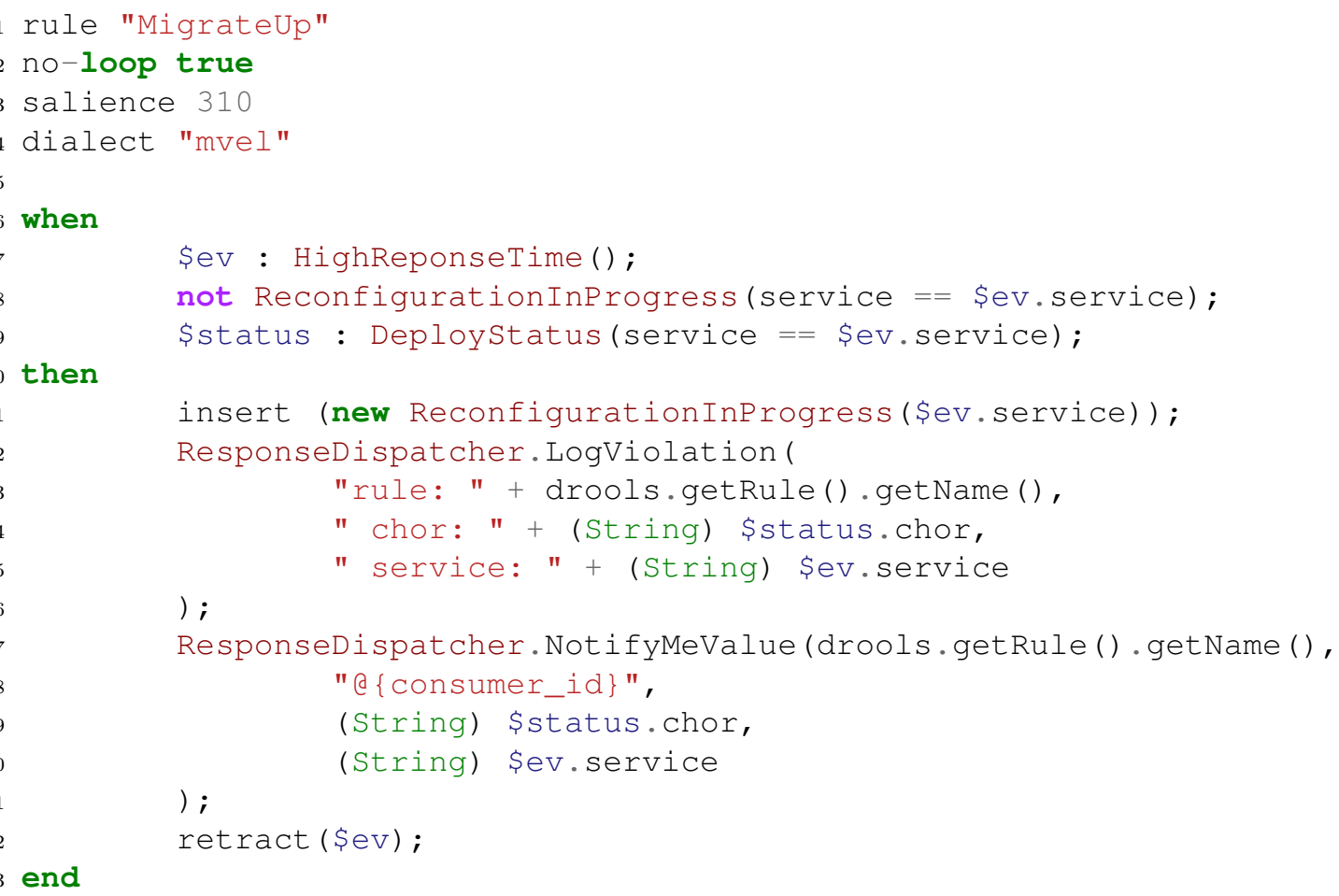

Listing 5: Regra criada para ativar migração de serviço para máquina maior.

O RMA disponibiliza quatro regras destinadas a notificações de reconfiguração: MigrateUp (Exemplificada na Figura 5), MigrateDown, AddReplica e RemoveReplica. No exemplo dado, a linha 7 detecta a presença de um eventos completo de tempo de resposta alto. Na linha 8 é feita uma checagem para determinar se não há uma reconfiguração em progresso para esse evento. A linha 9 busca o estado atual do serviço. Quando as assertivas das linhas 7 e 8 são verdadeiras, um eventos para informar que uma reconfiguração está a acontecer é inserido na linha 11 e na linha 17, a regra notifica o consumidor que a inseriu. Aqui, o nome da regra remete ao nome da ação a ser tomada, que será mapeada devidamente a ação de atualização correta no DM.

Internamente, o CHOReOS EE mapeia as regras de acordo com seus nomes. Propositalmente para que o usuário do CHOReOS EE pudesse estender as regras e ações a ser tomadas, a extensão é realizada criando novas regras, e classes correspondentes para receber as notificações dessas regras. Essas classes devem estender a classe ComplexEventHandler e devem estar contidas no pacote org.ow2. choreos.ee.reconfiguration. events. Na próxima seção, as ações de atualização são explicadas com mais detalhes.

\subsubsection{Execução}

A última fase do laço MAPE é a fase onde as reconfigurações planejadas são aplicadas. Para realização desta fase, incorporamos na interface do CHOReOS EE a operação choreographyUpdate. Essa operação recebe como entrada uma nova especificação de coreografia, contendo as mudanças necessárias avaliadas no monitoramento e calculadas nas fases de análise e planejamento. Nesse trabalho, essa nova operação é utilizada automaticamente pelo gerenciador de QoS.

Para executar atualizações de coreografia, ao CHOReOS EE foi integrado um consumidor de eventos responsável por chamar a operação citada acima. Assim, a cada evento de notificação 
enfileirado, o CHOReOS EE consome esse evento, realiza a leitura da ação decidida pela fase de Panejamento, e monta uma nova especificação de coreografia a partir do plano com base nos dados de especificação armazenados.

O DM armazena as especificações de cada composição implantada. A primeira tarefa executada pela operação choreographyUpdate é comparar a especificação existente para a coreografia que está sob reconfiguração à nova especificação resultante do plano de reconfiguração. Para minimizar o impacto e o tempo de reconfiguração, o DM avalia a situação da composição e as mudanças enviadas pelo RMA; apenas as as mudanças necessárias são realizadas para a construção da nova especificação de composição. Para isso o DM implementa um mecanismo denominado Status Diff que visa a diminuir a quantidade de alterações que serão implantadas.

Baseado na execução do Status Diff, o DM realiza uma categorização das mudanças necessárias entre novos serviços, novas réplicas, serviços a serem removidos e serviços a serem atualizados. O DM disponibiliza ações de atualização que são usadas para a reconfiguração. Nessa categorização uma ação é agendada para execução. As ações disponíveis para o DM são as seguintes:

IncreaseNumberOfReplicas: Ação responsável por adicionar novas réplicas a um determinado serviço. Esta ação tem como entrada a especificação do serviço em questão e a quantidade de réplicas novas que deve ser criadas.

DecreaseNumberOfReplicas: Similar a ação anterior, esta reduz a quantidade de réplicas em execução para um determinado serviço. Recebe como parâmetros de entrada os mesmos usado na ação anterior, porém, remove as réplicas subutilizadas. No caso de uma requisição de remoção de réplica ser realizada, e o serviço hospedeiro só tem uma réplica em execução, o CHOReOS EE realiza uma tentativa de migração para uma máquina de menor poder de processamento.

A remoção de uma réplica é feita por uma espécie de agendamento. Para isso, o DM insere uma receita do Chef chamada de shutdown. Após o DM reconfigurar os endereços de enlace usando a operação setInvocationAddress, a receita é executada e o serviço removido. Quando um serviço não é mais utilizado, todas as réplicas devem ser removidas. Nesse caso, cada um dos hosts onde executa uma réplica executa a receita Chef. Geralmente, máquinas virtuais são cobradas por hora de uso, o que inviabiliza a sua remoção imediata. Portanto, a remoção da máquina virtual ocorre pouco antes da contabilização da última hora paga para provedor de infraestrutura.

Migrate: Migra as réplicas de um serviço de acordo com a especificação de máquina presente na nova especificação do serviços. Se a máquina virtual é maior do que a que está em execução, a migração implanta as réplicas em máquinas com maior poder de processamento. Quando as máquinas utilizadas já são de maior poder, e uma requisição de migração para máquina maior é realizada, para que o QoS seja mantido o CHOReOS EE opta por aumentar uma réplica do serviço implantando-a numa máquina de mesmo poder operacional.

Quando a nova especificação do serviço indica uma máquina de menor poder de processamento, as réplicas de serviço são migradas para máquinas menores. Similarmente ao mecanismo anterior caso seja a menor máquina e ainda sim é necessário migrar, uma réplica é removida para evitar máquinas subutilizadas.

\subsection{Suporte a coreografias reflexivas}

Sistemas reflexivos são sistemas que têm o conhecimento de sua própria estrutura, mantémse atualizados em relação ao estado dos seus componentes e é capaz de dinamicamente adaptar sua estrutura de acordo com condições ocorridas durante sua execução [KCBC02]. Devido à forma como o SM foi concebido, o CHOReOS EE mantém atualizadas as informações das coreografias como sua estrutura, topologia e variáveis de gestão de SLA [FFLK14]. Dessa forma, as coreografias 
usufruem dessas informações permitindo que, com a intervenção do middleware, possa decidir sobre seu próprio estado, reconhecendo os componentes internos (serviços) e as conexões que demandam reconfiguração, dando suporte a reflexão às coreografias.

No próximo capítulo, descrevemos a avaliação experimental do middleware. Essa descrição, engloba a plataforma experimental compreendendo ambiente de nuvem e configurações do experimento e os resultados avaliando a manutenção da QoS na composição utilizada. 


\section{Capítulo 5}

\section{Avaliação Experimental}

Como já dito no Capítulo 1, nosso objetivo neste trabalho foi criar um middleware capaz de implantar composições de serviços e gerir o QoS de cada uma delas. Os experimentos realizados em nossa pesquisa têm o objetivo de mostrar que é possível adaptar composições de serviços de maneira automatizada, mantendo o QoS das composições em níveis aceitáveis. Além disso, mostramos a necessidade de diminuir o tempo de deteç̧ão e reação no momento em que o sistema se confronta com uma possível violação de SLA, deixando clara a vantagem em realizar a adaptação de forma automática. A avaliação experimental do middleware desenvolvido foi realizada usando uma composição de serviços simples apenas para fins de validação do desempenho das técnicas utilizadas. Os códigos de ambos, middleware e composição, estão disponíveis como software livre sob licença MPL v2. O código está disponível em: https://github.com/choreos/enactment_engine/releases/tag/v2014-09.

Para avaliar o desempenho do middleware, verificamos quantitativamente o tempo para reação diante de uma violação de SLA, a porcentagem de requisições que apresentaram violações de SLA antes de uma reconfiguração acontecer e verificamos ainda que a remoção de recursos funcionou satisfatoriamente.

\subsection{Configuração dos experimentos}

A composição usada para avaliação do middleware consiste de dois serviços: Serviço A, que expõe uma operação que executa uma tarefa de processamento intensivo (o algoritmo recursivo do cálculo da sequência de Fibonacci) e o Serviço $B$ que depende do Serviço $A$ para sua execução. O Serviço B implementa a operação setInvocationAddress vista anteriormente na Seção 4.1. Assim, é possível reconfigurar os endereços de enlace resultantes da dependência entre os serviços em tempo de execução. Isso permite que, frente às flutuações de carga, a carga sobre o Serviço A seja dividida entre réplicas. Nos experimentos realizados, consideramos que os serviços não guardam estados, usando assim um algoritmo Round Robin para realizar essa divisão de carga. Esse algoritmo é implementado no Serviço B. Quando os endereços disponíveis para o Serviço A a são renovados com a chamada à operação setInvocationAddress, a escolha da réplica do Serviço $A$ a utilizar é reiniciada.

A avaliação experimental foi baseada na observação das reações tomadas pelo middleware frente a variações do tempo de resposta do Serviço $B$. Essas variações foram induzidas por uma aplicação cliente que acessa o Serviço $B$ variando a quantidade de requisições por segundo. No entanto, ao invés de imprimir variações aleatórias, usamos um padrão de acesso real correspondendo a 24 horas de acessos à página principal da Wikipédia em português ${ }^{1}$. Essa escolha foi importante para que pudéssemos ao mesmo tempo analisar uma curva de acessos real com uma variação de carga relevante.

A taxa de acessos usada apresenta duas particularidades. A primeira é que o ponto inicial do experimento apresenta uma taxa alta de acessos, algo que não é tão natural. É comum que, ao ser

\footnotetext{
${ }^{1}$ Acesso à página Wikipédia - Página Principal realizados no dia 27 de Agosto de 2014. Os dados podem ser encontrados em http://tools.wmflabs.org/wikiviewstats/.
} 
implantada um composição, a taxa de requisições comece baixa, e suba conforme mais usuários fazem seu uso. No entanto, essa taxa de acessos foi importante para mostrar a habilidade de reação. A segunda particularidade ocorre às 16:00 e 20:00 horas, onde subitamente ocorre uma queda de acessos. Pela curva total, julgamos que possa ter ocorrido algum problema na página, ou até mesmo na coleta de dados de monitoramento da Wikipédia.

Por motivos de praticidade, nos experimentos reduzimos linearmente essas 24 horas para duas horas de simulação.

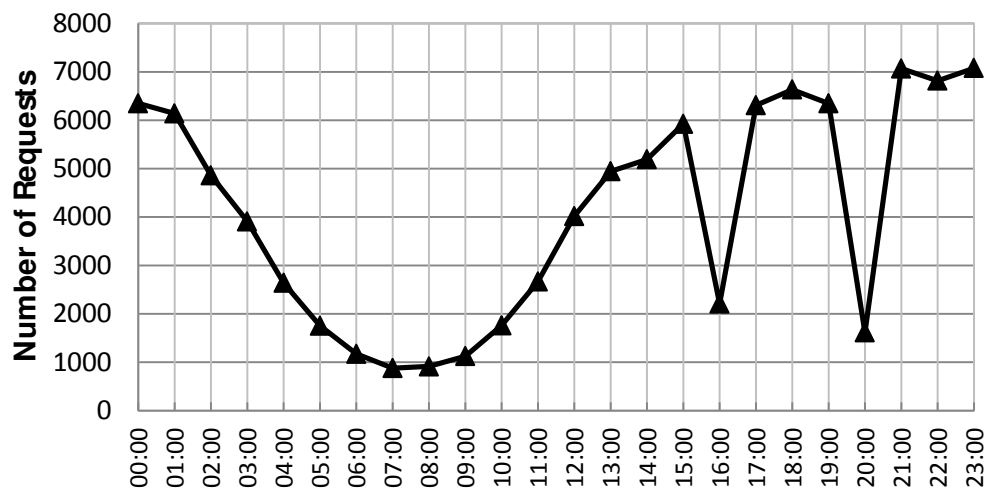

Time of Day

Figura 5.1: Taxa de acessos de um dia da página principal em português da Wikipedia.

Devido à natureza da composição utilizada, foi possível simplificar os experimentos realizados assumindo que, além dos requisitos de recursos virtuais, apenas o tempo de resposta seria suficiente para avaliar a composição e tomar decisões em relação ao seu desempenho. No entanto, para aplicações reais em ambientes de produção, vários outros atributos de QoS devem ser levados em conta no processo de monitoramento da composição. Dependendo da aplicação, um subconjunto dos atributos vistos na Seção 2.3.2 devem ser selecionados para melhor desempenho na adaptação dinâmica. Por exemplo, uma aplicação composta de serviços que fazem uso exaustivo de entrada e saída de dados, requer regras com fatores de importância mais altos para detecção de eventos de disco e eventos de rede. Assim, o middleware pode fazer melhores decisões na escolha das estratégias.

Em nossos testes, o middleware foi configurado de maneira a evitar tempos de resposta maiores que um segundo e porcentagem de uso de CPU menores do que 35\%. As regras utilizadas para aplicar o operadores de CEP vistos na Seção 2.4.2, foram escritas com a sintaxe da linguagem MVEL $^{2}$. No entanto, o Drools permite que sejam criadas regras com a sintaxe do Java.

A adaptação dinâmica é realizada em duas fases. Na primeira fase um conjunto de regras é usado para detecção de problemas. Como resultado da primeira fase, um evento complexo é criado. Na segunda fase esse evento complexo é processado de modo a enviar uma notificação ao DM. Essa notificação inclui as informações de composição e serviço problemático e qual reconfiguração deve ser aplicada.

$\mathrm{Na}$ primeira fase, para evitar os tempos de resposta altos, a regra ilustrada na Figura 5.2 foi utilizada. Ela foi criada pelo próprio middleware a partir do seu modelo existente. Nas linhas 0104 são definidas propriedades da regra. Nas linhas 07-13, o evento e o contexto que dispararam a regra são capturados em variáveis locais incluindo o tempo de resposta, as configurações de SLA para o serviço referente ao tempo de resposta e a política de escalabilidade. Na sequência, nas linhas 15-20 são contados quantos eventos de tempo de resposta para o serviço nos últimos 30 segundos. Nas linhas 22-27 esses eventos que ocorreram nesse intervalo de 30 segundos são analisados e verificados quanto à porcentagem que ultrapassou o limite configurado no SLA. Na nossa configuração, até $5 \%$ de violações de SLA são permitidas). As linhas 29 e 30 evitam que reconfigurações equivalentes ocorram simultaneamente e que novas reconfigurações sejam iniciadas

\footnotetext{
${ }^{2}$ Drools' Rule Language - http://docs.jboss.org/drools/release/5.2.0.Final/drools-expert-docs/html/ch05. html
} 
durante o tempo de estabilização da coreografia, respectivamente. Quando todas essas condições têm valores verdadeiros as linhas do bloco then são executadas. Nas linhas 33-35 é criado um evento complexo sinalizando tempo de resposta acima do limiar definido para o serviço, a origem (seu IP) e a política de escalabilidade que deve ser aplicada. Na linha 36, esse evento complexo é inserido na memória do Drools para ser processado.

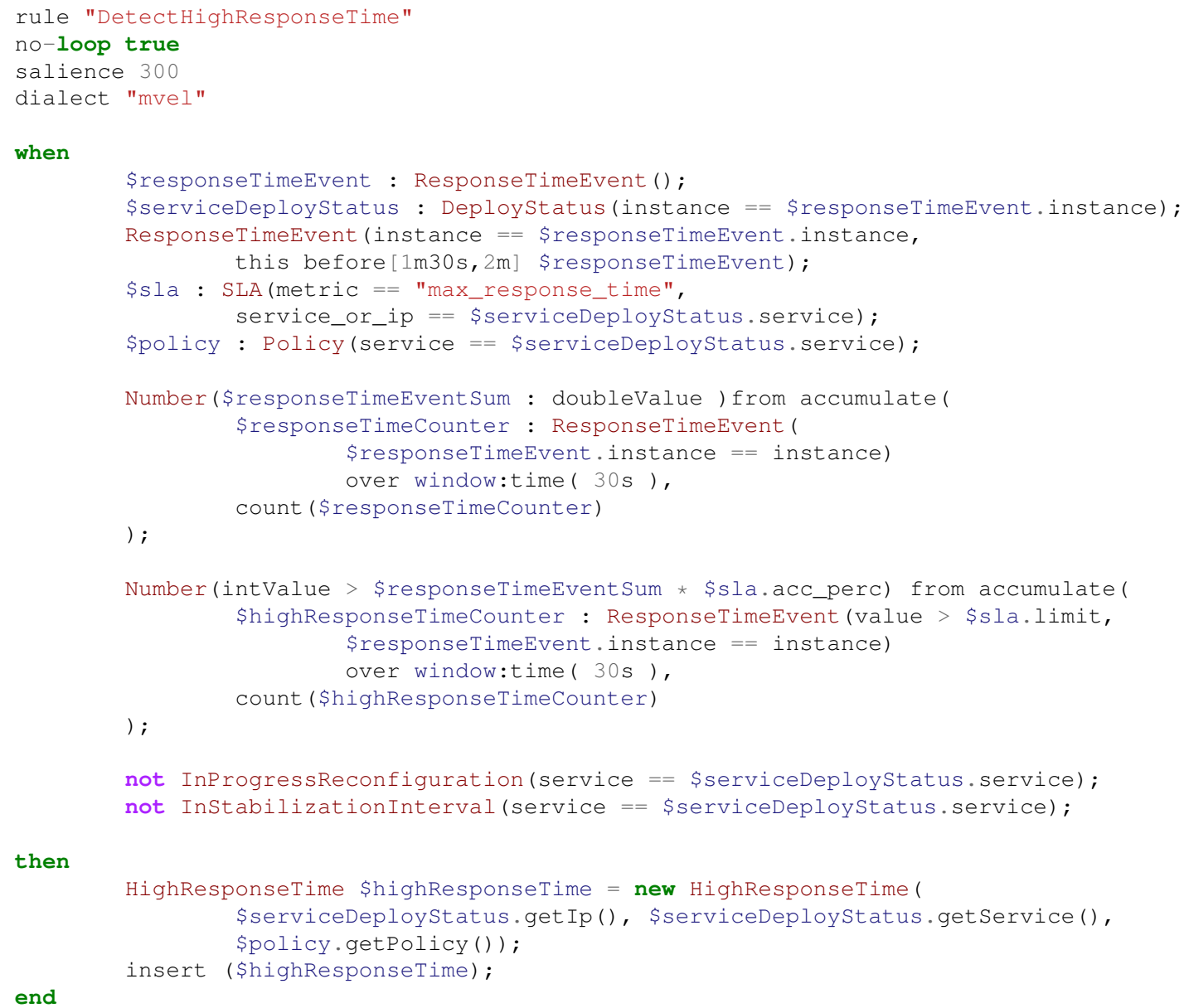

Figura 5.2: Regra usada para deteç̧ão de tempo de resposta alto.

Além disso, ainda para a primeira fase, no intuito de manter reduzida o consumo de recursos computacionais, uma vez que cada réplica é implantada em uma máquina virtual diferente, foi utilizada a regra mostrada na Figura 5.3. Analogamente à regra anterior, nas linhas 01-04 são capturados o evento e o contexto que dispararam a regra enquanto nas linhas 07-10 são armazenados em variáveis locais o uso de CPU, as configurações de SLA para o serviço referente à porcentagem de uso de CPU mínima e a política de escalabilidade escolhida para o serviço. Nas linhas 12-17 é analisada a porcentagem de uso de CPU para cada máquina hospedeira de um determinado serviço. Essa análise leva em conta uma janela com eventos de no máximo seis minutos. As linhas 19 e 20 evitam reconfigurações concorrentes ou reconfiguração antes do fim do tempo de estabilização. Na linha 22, é criado um evento complexo sinalizando uso de CPU baixo é criado e, na sequência (linha 24), ele é inserido na memória do Drools.

A avaliação foi realizada com estratégias de reconfiguração horizontal e vertical. Dependendo da escolha de política, o middleware usa diferentes estratégias para adequar a quantidade de recursos em uso à demanda atual. Ele pode implantar e remover réplicas de serviços através da criação e destruição de máquinas virtuais (escalabilidade horizontal), ou migrar serviços para máquinas virtuais de maior ou menor poder de processamento (escalabilidade vertical). 


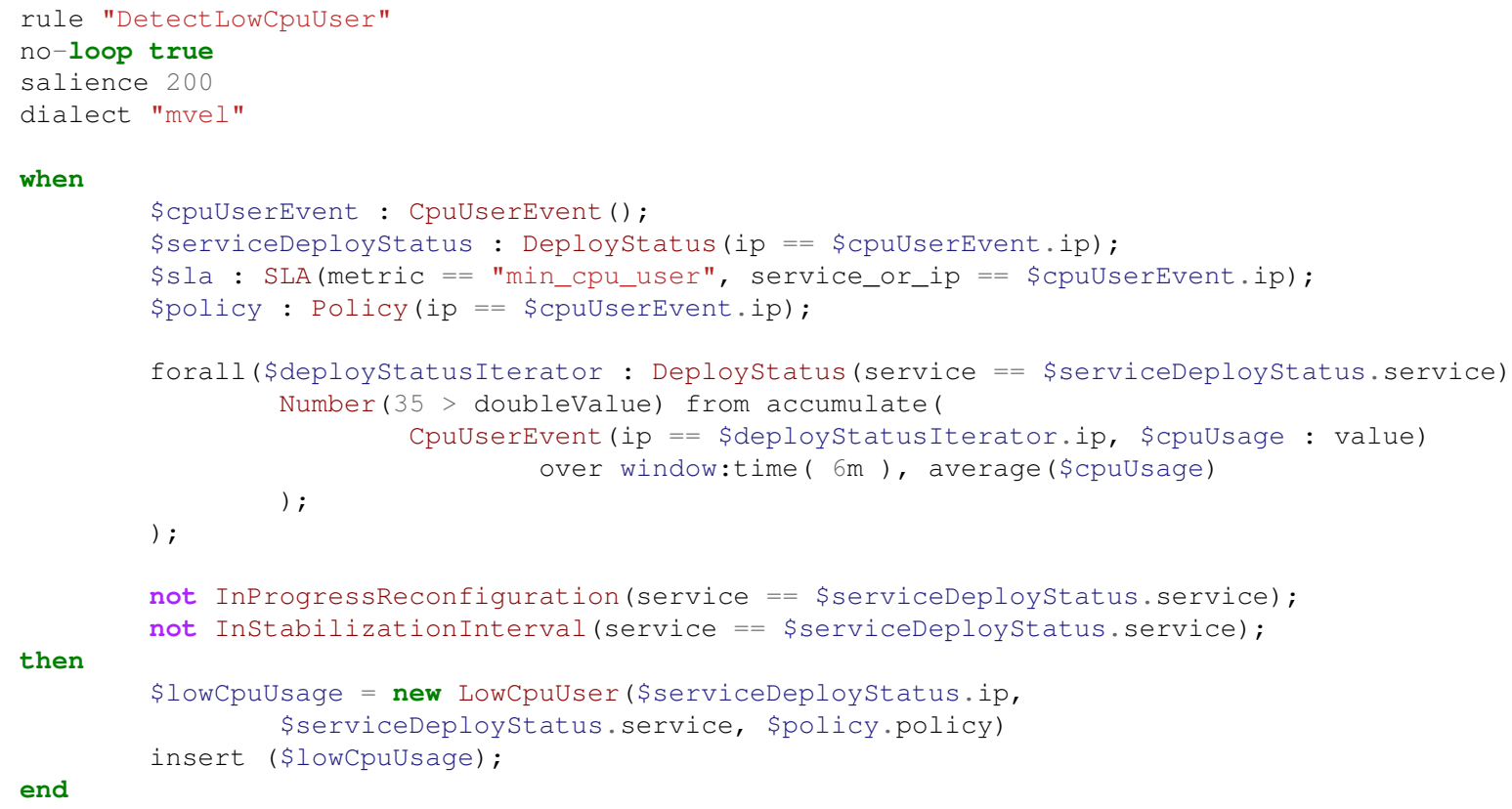

Figura 5.3: Regra usada para deteç̧ão de máquinas virtuais subutilizadas.

\subsubsection{Plataformas}

Para execução dos experimentos utilizamos servidores privados e máquinas virtuais em ambientes de computação em nuvem. Para o middleware, dois servidores privados foram usados. Para implantação da composição de avaliação, foram utilizadas máquinas virtuais na Amazon EC2 (primeira geração ${ }^{3}$ ). A Tabela 5.1 apresenta a descrição detalhada das plataforma utilizadas. O componente DM do middleware e o RMA foram executados nas máquinas Servidor Privado 1 e Servidor Privado 2, respectivamente. A composição de serviços foi executada em três diferentes tipos de máquinas da segunda geração: small, medium e large.

No experimento usando estratégia de reconfiguração horizontal, usamos apenas máquinas com configuração Amazon Small enquanto no experimento com estratégia vertical usamos máquinas com configurações Amazon Small, Amazon Medium e Amazon Large.

\subsection{Resultados}

Os experimentos realizados nesta pesquisa foram desenvolvidos para avaliar a capacidade de reação do middleware em condições de violação de SLA nas composições de serviços aplicando escalabilidade vertical e horizontal. As Figuras 5.4 e 5.7 mostram os resultados do experimento incluindo dados de monitoramento e reconfiguração. Dividimos cada gráfico em dois: um gráfico superior onde é possível ver o tempo de resposta coletado no Serviço $B$ e um gráfico inferior contendo os dados de monitoramento das máquinas virtuais hospedeiras das réplicas do Serviço A, para realçar a relação entre ambas.

No gráfico superior, em seu eixo à esquerda, é mostrado o tempo de resposta do Serviço B. Esse eixo está em escala logarítmica por conta de alguns picos pontuais no tempo de resposta. No eixo à direita, mostramos o número de requisições por segundo feitas para o serviço Serviço $B$. No gráfico inferior da figura, mostramos os dados da coleta da carga de trabalho nas máquinas virtuais. A carga de trabalho foi medida pela porcentagem de uso de CPU no nível de usuário mostrada no eixo à esquerda. Colorimos em azul os intervalos de tempo onde aconteceram as reconfigurações. Esses intervalos representam o tempo entre o momento em que o sistema detecta a necessidade de aplicar uma reconfiguração e o final (implantação) da tarefa de reconfiguração.

\footnotetext{
${ }^{3}$ http://aws.amazon.com/ec2/previous-generation
} 
Tabela 5.1: Especificação das plataformas usadas nos experimentos

\begin{tabular}{|c|c|c|c|}
\hline Configuração & CPU & Memória & Software \\
\hline$\overline{\text { Servidor Privado } 1}$ & $\begin{array}{l}\text { Servidor com } 2 \text { Núcleos } \\
\text { (4 Threads) } \\
2.53 \mathrm{GHz} \\
\text { Core } 2 \text { Duo P8700 }\end{array}$ & $4 \mathrm{~GB}$ & $\begin{array}{l}\text { Linux Kernel 3.2.0 } \\
\text { Java OpenJDK } 6\end{array}$ \\
\hline Servidor Privado 2 & $\begin{array}{l}\text { Máquina virtual com } \\
4 \text { Núcleos } \\
2.40 \mathrm{GHz} \\
\text { Intel Xeon E7-3870 }\end{array}$ & $16 \mathrm{~GB}$ & $\begin{array}{l}\text { Linux Kernel 3.2.0 } \\
\text { Java OpenJDK } 6\end{array}$ \\
\hline Amazon Small & $\begin{array}{l}\text { Máquina virtual com } \\
1 \text { Núcleo } \\
\text { at } 2.6 \mathrm{GHz} \\
\text { Xeon E5-2650 }\end{array}$ & $1.7 \mathrm{~GB}$ & $\begin{array}{l}\text { Kernel } 3.2 .0 \\
\text { OpenJDK } 6.0 \\
\text { Tomcat } 6\end{array}$ \\
\hline Amazon Medium & $\begin{array}{l}\text { Máquina virtual com } \\
1 \text { Núcleo } \\
\text { at } 2.26 \mathrm{GHz} \\
\text { Xeon E5-2650 }\end{array}$ & $3.7 \mathrm{~GB}$ & $\begin{array}{l}\text { Kernel } 3.2 .0 \\
\text { OpenJDK } 6.0 \\
\text { Tomcat } 6\end{array}$ \\
\hline Amazon Large & $\begin{array}{l}\text { Máquina virtual com } \\
2 \text { Núcleos } \\
\text { at } 2.0 \mathrm{GHz} \\
\text { Xeon E } 5645\end{array}$ & $7.5 \mathrm{~GB}$ & $\begin{array}{l}\text { Kernel } 3.2 .0 \\
\text { OpenJDK } 6.0 \\
\text { Tomcat } 6\end{array}$ \\
\hline
\end{tabular}

É possível verificar que a carga de trabalho imposta sobre o Serviço A acarreta o aumento do tempo de resposta da composição. De fato, esse era o comportamento esperado como dito anteriormente. Conforme a carga sobre, o tempo de resposta também aumenta. O comportamento da curva de acessos usado causa essas variações de carga, que demandam reações por parte do RMA para que seja mantido o QoS.

\subsubsection{Escalabilidade horizontal}

Em complemento às regras apresentadas anteriormente, os experimentos realizados coma a escolha de política de escalabilidade horizontal utilizam para a segunda fase a regra de adição de réplicas ilustrada na figura Figura 5.5. Nessa regra, temos na linha 7 a captura de um evento complexo que sinaliza um tempo de resposta alto para um serviço. Na linha 8 é capturado o contexto desse evento e na linha 10 é verificado se não há uma reconfiguração em andamento. Quando essas assertivas são verdadeiras, o bloco then executa a inserção de um evento sinalizador de reconfiguração em progresso na linha 12, nas linha 13-17 uma notificação é enviada ao CHOReOS EE contento o nome da regra, o identificador da coreografia a que o serviço pertence e o serviço em si. Na sequência, o evento é removido da memória de trabalho do Drools.

A regra para remoção de réplicas é similar à regra de adição. As diferenças podem ser vistas na Figura 5.6: na linha 7, a regra busca nesse caso um evento complexo que representa uma condição de máquina com pouco uso de CPU e nas linhas 14-18 a regra causará uma notificação onde o nome da regra a ser mapeada pelo CHOReOS EE é "RemoveReplica".

Nos experimentos realizados, iniciamos a composição com apenas um Serviço A e um Serviço B em máquinas do tipo Amazon Small. Porém o número de requisições é alto no início, o que causa violações de SLA logo no começo do experimento. Esse comportamento pode ser visto nos 100 


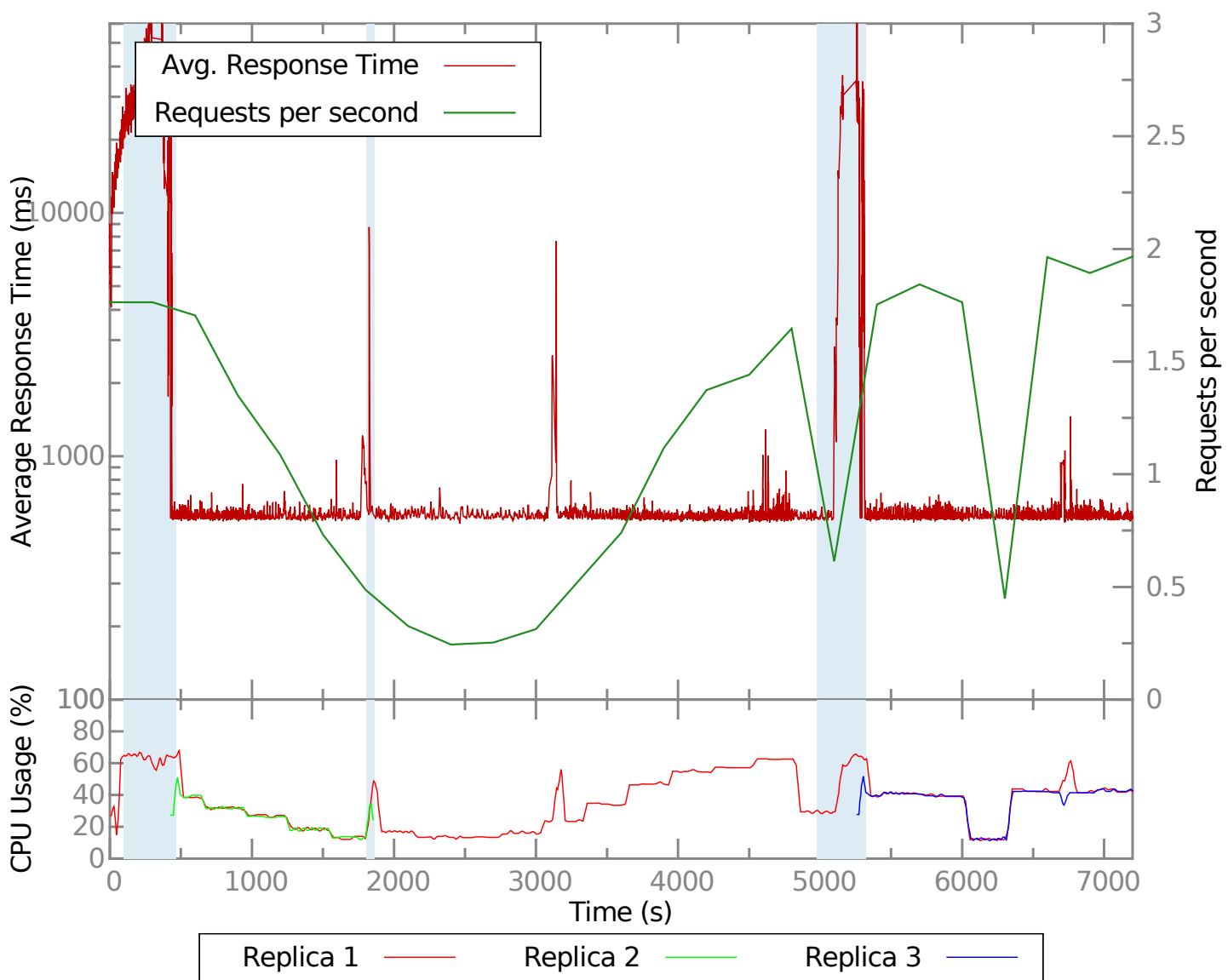

Figura 5.4: Tempo de resposta e uso de CPU durante o experimento com política horizontal.

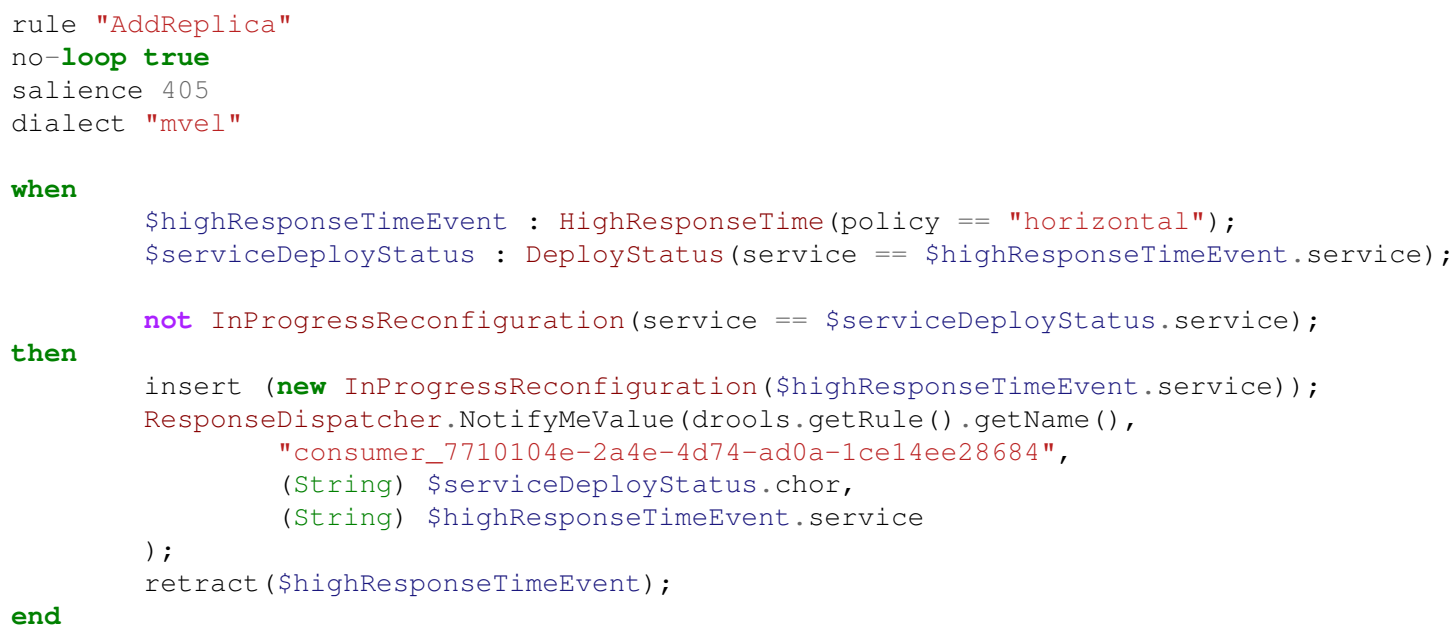

Figura 5.5: Regra usada para notificar que adição de uma réplica é necessária. 


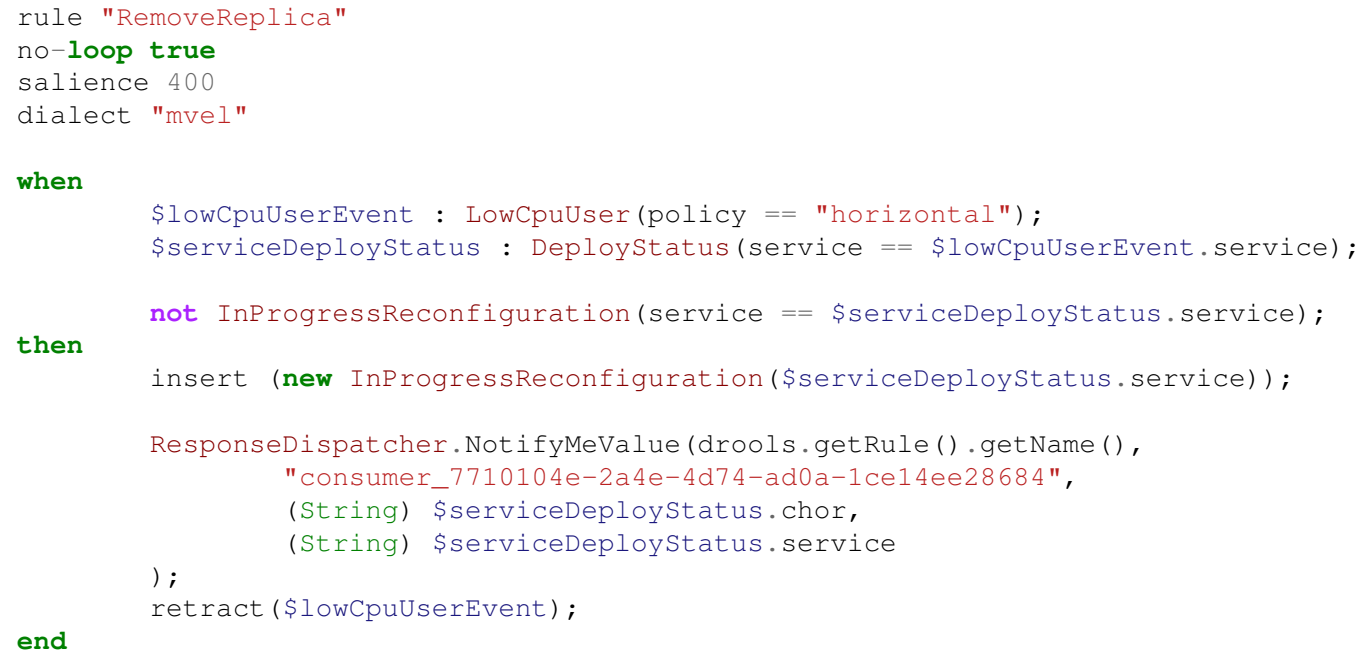

Figura 5.6: Regra para notificar que uma réplica de serviço pode ser removida.

primeiro segundos de experimento. Essas violações iniciam os mecanismos de reconfiguração do middleware. Dado que a composição foi configurada com política horizontal para escalabilidade, o CHOReOS EE decide então adicionar uma réplica. Conforme o número de requisições diminui a partir dos 600 segundos de experimento até os 2000 segundos, a porcentagem de uso de CPU diminui iniciando uma nova reconfiguração que remove a réplica recém adicionada. Novamente, conforme a carga volta a aumentar, uma nova reconfiguração é executada aos 4980 segundos aumentando o número de réplicas para duas. No final de cada reconfiguração, podemos observar um breve aumento na média do tempo de resposta.

É possível notar que a remoção de réplicas acontece num tempo menor do que a adição. Essa diferença acontece por ser necessária a configuração das máquinas logo após sua criação. Portanto, o tempo que o experimento levou para realizar a diminuição de recursos foi menor. Comparando o somatório dos intervalos de tempo em que o middleware permaneceu fazendo as reconfigurações em relação ao tempo total do experimento, as operações de atualização que realizaram remoção de réplicas somam cerca de 55 segundos. Em contrapartida, a adição de novas réplicas levou aproximadamente 355 segundos (6 minutos) do tempo total do experimento. Tal diferença pode ser atribuída ao tempo de criação de instâncias de máquinas virtuais no provedor de nuvem.

\subsubsection{Escalabilidade Vertical}

Da mesma maneira que regras complementares foram utilizadas para realização da segunda fase da adaptação, para essa política de escalabilidade também foram utilizadas regras similares. A diferença está na ação que será notificada ao middleware; o mecanismo de detecção de tempo de resposta alto e uso de CPU baixo foram os mesmos, porém, as ações de atualização a serem mapeadas pelo middleware são "MigrateUp" e "MigrateDown" para aumento e diminuição do tamanho da máquina virtual, respectivamente.

Em contraste à abordagem de escalabilidade horizontal, escalabilidade vertical realiza migração de serviços entre diferentes máquinas virtuais com capacidades de processamento diferentes a fim de manter o QoS; para aumentar a robustez do middleware, ainda é possível que, após o uso da configuração de melhor hardware virtual, réplicas de serviços sejam criadas a fim de continuar mantendo níveis aceitáveis de QoS. As configurações para o experimento com política vertical foram mantidas, com exceção, é claro, da política para o Serviço A. Portanto, o padrão de acesso e a aplicação cliente do experimento são similares, permitindo comparar os resultados entre as duas abordagens.

Uma diferença está relacionada à capacidade de processamento de uma máquina virtual do tipo Amazon Large. Embora o middleware estivesse preparado para criar novas réplicas ao longo do 
experimento caso ela não apresentasse desempenho suficiente, isso não foi necessário, como se pode ver na Figura 5.7.

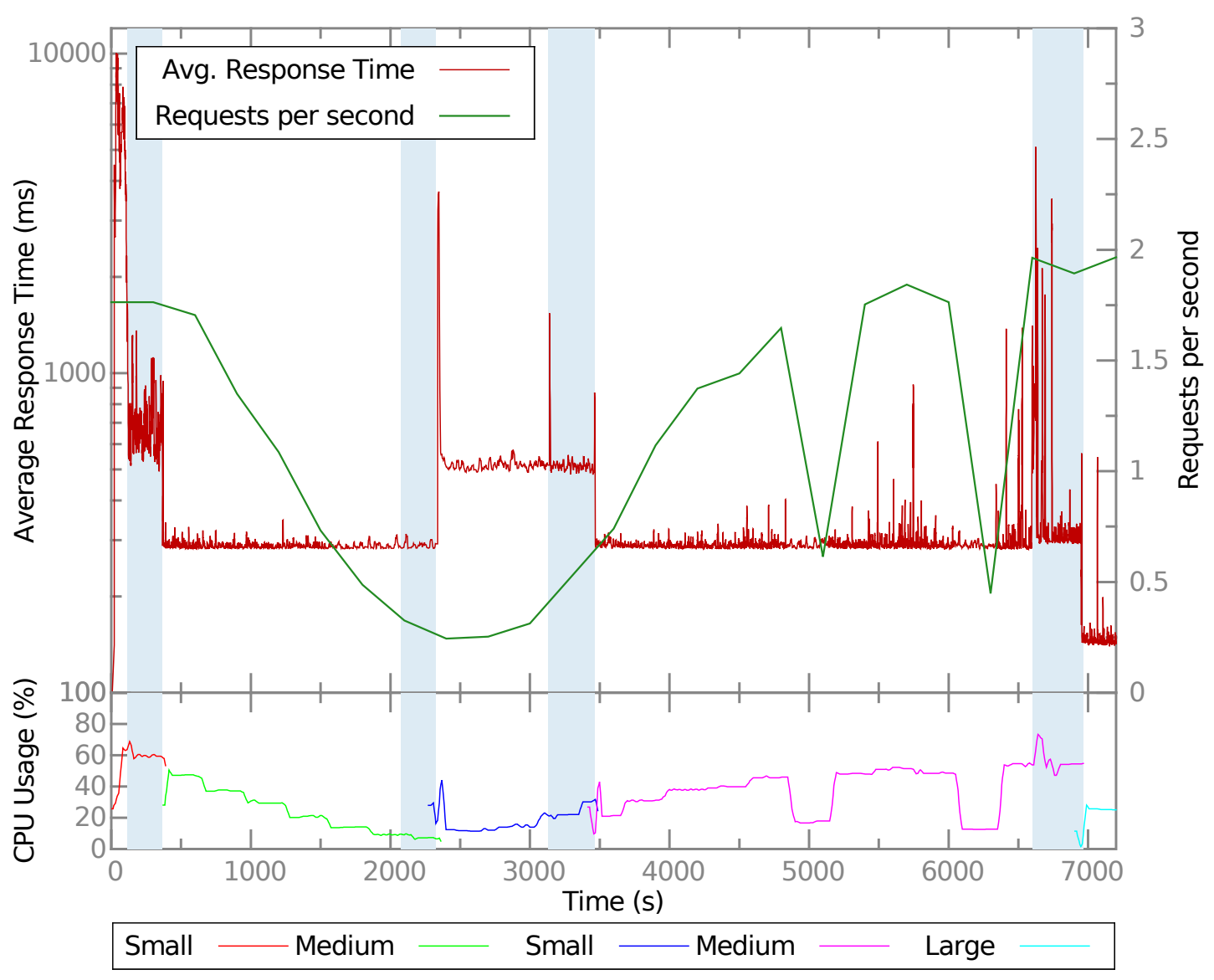

Figura 5.7: Tempo de resposta e uso de CPU durante o experimento com política horizontal.

Conforme aconteceu no experimento com escalabilidade horizontal, logo no início do experimento, o número de requisições é bem alto, o que implica na necessidade de uma máquina maior (a máquina inicial era do tipo Amazon Small). Assim, o SLA configurado é violado e, como esperado, uma reconfiguração é iniciada próximo aos 100 segundos da execução do experimento. Com o aumento da taxa de requisições entre os 600 e 2000 segundos de experimento, o uso de CPU diminui, levando o middleware a iniciar uma reconfiguração para migrar o Serviço $A$ para uma máquina virtual de menor capacidade. Novamente, a carga volta a aumentar, levando o middleware a iniciar uma reconfiguração para migrar o Serviço $A$ para uma máquina virtual de maior capacidade ( $A m a-$ zon Medium). Com essa configuração, foi possível atender as requisições até aproximadamente os 6540 segundos de experimento, quando uma máquina do tipo Amazon Large foi necessária. Na média, cada reconfiguração levou cerca de 298 segundos. A política de escalabilidade vertical apresenta desvantagem considerável em relação à política horizontal quando da redução de recursos, dado o fato de ser necessária sempre a criação de novas máquinas virtuais..

\subsection{Considerações}

Durante os experimentos, para a maior parte do tempo, o SLA configurado não foi violado. O middleware violou o SLA em 7\% do tempo de experimento para a política horizontal e 1,5\% para política vertical. Essas porcentagens não incluem as violações que ocorrem durante a primeira reconfiguração, iniciada logo no começo do experimento. Considerando essas violações, as porcentagens aumentam para $22 \%$ e 3,7\% respectivamente. Essa diferença enfatiza o impacto sobre o QoS quando em uma implantação a escolha das máquinas inicialmente usadas é ruim. Entretanto, tam- 
bém demonstra a capacidade do middleware de dinamicamente adaptar composições rapidamente diante de situações de degradação de QoS. O middleware também realizou reconfigurações para a remoção de recursos virtuais com o intuito de reduzir o custo de operação, como se pode observar em torno dos 1800 e 2000 segundos de execução do experimento para as políticas horizontal e vertical respectivamente.

Portanto, analisando o tempo de resposta do serviço, notamos que os mecanismos de adaptação do middleware são capazes de manter o QoS esperado para a maior parte do tempo. Existem alguns picos ocasionais no tempo de resposta, que podem ser atribuídos ao o atraso que há entre o aumento de carga sobre o serviço e a reação tomada pelo middleware, devido ao uso de uma janela deslizante de 30 segundos no mecanismo de regras.

Além disso, nos experimentos realizados, o Glimpse utiliza uma versão do Drools que causa inconsistência na atualização de fatos e eventos quando se está usando janelas deslizantes. Mais especificamente, a definição de duas janelas deslizantes com tamanhos diferentes, analisando o mesmo tipo de evento, causa erros na memória de trabalho do Drools, fazendo-o parar sua execução. Quando isso acontecia, o experimento era reiniciado. Isso fica mais evidente para o caso onde a política escolhida foi horizontal. Aparentemente, o uso de janelas deslizantes re-define o tempo de expiração dos eventos. Se esse tempo já está configurado com outros valores, essa inconsistência ocorre. Para solucionar o problema, adicionamos pré-condições nas regras, para que fosse possível analisar apenas os eventos relevantes.

Como citado no Capítulo 1, tínhamos também o objetivo de esconder detalhes técnicos da implantação e gestão de QoS nas composições. Nos experimentos, utilizamos o conjunto de regras criado para avaliação do middleware. Devido à parametrização dos valores das métricas de QoS, não foi necessária a criação de fragmentos de regras. Ao invés disso, toda a configuração das regras foram realizadas pelo middleware, ficando a cargo do desenvolvedor da composição e do cliente de acesso a seus pontos de acesso, a configuração dos parâmetros permitidos. 


\section{Capítulo 6}

\section{Conclusões}

Nesta dissertação apresentamos uma evolução no sistema de middleware CHOReOS EE, adicionando gestão de QoS para composições de serviços web. Considerando ambientes de computação em nuvem, o middleware apresentado é uma solução à lacuna existente entre a elasticidade de recursos provida por esses ambientes e a falta de soluções de software livre que refletem essa elasticidade na camada de serviços; Identificamos a necessidade de automatizar o processo de monitoramento e adaptação de composições em ambientes de produção para viabilizar a elasticidade. O monitoramento manual é suscetível a erros, levando os administradores a detectar anomalias tardiamente, o que causaria intervalos de violação de SLA maiores que os aceitáveis. A tomada de ação por parte dos administradores do ambiente de execução dependeria de análise também manual, o que tornaria ainda mais inviável o processo de manutenção de QoS feito dessa forma.

O sistema de middleware implementado mantém informações sobre as composições implantadas em dois níveis: no Deployment Manager, que detém as informações tanto de especificação como de implantação, e no Resource Manager Aggregator, que armazena os dados de implantação atual para fins de análise. Conforme as composições vão sendo modificadas, as alterações são refletidas no RMA. As informações armazenadas são os dados de especificação de cada composição contendo os detalhes comuns e suficientes para implantação como, por exemplo, a relação de colaboração entre os serviços, o estado da implantação como, por exemplo, a máquina virtual utilizada para cada serviço e suas configurações de hardware virtual, além dos atributos de QoS a ser monitorados e mantidos em bom estado e as configurações do contrato de SLA. Com base nesses dados, é possível monitorar e analisar as composições em tempo de execução.

Como parte deste trabalho, apresentamos uma plataforma de monitoramento que pode ser usada em outros projetos. Essa plataforma utiliza o Ganglia como sonda de coleta que permite um monitoramento pouco intrusivo. Ela foi construída usando o protocolo JMS que utiliza como modelo de envio de dados, mensagens assíncronas, sendo possível usá-la em arquiteturas implementadas com esse protocolo. Com pouco esforço, é possível ainda criar estruturas de dados de acordo com a necessidade encapsulando-as em tais mensagens. Usando os dados dessa plataforma, realizamos reconfiguração de composições de serviços baseada em CEP. O processo de adaptação segue o padrão arquitetural MAPE de implementação de sistemas autônomos. Através de CEP o middleware é capaz de tomar decisões em tempo de execução, munido dos dados estruturais das composições e dos dados de monitoramento.

Para desempenhar o papel do CEP, utilizamos o mecanismo de regras existente no Drools. Criamos modelos de regras que são aplicados às composições monitoradas. Esses modelos são responsáveis pela análise e adaptação das composições e baseiam-se nos valores coletados para métricas de QoS e de uso de recursos virtuais e limites de SLA impostos pelo cliente capturados periodicamente. O middleware é responsável pela definição final das regras. Embora nos experimentos tenhamos utilizado regras baseadas em métricas relacionadas a uso de CPU e tempo de resposta funcional, o middleware está preparado para que novos modelos de regras sejam criados para atender composições que demandem a análise de outros atributos.

Avaliamos o middleware por meio de experimentos simulando um cenário real de acesso a uma 
página da Wikipédia com o objetivo de mostrar a capacidade de reação frente a situações de sobrecarga e recursos subutilizados. Conseguimos mostrar que o middleware é capaz detectar e reagir diante de tais situações. Para isso, implantamos uma composição formada por dois serviços, e um cliente para acessar a composição segundo o padrão de acesso citado acima. Esse cliente foi responsável por situações de flutuação de carga onde a carga de CPU foi alterada causando variação no tempo de resposta. Assim, foi possível limitar o uso de CPU por parte dos serviços de modo que a QoS fosse violada e, em pouco tempo, o middleware realizou as adaptações necessárias.

\subsection{Desafios e Limitações}

A combinação da arquitetura MAPE e os mecanismos do CEP favorece a criação de várias possibilidades de melhorar sistemas autônomos em relação à flexibilidade. O MAPE se consolida cada vez mais como um padrão arquitetural [MBEB11]. O CEP provê análise de eventos distribuídos, baseada em regras de decisão que podem ser geradas arbitrariamente, de acordo com a necessidade. É possível criar desde regras simples até combinações de regras bastante complexas, com análise de vários eventos concernentes a quaisquer métricas de QoS.

Durante a implementação, foi pesquisado sobre a configuração das dependências entre os serviços que colaboram entre si. Observamos vantagens no padrão de injeção de dependências. Assim, implementamos a operação setInvocationAddress que é responsável por determinar a localização das dependências de um serviço. Embora tenha se mostrado suficiente para nossos experimentos, essa operação causa um efeito colateral: serviços devem implementar uma operação específica (setInvocationAddress) para que seja possível ser implantado e corretamente configurado pelo middleware. Consideramos isso uma desvantagem pelo fato de que a execução se limita a serviços que tenha essa operação em sua interface, ferindo a transparência na elasticidade. Com base nas conclusões obtidas, listamos algumas limitações encontradas:

- Nos experimentos realizados, ocorreram mais violações do que esperávamos. Parte dessa limitação está no atraso de 30 segundos usado pelo middleware; se o aumento de carga é súbito, as violações ocorrem praticamente de imediato. Esse comportamento fica nítido nos instantes iniciais da execução. Alguns atrasos que geraram picos de tempo de resposta também podem ser verificados. Quanto a esse problema, cabe análises futuras quanto ao funcionamento do mecanismo de regras. Houve casos em que o atraso para ativação de uma regra foi maior do que gostaríamos.

- Na implementação atual, criamos as regras de ações corretivas com base no conhecimento prévio do serviço a ser analisado. É importante ressaltar que, para nossos experimentos, sabíamos de antemão qual o comportamento aproximado do serviço baseado no algoritmo implementado para consumo de recursos.

- Devido à cooperação existente com a Comissão Europeia no projeto CHOReOS, usamos o Glimpse como servidor de CEP. Em sua versão mais atual, ele encapsula o Drools na versão 5.2.0, que apresentou instabilidades na definição de janelas de análise deslizantes. Isso dificultou a criação das regras de análise de eventos.

\subsection{Trabalhos Futuros}

Com base nos conhecimentos obtidos, listamos abaixo algumas possibilidades de trabalhos futuros tanto em termos de software livre como de pesquisa na área de gestão de QoS:

- Realização de testes e experimentos com maior quantidade de coreografias e serviços. Nos testes realizados para esta dissertação usamos uma única coreografia. Além disso, pelo fato de estarmos preocupados em medir a eficiência em detectar violações de SLA, a coreografia de testes usada era bem simples. Testes com composições realistas ou que simulem regras de 
negócio reais poderiam ser realizados. Além disso, com uma grande quantidade de composições é possível obter resultados mais próximos do que seria um cenário real para um sistema de middleware.

- Inclusão de CEP na fase de implantação assim como é feito na detecção de eventos de monitoramento. Na versão apresentada, as ações de implantação de serviços são iniciadas por rotinas do próprio CHOReOS EE. Entretanto, para fins de monitoramento e reação, é usado CEP através de mecanismos de regras que analisam eventos de monitoramento. Isso causa a necessidade de sincronismo entre os detalhes de implantação das composições que estão no middleware e as variáveis de estado presentes na memória de trabalho usada pelas regras. Possíveis vantagens estaria no compartilhamento da memória de trabalho entre Deployment Manager e Resource Manager Aggregator, facilitando o monitoramento da execução das composições bem como das tarefas do próprio CHOReOS EE, por exemplo, a escolha de um provedor de nuvem dado o tempo de criação das máquinas virtuais.

- Análise de escalabilidade por parte dos componentes apresentados. Em relação ao Platform Monitor, o middleware baseia-se na arquitetura em hierarquia provida pelo Ganglia. Porém, é necessário que o RMA suporte grandes cargas de eventos. Como visto, nos experimentos realizados, não geramos grandes quantidades de reconfigurações simultâneas. Embora seja possível distribuir clientes do CHOReOS EE em várias instâncias de RMA, há um limite natural na tomada de decisões baseados nos eventos presentes na memória usada pela JVM que executa o RMA. Para solucionar isso, há um esforço em distribuir a execução das regras. O Drools Server ${ }^{1}$, implementa um módulo capaz de executar regras usando como base de conhecimento em memórias distribuídas.

- Realização de análise de comportamento dos serviços de antemão (mantendo a análise durante a execução) aumenta o desempenho tanto na escolha inicial como na escolha da adaptação a ser feita. Durante os experimentos, notamos que a escolha inicial das máquinas virtuais tem influência no desempenho inicial da composição de serviços. Uma escolha equivocada pode causar uma cadeia de reconfigurações causando violações de SLA nos momentos iniciais de execução. A ferramenta Scalability Explorer (SE) [MK13, BMKM15], desenvolvida inicialmente no projeto CHOReOS pelo aluno de doutorado Paulo Moura, tem como objetivo estimar o uso de recurso diante de variações na quantidade de recursos disponíveis, capacidade de processamento, armazenamento, memória etc. das máquinas virtuais e carga gerada de acordo com o volume e tipo das requisições atendida. A inclusão dessa ferramenta no CHOReOS EE seria um trabalho importante a ser realizado. Com seus resultados, as regras utilizadas poderiam ser adaptadas para melhores escolhas de planos de reconfiguração.

- Inclusão de padrões de monitoramento para métricas de QoS. Atributos como tempo de resposta são mais fáceis de medir, e padrões já foram determinados para esse tipo de atributo. Entretanto, monitorar métricas de atributos como segurança não é uma tarefa trivial. A evolução do modelo de QoS apresentado, inclusão de novos atributos, definição de novas métricas e heurísticas podem enriquecer o sistema.

- Inclusão de técnicas para garantir o QoS durante o processo de adaptação para que durante as reconfigurações, o SLA ainda seja observado. Além do mais, a implementação de controles de admissão não foi abordada nessa dissertação. No entanto, são necessários no processo de adaptação dinâmica; nem sempre uma ação corretiva está disponível para uma determinada situação.

- Outro tópico interessante é a criação de regras mais robustas. Regras dinâmicas que se adaptam conforme os dados de predição de QoS ou análise de comportamento podem, com o tempo de execução, permitir a criação de eventos complexos com dados mais refinados aprimorando a

\footnotetext{
${ }^{1}$ https://docs.jboss.org/drools/release/5.3.0.Final/droolsjbpm-integration-docs/html/ch03.html
} 
qualidade das decisões realizadas pelo CEP. Assim, o uso de aprendizado de máquina ou análise estatística pode ajudar na definição do melhor conjunto de regras para uma composição ao longo do tempo de execução.

- Criação de famílias de regras reutilizáveis e extensíveis. Considerando os vários perfis de utilização de recursos computacionais, é possível criar um conjunto de regras que podem ser usadas pelos desenvolvedores das composições de serviços. Várias combinações incluindo tempos de reação, métricas utilizadas e valores limites podem ser usadas para fins de experimentos.

- Uso de predição de QoS para melhorar a tomada de decisões de adaptação. Predição de QoS é um tópico que está aquecido há algum tempo em várias abordagens de pesquisa. O uso de técnicas de predição de QoS podem evitar comportamentos indesejados como, por exemplo, a remoção prematura de réplicas de serviços. Além disso, com o uso de predição, uma ação de adaptação pode ser iniciada antes mesmo que um aumento de carga comece, diminuindo o tempo de execução onde o SLA é violado. O uso de predição ainda pode evitar o tempo da criação de máquinas virtuais e implantação, uma vez que, antecipadamente, é possível implantar réplicas novas; o tempo de reconfigurar seria o tempo de configurar os novos endereços da dependências.

- Estudo de arquiteturas de composições a fim de aprimorar a forma como as dependências entre os serviços são geridas. O uso da operação setInvocationAddress causou um efeito colateral: serviços têm de implementar uma operação específica. Sem essa limitação, o CHOReOS EE favoreceria ainda mais a reflexividade.

- Utilizar CEP distribuído para realização das fases do MAPE. Embora, nos experimentos, a fase de monitoramento é realizada em cada nó de maneira distribuída, as demais fases do MAPE é centralizada: a análise e o planejamento são realizados no RMA e a execução no DM.

Somente monitorar sistemas não é suficiente. O trabalho recente realizado por Newman [New15] cita o caso do website Gilt, que utiliza cerca de 450 micro serviços. Monitorar, detectar falhas e tomar ações corretivas ou melhor ainda, preventivas automaticamente, é de grande importância. Nesse panorama, a adaptação de composições de serviços baseado em dados de monitoramento de QoS tem se mostrado um tópico importante. No momento em que ambientes de computação em nuvem passam a ser aceitos por grandes empresas, alguns provedores já oferecem a elasticidade como um serviço. Entretanto, na comunidade de Software Livre, não há uma solução bem aceita para a realização dessa tarefa. Contudo, para realização de monitoramento, ferramentas como Ganglia e Zabbix $^{2}$ são largamente utilizados. Esses possibilitam a detecção de condições impróprias além de permitir a configuração de alertas.

Acreditamos que a quantidade de serviços conectados, executando em modo colaborativo continuará aumentando. A grande e crescente quantidade de dispositivos em uso demandam soluções robustas compostas por vários serviços. Nesta pesquisa, abordamos a manutenção de QoS automatizada, incluindo o monitoramento desses serviços e a infraestrutura utilizada e a adaptação dinâmica sem intervenção dos mantenedores de sistemas. Nesse contexto, o CHOReOS EE fornece uma solução automatizada auxiliando tais mantenedores com as tarefas de reconfiguração de composições de serviços. Além disso, a pesquisa realizada neste trabalho pode apoiar novas pesquisas, tanto em relação as técnicas utilizadas, quanto para modelagem de QoS. Futuramente, esperamos que novas pesquisas sejam realizadas a partir do CHOReOS EE, evoluindo o middleware como um software livre para implementação de PaaS através da melhoria das técnicas apresentadas.

\footnotetext{
${ }^{2}$ https://www.zabbix.org/wiki/Main_Page
} 


\section{Referências Bibliográficas}

$\left[\mathrm{ACC}^{+} 14\right]$ Danilo Ardagna, Giuliano Casale, Michele Ciavotta, JuanF Pérez e Weikun Wang. Quality-of-service in cloud computing: modeling techniques and their applications. Journal of Internet Services and Applications, 5(1), 2014. 27

$\left[\mathrm{ACD}^{+} 03\right]$ Tony Andrews, Francisco Curbera, Hitesh Dholakia, Yaron Goland, Johannes Klein, Frank Leymann, Kevin Liu, Dieter Roller, Doug Smith, Satish Thatte et al. Business process execution language for web services. Microsoft, IBM, Siebel Systems, BEA, and $S A P$, version, 1, 2003. 29

[ACD ${ }^{+}$07] Alain Andrieux, Karl Czajkowski, Asit Dan, Kate Keahey, Heiko Ludwig, Toshiyuki Nakata, Jim Pruyne, John Rofrano, Steve Tuecke e Ming Xu. Web services agreement specification (ws-agreement). Em Open Grid Forum, volume 128, 2007. 10

[ADC10] Mohammed Alhamad, Tharam Dillon e Elizabeth Chang. Conceptual sla framework for cloud computing. Em 2010 4th IEEE International Conference on Digital Ecosystems and Technologies (DEST), páginas 606-610. IEEE, 2010. 10

[ADG10] Françoise André, Erwan Daubert e Guillaume Gauvrit. Towards a generic contextaware framework for self-adaptation of service-oriented architectures. Em 2010 Fifth International Conference on Internet and Web Applications and Services (ICIW), páginas 309-314. IEEE, 2010. 21, 28, 32

$\left[\mathrm{AFG}^{+} 10\right]$ Michael Armbrust, Armando Fox, Rean Griffith, Anthony D. Joseph, Randy Katz, Andy Konwinski, Gunho Lee, David Patterson, Ariel Rabkin, Ion Stoica e Matei Zaharia. A view of cloud computing. Commun. ACM, 53(4):50-58, Abril 2010. 45

[ALRL04] A. Avizienis, J.-C. Laprie, B. Randell e C. Landwehr. Basic concepts and taxonomy of dependable and secure computing. IEEE Transactions on Dependable and Secure Computing, 1(1):11-33, Jan 2004. 13, 17, 18, 28, 29

[AR09] Mohammad Alrifai e Thomas Risse. Combining global optimization with local selection for efficient qos-aware service composition. Em Proceedings of the 18th international conference on World wide web, páginas 881-890. ACM, 2009. 19, 28, 31

[AS14] Tanveer Ahmed e Abhishek Srivastava. Service choreography: Present and future. Em 2014 IEEE International Conference on Services Computing (SCC), páginas 863-864. IEEE, 2014. 8

$\left[\mathrm{BBB}^{+} 11\right]$ Dominique Bellenger, Jens Bertram, Andy Budina, Arne Koschel, Benjamin Pfänder, Carsten Serowy, Irina Astrova, Stella Gatziu Grivas e Marc Schaaf. Scaling in cloud environments. Recent Researches in Computer Science, 2011. 33

$\left[\mathrm{BBC}^{+} 12\right]$ Cesare Bartolini, Antonia Bertolino, Andrea Ciancone, Guglielmo De Angelis e Raffaela Mirandola. Quality requirements for service choreographies. Em WEBIST, páginas 143-148, 2012. 42 
[BCLS11] Antonia Bertolino, Antonello Calabrò, Francesca Lonetti e Antonino Sabetta. GLIMPSE: a generic and flexible monitoring infrastructure. Em Proceedings of the 13th European Workshop on Dependable Computing, EWDC '11, páginas 73-78, New York, NY, USA, 2011. ACM. 47

[BDML12] Antonia Bertolino, Antinisca Di Marco e Francesca Lonetti. Complex events specification for properties validation. Em Quality of Information and Communications Technology (QUATIC), 2012 Eighth International Conference on the, páginas 85-94. IEEE, 2012. 33

[BDNG06] L. Baresi, E. Di Nitto e C. Ghezzi. Toward Open-World Software: Issue and Challenges. Computer, 39(10):36-43, 2006. 1

$\left[\mathrm{BHBC}^{+} 12\right]$ Amira Ben Hamida, Antonia Bertolino, Antonello Calabrò, Guglielmo Angelis, Nelson Lago e Julien Lesbegueries. Monitoring Service Choreographies from Multiple Sources. Em Paris Avgeriou, editor, Software Engineering for Resilient Systems, volume 7527 of Lecture Notes in Computer Science, páginas 134-149. Springer Berlin Heidelberg, 2012. 22,33

[BMKM15] Felipe Besson, Paulo Moura, Fabio Kon e Dejan Milojicic. Bringing test-driven development to web service choreographies. Journal of Systems and Software, 99(0):135 154, 2015. 67

[BN10] Pamela Bhattacharya e Iulian Neamtiu. Dynamic updates for web and cloud applications. Em Proceedings of the 2010 Workshop on Analysis and Programming Languages for Web Applications and Cloud Applications, APLWACA '10, páginas 21-25, New York, NY, USA, 2010. ACM. 24

[BR09] M Brian Blake e Florian Rosenberg. Qos-aware composition of adaptive serviceoriented systems. 2009. 29

$\left[\mathrm{BSG}^{+}\right.$09] Yuriy Brun, Giovanna Di Marzo Serugendo, Cristina Gacek, Holger Giese, Holger Kienle, Marin Litoiu, Hausi Müller, Mauro Pezzè e Mary Shaw. Engineering selfadaptive systems through feedback loops. Em Software engineering for self-adaptive systems, páginas 48-70. Springer, 2009. 21

[BWR09] A. Barker, C.D. Walton e D. Robertson. Choreographing Web Services. IEEE Transactions on Services Computing, 2(2):152-166, 2009. 1, 8

$\left[\mathrm{BYV}^{+} 09\right]$ Rajkumar Buyya, Chee Shin Yeo, Srikumar Venugopal, James Broberg e Ivona Brandic. Cloud computing and emerging it platforms: Vision, hype, and reality for delivering computing as the 5th utility. Future Generation computer systems, 25(6):599-616, 2009. 9

[CdLG ${ }^{+}$09] BettyH.C. Cheng, Rogério de Lemos, Holger Giese, Paola Inverardi, Jeff Magee, Jesper Andersson, Basil Becker, Nelly Bencomo, Yuriy Brun, Bojan Cukic, Giovanna Di Marzo Serugendo, Schahram Dustdar, Anthony Finkelstein, Cristina Gacek, Kurt Geihs, Vincenzo Grassi, Gabor Karsai, HolgerM. Kienle, Jeff Kramer, Marin Litoiu, Sam Malek, Raffaela Mirandola, HausiA. Müller, Sooyong Park, Mary Shaw, Matthias Tichy, Massimo Tivoli, Danny Weyns e Jon Whittle. Software engineering for selfadaptive systems: A research roadmap. Em BettyH.C. Cheng, Rogério de Lemos, Holger Giese, Paola Inverardi e Jeff Magee, editors, Software Engineering for SelfAdaptive Systems, volume 5525 of Lecture Notes in Computer Science, páginas 1-26. Springer Berlin Heidelberg, 2009. 3 
[CDPEV05] Gerardo Canfora, Massimiliano Di Penta, Raffaele Esposito e Maria Luisa Villani. An approach for qos-aware service composition based on genetic algorithms. Em Proceedings of the 2005 conference on Genetic and evolutionary computation, GECCO '05, páginas 1069-1075, New York, NY, USA, 2005. ACM. 28, 31

$\left[\mathrm{CGK}^{+} 11\right]$ R. Calinescu, L. Grunske, M. Kwiatkowska, R. Mirandola e G. Tamburrelli. Dynamic qos management and optimization in service-based systems. IEEE Transactions on Software Engineering, 37(3):387-409, 2011. 19, 20, 28, 32, 43

[CHK07] Si Won Choi, Jin Sun Her e Soo Dong Kim. Modeling qos attributes and metrics for evaluating services in soa considering consumers' perspective as the first class requirement. Em Asia-Pacific Service Computing Conference, The 2nd IEEE, páginas 398-405. IEEE, 2007. 8, 28

$\left[\mathrm{CKM}^{+}\right.$03] Francisco Curbera, Rania Khalaf, Nirmal Mukhi, Stefan Tai e Sanjiva Weerawarana. The next step in web services. Communications of the ACM - Service-oriented computing, 46(10):29-34, Outubro 2003. 29

[CLZ14] Shu-ping Cheng, Xiao-ming Lu e Xian-zhong Zhou. Globally optimal selection of web composite services based on univariate marginal distribution algorithm. Neural Computing and Applications, 24(1):27-36, 2014. 30

$\left[\mathrm{CSM}^{+} 04\right]$ Jorge Cardoso, Amit Sheth, John Miller, Jonathan Arnold e Krys Kochut. Quality of service for workflows and web service processes. Web Semantics: Science, Services and Agents on the World Wide Web, 1(3):281-308, 2004. 28, 29

[D'A06] Andrea D'Ambrogio. A model-driven wsdl extension for describing the qos of web services. Em International Conference on Web Services, 2006 (ICWS'06), páginas 789-796. IEEE, 2006. 42

$\left[\mathrm{DNGM}^{+}\right.$08] Elisabetta Di Nitto, Carlo Ghezzi, Andreas Metzger, Mike Papazoglou e Klaus Pohl. A journey to highly dynamic, self-adaptive service-based applications. Automated Software Engineering, 15(3-4):313-341, 2008. 8, 30

[DPC11] Jiang Dejun, Guillaume Pierre e Chi-Hung Chi. Resource provisioning of web applications in heterogeneous clouds. Em Proceedings of the 2nd USENIX conference on Web application development, páginas 5-5. USENIX Association, 2011. 19, 32

[DS05] Schahram Dustdar e Wolfgang Schreiner. A survey on web services composition. International journal of web and grid services, 1(1):1-30, 2005. 29

[eSEK03] Francisco José da Silva e Silva, Markus Endler e Fabio Kon. Developing adaptive distributed applications: A framework overview and experimental results. Em On The Move to Meaningful Internet Systems 2003: CoopIS, DOA, and ODBASE, páginas 1275-1291. Springer, 2003. 28

[eSKYJ05] Francisco José da Silva e Silva, Fabio Kon, Joseph Yoder e Ralph Johnson. A pattern language for adaptive distributed systems. Em SugarLoafPLoP'2005: Proceedings of the 5th Latin American Conference on Pattern Languages of Programming, páginas 19-48, 2005. 28

[FFLK14] Thiago Furtado, Emilio Francesquini, Nelson Lago e Fabio Kon. A middleware for reflective web service choreographies on the cloud. Em Proceedings of the 13th Workshop on Adaptive and Reflective Middleware, página 9. ACM, 2014. 52

[FHTG10] Markus Fiedler, Tobias Hossfeld e Phuoc Tran-Gia. A generic quantitative relationship between quality of experience and quality of service. Network, IEEE, 24(2):36-41, 2010. 43 
[FK98] Svend Frølund e Jari Koistinen. Quality of services specification in distributed object systems design. Em Proceedings of the 4th Conference on USENIX Conference on Object-Oriented Technologies and Systems - Volume 4, COOTS'98, páginas 1-1, Berkeley, CA, USA, 1998. USENIX Association. 28, 29

[GMYB05] Tong Gao, Hui Ma, I-ling Yen e Farokh Bastani. Toward QoS Analysis of Adaptive Service-Oriented Architecture. Em IEEE International Workshop on Service-Oriented System Engineering, 2005 (SOSE 2005), páginas 219-226. IEEE, 2005. 20, 28, 30

[GN12] Alfredo Goldman e Yanik Ngoko. On graph reduction for qos prediction of very large web service compositions. Em IEEE 9th International Conference on Services Computing (SCC), 2012, páginas 258-265. IEEE, 2012. 30

[GNM12] Alfredo Goldman, Yanik Ngoko e Dejan Milojicic. An analytical approach for predicting qos of web services choreographies. Em Proceedings of the 10th International Workshop on Middleware for Grids, Clouds and e-Science, página 4. ACM, 2012. 30

[Gun08] Neil J. Gunther. A general theory of computational scalability based on rational functions. CoRR, abs/0808.1431, 2008. 19, 28

[HGDJ08] Riadh Ben Halima, Karim Guennoun, Khalil Drira e Mohamed Jmaiel. Non-intrusive QoS monitoring and analysis for self-healing web services. Proceedings of the 1st International Conference on the Applications of Digital Information and Web Technologies (ICADIWT), (1):549-554, 2008. 28, 31

[HK11] CN Höfer e G Karagiannis. Cloud computing services: taxonomy and comparison. Journal of Internet Services and Applications, 2(2):81-94, 2011. 9

[IGH+11] Valérie Issarny, Nikolaos Georgantas, Sara Hachem, Apostolos Zarras, Panos Vassiliadist, Marco Autili, Marco Aurélio Gerosa e Amira Ben Hamida. Service-oriented middleware for the future internet: state of the art and research directions. Journal of Internet Services and Applications, 2(1):23-45, 2011. 1, 8

[IT09] Paola Inverardi e Massimo Tivoli. The future of software: Adaptation and dependability. Em Software Engineering, páginas 1-31. Springer, 2009. 20

[JPC10] Dejun Jiang, Guillaume Pierre e Chi-Hung Chi. Autonomous resource provisioning for multi-service web applications. Em Proceedings of the 19th international conference on World wide web, páginas 471-480. ACM, 2010. 19, 32

[JRGM04] Michael C Jaeger, Gregor Rojec-Goldmann e Gero Muhl. Qos aggregation for web service composition using workflow patterns. Em Eighth IEEE International Enterprise distributed object computing conference, 2004 (EDOC 2004), páginas 149-159. IEEE, 2004. 8

$\left[\mathrm{KBR}^{+}\right.$05] Nickolas Kavantzas, David Burdett, Gregory Ritzinger, Tony Fletcher, Yves Lafon e Charlton Barreto. Web services choreography description language version 1.0, 2005. 29

[KCBC02] Fabio Kon, Fabio Costa, Gordon Blair e Roy H Campbell. The case for reflective middleware. Communications of the ACM, 45(6):33-38, 2002. 52

[KGI13] Ajay Kattepur, Nikolaos Georgantas e Valérie Issarny. Qos composition and analysis in reconfigurable web services choreographies. Em 2013 IEEE 20th International Conference on Web Services (ICWS), páginas 235-242. IEEE, 2013. 14, 28 
$\left[\mathrm{KKC}^{+} 07\right] \mathrm{J}$ Kephart, J Kephart, D Chess, Craig Boutilier, Rajarshi Das, Jeffrey O Kephart e William E Walsh. An architectural blueprint for autonomic computing. IEEE internet computing, 18(21), 2007. 21

[KM90] J. Kramer e J. Magee. The evolving philosophers problem: dynamic change management. IEEE Transactions on Software Engineering, 16(11):1293-1306, 1990. 25, 33

[LF98] David C Luckham e Brian Frasca. Complex event processing in distributed systems. Computer Systems Laboratory Technical Report CSL-TR-98-754. Stanford University, Stanford, 28, 1998. 3, 10, 33

[Li12] Wei Li. QoS Assurance for Dynamic Reconfiguration of Component-Based Software Systems. IEEE Transactions on Software Engineering, 38(3):658 -676, may-june 2012. $22,25,26,33$

[LMC $\left.{ }^{+} 14\right]$ Leonardo Leite, Carlos Eduardo Moreira, Daniel Cordeiro, Marco Aurélio Gerosa e Fabio Kon. Deploying large-scale service compositions on the cloud with the choreos enactment engine. Em 2014 IEEE 13th International Symposium on Network Computing and Applications (NCA), páginas 121-128. IEEE, 2014. 35

[LON $\left.{ }^{+} 12\right]$ Leonardo AF Leite, Gustavo Ansaldi Oliva, Guilherme M Nogueira, Marco Aurélio Gerosa, Fabio Kon e Dejan S Milojicic. A Systematic Literature Review of Service Choreography Adaptation. Service Oriented Computing and Applications, páginas 1-18, 2012. 27

[LS00] Bev Littlewood e Lorenzo Strigini. Software reliability and dependability: A roadmap. Em Proceedings of the Conference on The Future of Software Engineering, ICSE '00, páginas 175-188, New York, NY, USA, 2000. ACM. 17, 28

[Luc02] David C. Luckham. The power of events: An Introduction to Complex Event Processing in Distributed Enterprise Systems, volume 204. Addison-Wesley Reading, Boston, MA, USA, 2002. 22, 33

[LZYW10] Ying Li, Xiaorong Zhang, YuYu Yin e Jian Wu. QoS-Driven Dynamic Reconfiguration of the SOA Based Software. Em 2010 International Conference on Service Sciences (ICSS), páginas 99 -104, may 2010. 20, 28, 31

[M. 13] M. Bali. Drools JBoss Rules 5. X Developer's Guide. Packt Publishing Ltd, 2013. 48

[MBEB11] M. Maurer, I. Breskovic, V.C. Emeakaroha e I. Brandic. Revealing the MAPE loop for the autonomic management of Cloud infrastructures. Em 2011 IEEE Symposium on Computers and Communications (ISCC), páginas 147-152, 2011. 3, 20, 21, 22, 66

$\left[\mathrm{MBK}^{+} 09\right]$ Nebil Ben Mabrouk, Sandrine Beauche, Elena Kuznetsova, Nikolaos Georgantas e Valérie Issarny. Qos-aware service composition in dynamic service oriented environments. Em Middleware 2009, páginas 123-142. Springer, 2009. 28, 29

[MCC04] Matthew L Massie, Brent N Chun e David E Culler. The ganglia distributed monitoring system: design, implementation, and experience. Parallel Computing, 30(7):817 - 840, 2004. 39,45

[MG09] Peter Mell e Tim Grance. The NIST definition of cloud computing. National Institute of Standards and Technology, 53(6):50, 2009. 9

[MK13] Paulo Moura e Fabio Kon. Automated Scalability Testing of Software as a Service. Em Proceedings of the 8th International Workshop on Automation of Software Test, AST 2013, páginas 8-14. IEEE, May 2013. 19, 32, 67 
[MN93] Gennady Medvinsky e Clifford Neuman. Netcash: A design for practical electronic currency on the internet. Em Proceedings of the 1st ACM Conference on Computer and Communications Security, CCS '93, páginas 102-106, New York, NY, USA, 1993. ACM. 1

[MRLD09] Anton Michlmayr, Florian Rosenberg, Philipp Leitner e Schahram Dustdar. Comprehensive qos monitoring of web services and event-based sla violation detection. Em Proceedings of the 4th International Workshop on Middleware for Service Oriented Computing, MWSOC '09, páginas 1-6, New York, NY, USA, 2009. ACM. 13, 28

[MSKC04] Philip K McKinley, Seyed Masoud Sadjadi, Eric P Kasten e Betty HC Cheng. Composing adaptive software. Computer, (7):56-64, 2004. 1

[New15] Sam Newman. Building Microservices. "O'Reilly Media, Inc.", 2015. 39, 68

[OMB07] Liam O'Brien, Paulo Merson e Len Bass. Quality attributes for service-oriented architectures. Em Proceedings of the International Workshop on Systems Development in SOA Environments, SDSOA '07, páginas 3-, Washington, DC, USA, 2007. IEEE Computer Society. 7

[OZD10] Ernst Oberortner, Uwe Zdun e Schahram Dustdar. Patterns for measuring performance-related qos properties in service-oriented systems. Em Proceedings of the 17th Conference on Pattern Languages of Programs, PLOP '10, páginas 20:1-20:21, New York, NY, USA, 2010. ACM. 43

[Pel03] Chris Peltz. Web services orchestration and choreography. Computer, 36(10):46-52, Outubro 2003. 29

[Pou11] Michael Poulin. Collaboration patterns in the soa ecosystem. Em Proceedings of the Third Workshop on Behavioural Modelling, BM-FA '11, páginas 12-16, New York, NY, USA, 2011. ACM. 7

[PTDL07] Michael P. Papazoglou, Paolo Traverso, Schahram Dustdar e Frank Leymann. Serviceoriented computing: State of the art and research challenges. Computer, 40(11):38-45, Novembro 2007. 7

[PvdH07] Michael P. Papazoglou e Willem-Jan van den Heuvel. Business process development life cycle methodology. Commununications of the ACM, 50(10):79-85, Outubro 2007. 8

[QZCY07] Zongyan Qiu, Xiangpeng Zhao, Chao Cai e Hongli Yang. Towards the theoretical foundation of choreography. Em Proceedings of the 16th International Conference on World Wide Web, WWW '07, páginas 973-982, New York, NY, USA, 2007. ACM. 1, 30

[RT05] Stephen Ross-Talbot. Orchestration and choreography: Standards, tools and technologies for distributed workflows. Em NETTAB Workshop-Workflows management: new abilities for the biological information overflow, Naples, Italy, 2005. 1, 8

[SAS11] Ashish Seth, Himanshu Agarwal e Ashim Raj Singla. Designing a soa based model. SIGSOFT Software Engineering Notes, 36(5):1-7, Setembro 2011. 7

[SBD11] Bruce Snyder, Dejan Bosnanac e Rob Davies. ActiveMQ in action. Manning, 2011. 47

[Str10] A. Strunk. Qos-aware service composition: A survey. Em 2010 IEEE 8th European Conference on Web Services (ECOWS), páginas 67-74, 2010. 31 
[TPPvdH11] Yéhia Taher, Michael Parkin, MikeP. Papazoglou e Willem-Jan van den Heuvel. Adaptation of web service interactions using complex event processing patterns. Em Gerti Kappel, Zakaria Maamar e HamidR. Motahari-Nezhad, editors, Service-Oriented Computing, volume 7084 of Lecture Notes in Computer Science, páginas 601-609. Springer Berlin Heidelberg, 2011. 20

$\left[\mathrm{TZC}^{+} 04\right]$ Wei-Tek Tsai, Dawei Zhang, Yinong Chen, Hai Huang, Raymond A Paul e Ning Liao. A software reliability model for web services. Em IASTED Conf. on Software Engineering and Applications, páginas 144-149, 2004. 7

[VEBD07] Y. Vandewoude, P. Ebraert, Y. Berbers e T. D'Hondt. Tranquility: A Low Disruptive Alternative to Quiescence for Ensuring Safe Dynamic Updates. IEEE Transactions on Software Engineering, 33(12):856-868, 2007. 25, 33

[VKvBG95] Andreas Vogel, Brigitte Kerherve, Gregor von Bochmann e Jan Gecsei. Distributed multimedia and qos: A survey. IEEE multimedia, 2(2):10-19, 1995. 29

[VS05] Patrice Vienne e Jean-Louis Sourrouille. A middleware for autonomic QoS management based on learning. Em Proceedings of the 5th International Workshop on Software Engineering and Middleware, SEM '05, páginas 1-8, New York, NY, USA, 2005. ACM. 20, 28, 30

[VWMA11] Pieter Vromant, Danny Weyns, Sam Malek e Jesper Andersson. On interacting control loops in self-adaptive systems. Em Proceedings of the 6th International Symposium on Software Engineering for Adaptive and Self-Managing Systems, páginas 202-207. ACM, 2011. 32

[WA02] Elaine J Weyuker e Alberto Avritzer. A metric to predict software scalability. Em Eighth IEEE Symposium on Software Metrics, 2002, páginas 152-158. IEEE, 2002. 19,28

[WWC ${ }^{+}$05] Guijun Wang, Changzhou Wang, Alice Chen, Haiqin Wang, Casey Fung, Stephen Uczekaj, Yi-liang Chen, Wayne Guthmiller, Joseph Lee e Boeing Phantom Works. Service Level Management using QoS Monitoring, Diagnostics, and Adaptation for Networked Enterprise Systems. 2005. 28, 30

[YL12] Yuyu Yin e Ying Li. Towards Dynamic Reconfiguration for QoS Consistent Services Based Applications. Em Chengfei Liu, Heiko Ludwig, Farouk Toumani e Qi Yu, editors, Service-Oriented Computing, volume 7636 of Lecture Notes in Computer Science, páginas 771-778. Springer Berlin / Heidelberg, 2012. 20, 28, 31

[YRPK07] Weider D. Yu, Rachana B. Radhakrishna, Sumana Pingali e Vijaya Kolluri. Modeling the measurements of qos requirements in web service systems. Simulation, 83(1):7591, Janeiro 2007. 14, 17, 28, 29

[YYSH08] S.S. Yau, N. Ye, H. Sarjoughian e D. Huang. Developing Service-Based Software Systems with QoS Monitoring and Adaptation. 2008 12th IEEE International Workshop on Future Trends of Distributed Computing Systems, páginas 74-80, 2008. 28, 31

$\left[Z_{B}{ }^{+}\right.$03] Liangzhao Zeng, Boualem Benatallah, Marlon Dumas, Jayant Kalagnanam e Quan Z. Sheng. Quality driven web services composition. Em Proceedings of the 12th International Conference on World Wide Web, WWW '03, páginas 411-421, New York, NY, USA, 2003. ACM. 8, 16, 28

$\left[\mathrm{ZBN}^{+}\right.$04] Liangzhao Zeng, B. Benatallah, A. H H Ngu, M. Dumas, J. Kalagnanam e H. Chang. Qos-aware middleware for web services composition. IEEE Transactions on Software Engineering, 30(5):311-327, 2004. 28, 30, 31 
[ZL13a] Zibin Zheng e Michael R Lyu. Neighborhood-based qos prediction of web services. Em QoS Management of Web Services, páginas 41-64. Springer, 2013. 14

[ZL13b] Zibin Zheng e MichaelR. Lyu. Qos evaluation of web services. Em QoS Management of Web Services, Advanced Topics in Science and Technology in China, páginas 19-39. Springer Berlin Heidelberg, 2013. 3, 14, 29

[ZWW11] Yanwei Zhang, Yefu Wang e Xiaorui Wang. GreenWare: Greening Cloud-Scale Data Centers to Maximize the Use of Renewable Energy. Em Middleware 2011, páginas 143-164. Springer, 2011. 2 